\title{
BRIDGING SCIENCE AND LAW ACROSS JURISDICTIONS IN CANADIAN SPECIES AT RISK POLICY: FOUR CASE STUDIES
}

\author{
by \\ Maria-Lena Di Giuseppe \\ Honours Bachelor of Science, York University, 2006 \\ A thesis \\ presented to Ryerson University \\ in partial fulfillment of the \\ requirements for the degree of \\ Master in Applied Science \\ in the Program of \\ Environmental Applied Science and Management \\ Toronto, Ontario, Canada, 2011
}

C(Maria-Lena Di Giuseppe) 2011 


\section{AUTHOR'S DECLARATION}

I hereby declare that I am the sole author of this thesis or dissertation. I authorize Ryerson University to lend this thesis or dissertation to other institutions or individuals for the purpose of scholarly research.

I further authorize Ryerson University to reproduce this thesis or dissertation by photocopying or by other means, in total or in part, at the request of other institutions or individuals for the purpose of scholarly research. 


\title{
BRIDGING SCIENCE AND LAW ACROSS JURISDICTIONS IN CANADIAN SPECIES AT RISK POLICY: FOUR CASE STUDIES
}

\author{
Maria-Lena Di Giuseppe \\ Master of Applied Science, 2011 \\ Environmental Applied Science and Management \\ Ryerson University
}

\begin{abstract}
The purpose of this thesis is to evaluate the effectiveness of current legal measures for protecting species at risk in Canada through an interpretive qualitative method. Four species case studies were analyzed: The Eastern Loggerhead Shrike, Jefferson Salamander, Northern Spotted Owl, and Vancouver Island Marmot. Policy recommendations for reforms arising from the research are: i) inter-jurisdictional cooperation is imperative for protecting species at risk; ii) dedicated species at risk legislation is crucial, and it is recommended that such legislation exist at both federal and provincial levels; iii) flexibility instruments and exemptions to existing law should be scientifically informed and used cautiously; iv) private landowners are significant stakeholders and stewardship efforts are important; v) scientific information and the definition of critical habitat for species at risk are crucial. The thesis concludes that a science-based precautionary approach to species protection is fundamental to address the plight of species at risk in Canada.
\end{abstract}




\section{ACKNOWLEDGEMENTS}

I give my utmost gratitude, first and foremost, to my thesis advisor, Dr. Alex Wellington, for her guidance and assistance throughout my whole research experience. She has very generously allowed me to tap into her wealth of legal and policy knowledge and helped me to see the world of biodiversity and conservation from a whole new perspective. Thanks to Dr. Allan Greenbaum who always had an appropriate answer to every query, and who is a wealth of knowledge in science and legal matters.

I would also like to thank the chair of my examination committee, Dr. Michal Bardecki, and the two members of my examination committee, Dr. Lynda McCarthy and Dr. Andrew Laursen, whose time, expertise, and input has been greatly considered and appreciated.

Last but not least, I would like to thank all of my friends and family who have supported and encouraged me throughout this lengthy research endeavour. A special thank you is reserved for my mother, Mary, my father, Philip, my grandparents, and Piero, who helped me to unveil a new realm that allowed me to view things from a different perspective. Each of you may take pride in sharing in this accomplishment with me. For in the absence of your support, this paper would not have been possible.

December 14, 2010 


\section{TABLE OF CONTENTS}

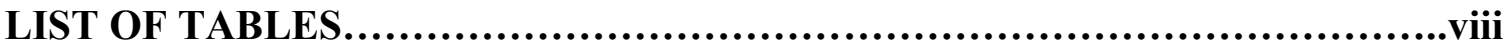

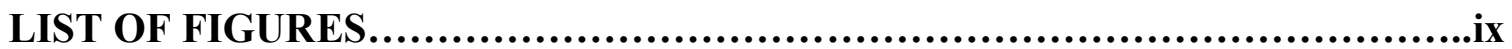

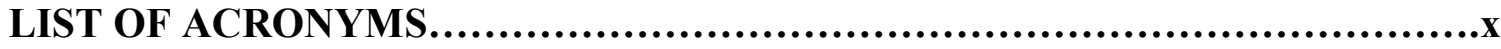

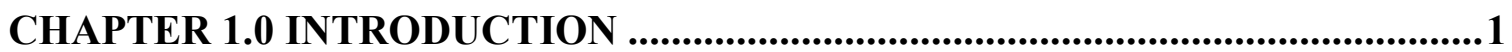

1.1 Importance of Biodiversity and Threats to Biodiversity: Why Should Biodiversity Be

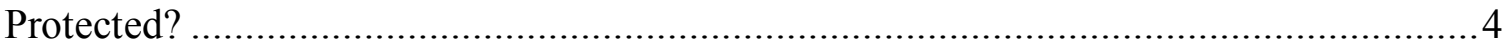

1.1.1 Importance of Biodiversity: Theories and Hypotheses on the Web of Life ....... 4

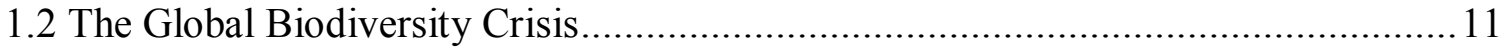

1.3 Uncertainty and Precaution in Species at Risk Policy and the Need for Local

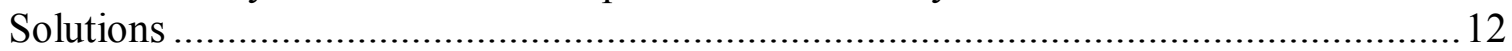

1.4 Importance of Biodiversity in Canada ................................................................... 14

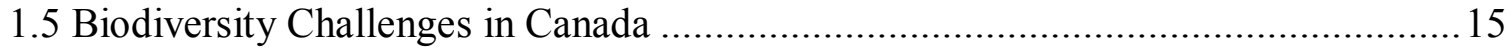

1.6 Canadian Legal Tools for the Protection of Species at Risk..................................... 16

CHAPTER 2.0 METHODS........................................................................................21

2.1 Rationale for the Selection of British Columbia and Ontario as Comparator Provinces

2.2 Rationale for the Selection of Case Study Subjects: Vertebrate Species at Risk.......25

CHAPTER 3.0 FEDERAL LEGAL MEASURES FOR SPECIES AT RISK IN

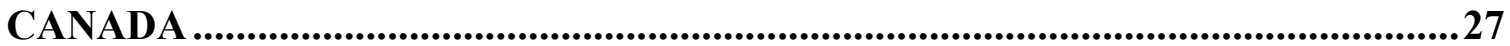

3.1 The Institutional Composition of Canadian Environmental Law and Policy .............28

3.2 Influences of International Law upon Canadian Law .............................................29

3.3 Policy Tools and Legal Measures at the Federal Level............................................ 32

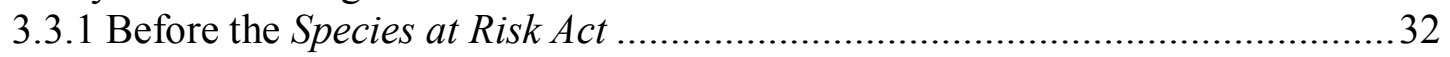

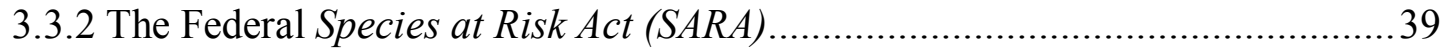

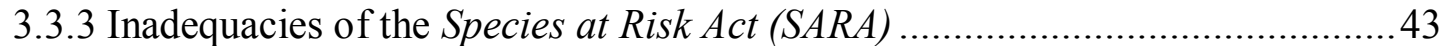

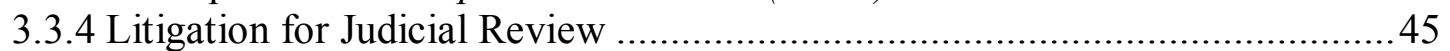

3.3.4.1 The Greater Sage-Grouse: Alberta Wilderness Association v. Canada

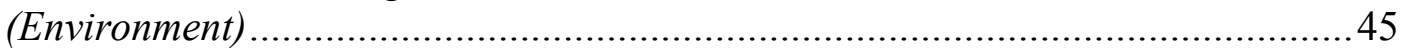

3.3.4.2 The Nooksack Dace: Environmental Defence Canada v. Canada .............46

3.4 Jurisdictional Challenges and Proposals for Reform................................................48

CHAPTER 4.0 PROVINCAL LEGAL MEASURES FOR SPECIES AT RISK IN

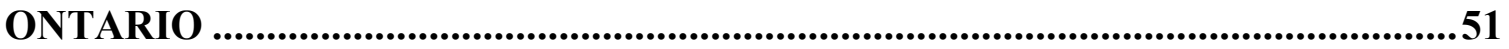

4.1 Before the Ontario Endangered Species Act, 2007 ...........................................52

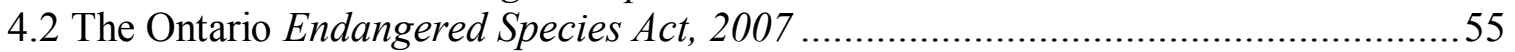

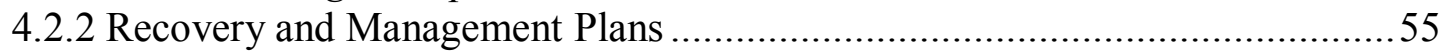

4.2.3 Stewardship Programs ............................................................................5

4.3 Exemptions and Flexibility Tools in the Ontario Endangered Species Act, 2007 ......61 
CHAPTER 5.0 ONTARIO SPECIES AT RISK: TWO CASE STUDIES .67

5.1 The Eastern Loggerhead Shrike

5.1.1 A Songbird on the Precipice of Extinction: Indicator of Southern Ontario

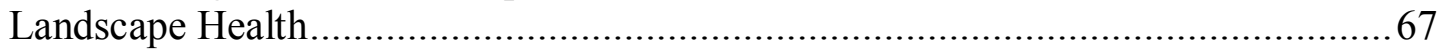

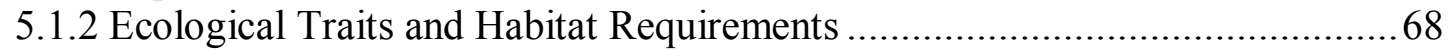

5.1.3 Current Status and Causes of Decline ......................................................69

5.1.4 Existing Legal Measures for the Protection of the Eastern Loggerhead Shrike 75

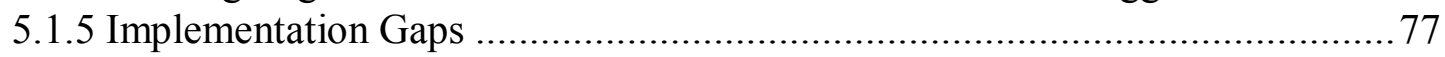

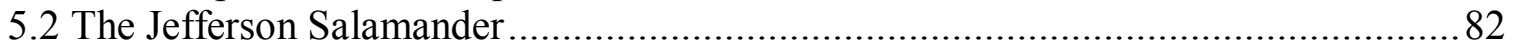

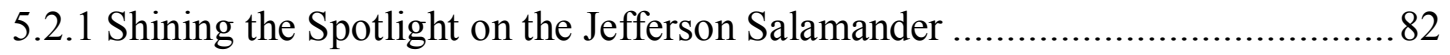

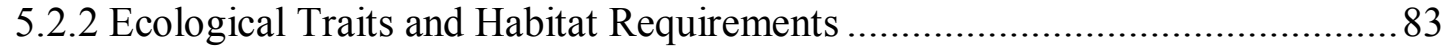

5.2.3 Current Status and Causes of Decline .......................................................... 86

5.2.4 Existing Legal Measures for the Protection of the Jefferson Salamander......... 87

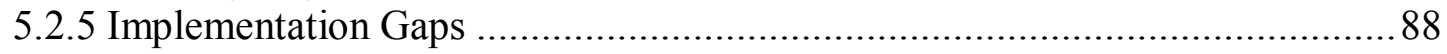

\section{CHAPTER 6.0 PROVINCIAL LEGAL MEASURES FOR SPECIES AT RISK IN

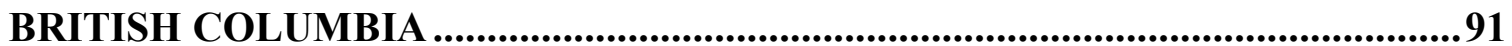

\section{CHAPTER 7.0 BRITISH COLUMBIA SPECIES AT RISK: TWO CASE STUDIES}

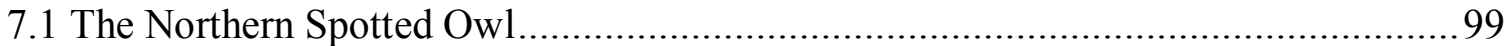

7.1.1 Canada's Most Endangered Bird and Indicator of West Coast Forest Health ..99

7.1.2 Ecological Traits and Habitat Requirements ............................................. 100

7.1.3 Current Status and Causes of Decline ................................................... 100

7.1.4 Existing Legal Measures for the Protection of the Spotted Owl .................... 101

7.1.5 The Plight of the Spotted Owl in the Courts:

Western Canada Wilderness Committee v. BC (Ministry of Forests) ..................... 104

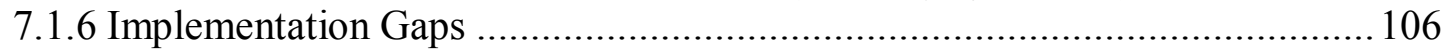

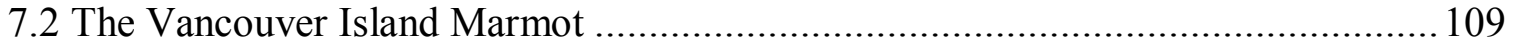

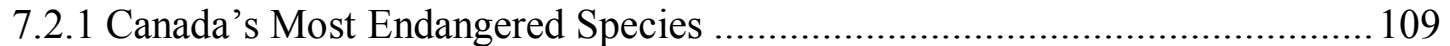

7.2.2 Ecological Traits and Habitat Requirements ............................................... 109

7.2.3 Current Status and Causes of Decline ...................................................... 110

7.2.4 Existing Legal Measures for the Protection of the Vancouver Island Marmot112

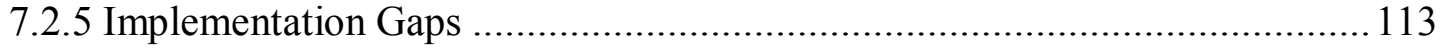

CHAPTER 8.0 POLICY RECOMMENDATIONS ...............................................117

8.1 Species at Risk in Ontario: Federal and Provincial Policy Recommendations........ 117

8.1.1 Inter-Jurisdictional and Intra-Jurisdictional Cooperation........................... 117

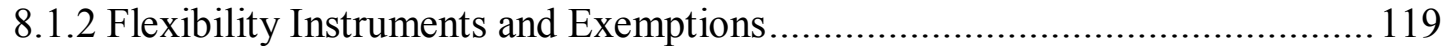

8.1.3 Private Landowner Rights and Stewardship .......................................... 120

8.1.4 Recovery Strategies, the Importance of Current Scientific Information, and

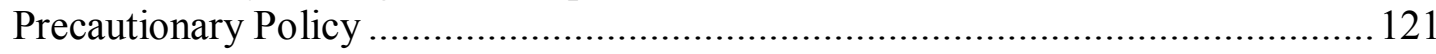

8.2 Species at Risk in British Columbia: Federal and Provincial Policy

Recommendations

8.2.1 Importance of Federal-Provincial Inter-Jurisdictional Cooperation ................ 123 
8.2.2 Provincial Recommendations

8.3 Charismatic Species, Public Exposure, and Scientific Information ........................ 126

CHAPTER 9.0 CONCLUSIONS AND APPLICATIONS FOR FUTURE

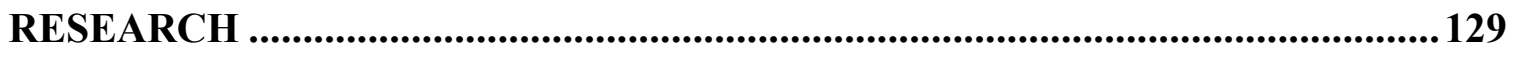

CHAPTER 10.0 REFERENCES ............................................................... 133

LIST OF PERTIENT STATUTES ........................................................... 145 


\section{LIST OF TABLES}

Table 1.1: Summary of COSEWIC's assessment results for the "risk" categories and for

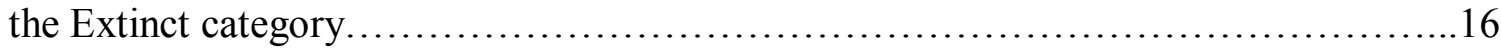

Table 1.2: Timeline of Significant Biodiversity Developments......................19-20

Table 3.1: COSEWIC Wildlife Species Definitions and Status Categories............35-36

Table 3.2: Elements of Recovery of Nationally Endangered Wildlife (RENEW).........37

Table 3.3: Elements of the Committee on the Status of Endangered Wildlife in

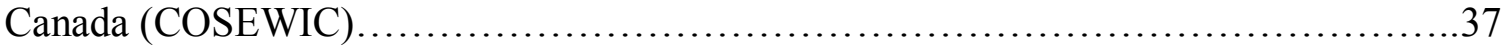

Table 3.4: A summary of the Species at Risk Act (Bill C-5)...........................39-40

Table 4.1: COSSARO Wildlife Species Definitions and Status Categories............53-54

Table 4.2: Elements of the Committee on the Status of Species at Risk in

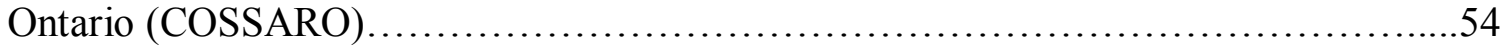

Table 4.3: Bill 184, [Ontario] Endangered Species Act, 2007

Explanatory Note ................................................................

Table 6.1: Selected Provisions of Environmental Laws in British Columbia Relevant for Species Protection...........................................96-98 


\section{LIST OF FIGURES}

Figure 1.1: The Policy Cycle...................................................

Figure 5.1: Eastern Loggerhead Shrike Historic and Present Breeding

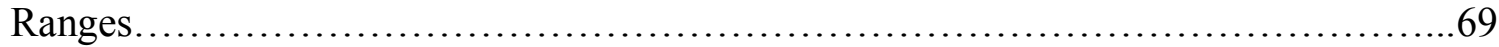

Figure 5.2: Population Monitoring of Eastern Loggerhead Shrike Breeding

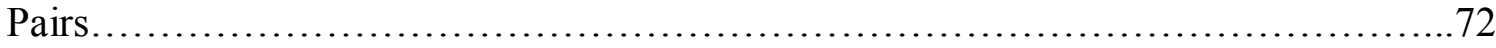

Figure 5.3: Documented individual occurrences of Ambystoma jeffersonianum in

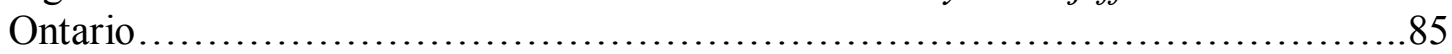

Figure 7.2: Distribution of active (as of 2005) and inactive (1896-2004) colony locations for the Vancouver Island marmot (Marmota vancouverensis) in Canada.................112 


\section{LIST OF ACRONYMS}

$\begin{array}{ll}\text { ATK } & \text { Aboriginal Traditional Knowledge } \\ \text { CBD } & \text { Convention on Biological Diversity } \\ \text { CESCC } & \text { Canadian Endangered Species Conservation Council } \\ \text { CLTIP } & \text { Canadian Land Tax Incentive Program } \\ \text { COSEWIC } & \text { Committee on the Statues of Endangered Wildlife in Canada } \\ \text { COSSARO } & \text { Committee on the Status of Species at Risk in Ontario } \\ \text { ECO } & \text { Environmental Commissioner of Ontario } \\ \text { ENGO } & \text { Environmental Non-Governmental Organization } \\ \text { ESA } & \text { Endangered Species Act } \\ \text { FDP } & \text { Forest Development Plan } \\ \text { IWMS } & \text { Identified Wildlife Management Strategy } \\ \text { MBCA } & \text { Migratory Birds Convention Act } \\ \text { MNR } & \text { Ministry of Natural Resources (Ontario) } \\ \text { MOE } & \text { Ministry of Environment } \\ \text { RAG } & \text { Recovery Action Group } \\ \text { RENEW } & \text { Recovery of Nationally Endangered Wildlife } \\ \text { SARA } & \text { Species at Risk Act } \\ \text { SARFIP } & \text { Species at Risk Farm Incentive Program } \\ \text { SARO } & \text { Species at Risk in Ontario } \\ \text { SOMP } & \text { Spotted Owl Management Plan } \\ \text { SORT } & \text { Spotted Owl Recovery Team } \\ \text { SRMZ } & \text { Species Resource Management Zone } \\ \text { SSC } & \text { Species Specialist Committee } \\ \text { UNEP } & \text { United Nations Environment Programme } \\ \text { WAPPRIITA } & \text { Wild Animal and Plant Protection and Regulation of International } \\ & \text { and Interprovincial Trade Act } \\ & \\ & \end{array}$




\section{CHAPTER 1.0 INTRODUCTION}

This thesis is the result of reflecting upon the current biodiversity and extinction crisis that is taking place on a global scale (Novacek and Cleland, 2001). Rates of species extinctions have reached alarming proportions, significantly threatening the interconnected web of biodiversity on the planet (Wilson, 1992: 254-279; Myers, 1993; Pimm et al., 1995). Canada is not immune to the biodiversity crisis. Despite the country's reputation for pristine wilderness and healthy natural ecosystems, it is beginning to exhibit the tolls of over a century of industrial and agricultural activity. Evidence indicates that biodiversity trends in Canada are pessimistic and numbers of species at risk continue to rise (Mosquin, 2000: 68-76). This thesis is motivated by the following question: Which policy tools and instruments could be more effective to address problems of species at risk in Canada? In response to that question, the primary objective was to undertake an interpretive qualitative evaluation of existing legal tools for species at risk in Canada. The purposes of this thesis are to contribute to the legal body of knowledge and to provide recommendations on 'program improvement' for species at risk preservation and legal measures, with a specific focus on provincial measures. The central focus of the thesis is that legal protection should be science based. The importance of scientifically informed species at risk policy and legal protection is emphasized throughout. The effectiveness of implementation of existing measures for individual species is analyzed through four case studies of species at risk in two provinces in Canada.

Legal and policy tools at the federal and provincial levels of government were evaluated. Case studies were used to stress the importance of current scientific information in taking a precautionary approach to the formulation of legal tools and policy instruments for the protection of species at risk. In order to assess the effectiveness of the implementation of policy goals, existing legal measures and policy instruments must be individually evaluated and improvements devised. This is the crux of the thesis.

By analyzing individual case studies, evidence for the application and implementation of existing policy and legal tools and the subsequent outcomes is accumulated and evaluated. The application of the legal tools and their implementation 
can be more readily understood. In addition, the importance of scientific information for the creation and implementation of legal tools is highlighted. Moreover, decisions and recommendations for improvement can be more easily pinpointed where flaws in the implementation or enforcement of legal tools are evident. Thus, the interpretive qualitative evaluation of case studies provides supporting material for new recommendations.

The protection of species at risk is central to mitigating extinctions. Scientific facts are also crucial to understanding causes of individual species declines. The existing legal tools currently relied upon for managing species at risk must be scrutinized. For a policy problem of this sort, legal measures tend to have a great deal of potential for controlling human activities and effecting meaningful and consequential changes. While education and social pressure are important determinants of human behaviour, law has the benefit of being imbued with enforcement powers that bind citizens to follow the rules. It is an important influence because it is backed by the power of the state (Cunningham and Kagan, 2005; Kube and Traxler, 2010). Law in the form of legislation is the main vehicle for the implementation of policy. Legislation and litigation have a significant role in inducing government action (Amos et al., 2001; Elgie, 2003; Illical and Harrison, 2007; Elgie, 2009).

Hence, the most feasible approach to mitigate species loss is by developing science-based policy and implementing science-based legal and policy tools. Implementation, to be effective, needs to be carried out at both the national and subnational levels in Canada. Many policy treatments of species at risk to date have focused attention on the federal level (Amos et al., 2001; Elgie, 2003; Illical and Harrison, 2007 Elgie, 2009). A very significant contribution of this thesis to the literature is to focus simultaneously on the policy tools available at the federal and provincial levels.

This thesis is very timely as biodiversity protection continues to remain on the international agenda. The United Nations proclaimed 2010 to be the International Year of Biodiversity, in order to draw attention to the protocols outlined in the Convention on Biological Diversity (CBD) in 1992 as well as to encourage continued action to safeguard biodiversity at present and onward into the future (CBD, 2010a). The main objectives of the Convention are as follows: "the conservation of biological diversity, the sustainable 
use of its components and the fair and equitable sharing of the benefits arising out of the utilization of genetic resources" (CBD, 2010b).

In attempts to address the biodiversity crisis within national borders, and by signing onto international treaties such as the Convention on Biological Diversity in 1992, Canada has committed to policy goals for the protection of species at risk. Some provincial governments have made these policy goals a priority as well. Some policy tools have been implemented over the last three decades to attempt to fulfill species at risk management goals. Presently, many such goals are not always entirely rooted in science. As is the case with much of the environmental policy realm, there is a great need for the intersection of science, law, and policy, for the effective implementation of policy goals based on legal and policy instruments. Sound science is imperative for defining environmental problems. To maximize the effectiveness of species at risk protection, scientists recommend that species at risk policy be based on sound scientific facts. The effectiveness of policy goal implementation and legal and policy instruments must also be individually evaluated. As scientific information changes, policies will be in constant need of evaluation and continuing reform. Where required, improvements must be developed and implemented. This thesis, an interpretive qualitative evaluation, fits into the final stages of the policy cycle, which include implementation of policy (in the form of legal tools), policy evaluation, and legal reformulation and restatement. The policy cycle is illustrated in Figure 1.1.

In order to provide legitimacy and justification for the investment and diversion of resources and personnel towards the preservation of biodiversity, and more specifically, species at risk, the importance of biodiversity and the benefits that the variety of life on Earth imparts must be comprehended. 

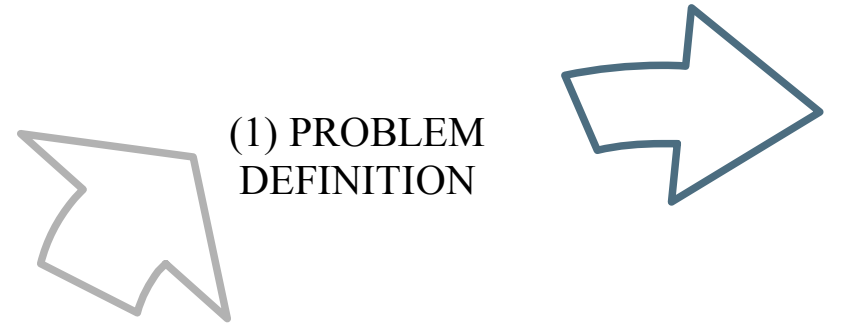

REFORMULATION

AND

RESTATEMENT

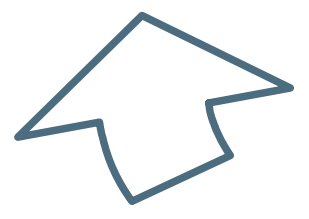

(5) POLICY

EVALUATION
(2) SETTING

THE

AGENDA

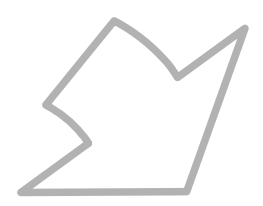

POLICY

FORMULATION

(3) DECISION

MAKING

(Choosing the

right solution)

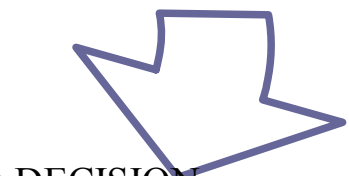

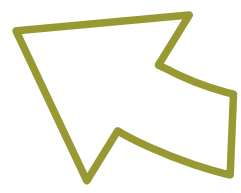

(4)

IMPLEMENTATION

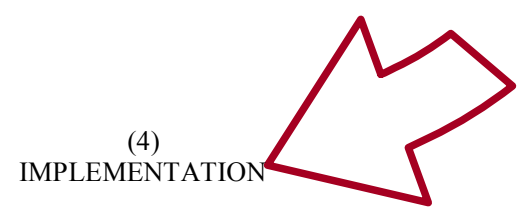

Figure 1.1: The Policy Cycle. (1) Problem: Biodiversity crisis in Canada; (2) Agenda: Canadian law; (3) Federal and provincial decision making bodies: COSEWIC, COSSARO, Government Departments; (4) Implementation of Policy (Legal Tools): Species at Risk Act, Ontario Endangered Species Act, 2007, various British Columbia laws; (5) Policy Evaluation: Main focus of this thesis.

\subsection{Importance of Biodiversity and Threats to Biodiversity: Why Should}

\section{Biodiversity Be Protected?}

\subsubsection{Importance of Biodiversity: Theories and Hypotheses on the Web of Life}

Human beings are bound to the planet, and rely on its resources to survive. On a global scale, humans are only a minuscule subset of the balanced and harmonious ecosystems that have existed for centuries. The web of life is a representation of the diversity of life forms (MacArthur, 1955; Hutchinson, 1959; Wilson, 1992). Every link within the web of life interacts with other portions or links, forming the building blocks 
to vast ecosystems and biomes that dot the planet extensively. The web of millions of species on Earth is the essence of biodiversity, or the diversity of life forms.

The variety and richness of life on Earth has captivated biologists for centuries. The concept of biodiversity began to surface in the works of prominent ecologists $\mathrm{G}$. Evelyn Hutchinson and Robert MacArthur in the late 1950s. In the 1970s, the term "natural diversity" was used to refer to the richness of species by the US environmental non-governmental organization, the Nature Conservancy. It was not until 1980 that the word biodiversity or "biological diversity" was coined by Thomas Lovejoy in the Global 2000 Report to the President (Barney, 1980; Kramer et al., 1997: 117).

Biodiversity represents the variety and diversity of all life forms on Earth, including genetic diversity, the diversity within species, between species, and of entire ecosystems. In simple and succinct ecological terms, biodiversity can also be defined as species richness, or the number of species present in a defined geographical area (Wilson, 1992: xii; Townsend et al., 2000: 354). B.A. Wilcox (1984) defines biodiversity more specifically as "the variety of life forms, the ecological roles they perform, and the genetic diversity they contain" " The notion that biodiversity encompasses the variety of all life forms highlights the importance of the existence of individual species. The diversity of life forms is apparent among the vast variety of species that are present on the planet. The working definition of biodiversity for the purposes of this thesis is based on that which has been stated by Wilcox. Each species performs specific ecological roles and contributes to the fabric of ecological and genetic diversity to enable the functioning of ecosystems.

The species concept is vital to the study and protection of biodiversity (Wilson, 1993: 38). Organisms can be biologically classified as being members of the same species if they are genetically distinct from other species, and are potentially capable of interbreeding and reproducing. In other words, members of a single species are members of genetically distinct reproductive communities that are geographically isolated from other genetically distinct reproducing communities (Mallett, 1995; Townsend et al., 2000: 59). The variety of species aids in maintaining 'biological integrity', wherein they

\footnotetext{
${ }^{1}$ This definition of biodiversity is cited by Dennis D. Murphy. 1986. "Challenges to Biological Diversity in Urban Areas". In E.O. Wilson, ed., Biodiversity. National Academy Press. Pages 71-72.
} 
sustain the delicate balance and functional organization of the ecosystem which they are a component of (Hughes and Nosh, 1992). Individual populations of species will shift, adapt, or disappear, in response to environmental changes. Hence, there is a necessity to thoroughly understand and protect species and their habitats in order to sustain biodiversity and biological integrity.

Eminent biologist and "dean" of biodiversity studies, E.O. Wilson (1988) describes a vision of "biodiversity" that is rooted in individual species but is expanded holistically to entire life systems. Intrinsic in this vision of biodiversity is the realization that it is in danger, and once it disappears it is irreversible. Wilson was the first scientist to introduce the notion of a "biodiversity crisis" on a large scale. Wilson (1993: 35) also accentuates the importance of biodiversity by asserting that "the variety of organisms, from alleles (differing gene forms) to species, once lost, cannot be regained". Every life form that exists within an ecosystem performs different functions and contributes to various ecosystem services that aid in maintaining the system over time. The ultimate response of ecosystems to a decline in biodiversity is not entirely known. Some theories are currently in existence.

Pioneering ecologists maintained that the stability of whole ecosystems is entirely related to their diversity. Prior to the 1970s, prominent ecologists such as Odum (1953), MacArthur (1955), and Elton (1958) subscribed to the theory that increasing diversity contributes to the stabilization of an ecosystem. This is also known as the diversitystability relationship. Charles Elton (1958) was the first to clearly state and build upon the arguments of Odum and MacArthur. Elton stated that "simple communities were more easily upset than richer ones; that is, more subject to destructive oscillations in populations, and more vulnerable to invasions" (Elton 1958: 45). Both Odum (1953) and Elton (1958) similarly observed that more violent fluctuations in population density were characteristic of simplified terrestrial communities as opposed to more stable population density in diverse terrestrial communities. For instance, it was found that invasions were more frequent on disturbed, cultivated land, where anthropogenic activity had largely simplified ecological communities (McCann, 2000: 228). According to this theory, any interruptions and deletions in the harmonious web of life has the possibility of disrupting 
natural processes and bringing about devastating negative consequences for environmental, ecosystem, and human health (Suzuki, 2001).

MacArthur (1955) illustrated the importance of interconnections in food webs and energy. He hypothesized that greater 'connectance' is a driver of community and ecosystem stability. A greater diversity of species within a food web causes an increase in the number of energy pathways, strengthening the food web and increasing the stability of the system (McCann, 2000: 228). In fact, more recently, Romanuk et al. (2006) corroborated MacArthur's hypothesis that populations that are present in a food web with greater connectance, and consequentially have access to a greater range of resources, are more stable than those which consume a more restricted range of resources. This appears to be a further "benefit of high levels of species richness in food webs" (Romanuk et al., 2006: 376).

In 1973, Robert May challenged the diversity-stability theory. He used mathematical relationships to come to the conclusion that diversity tends to destabilize community dynamics. Hence, he hypothesized that diversity, alone, is not a driver of stability (McCann, 2000: 228). This notion tends to concur with the consensus that food webs are a complex of energetic pathways. These webs do not rely solely on diversity for stability and support. The energy present in the diverse pathways of the various food webs that compose the fabric of complex ecosystems may be just as important as the diversity present within each web (McCann, 2000: 232).

Ultimately, based on theory and empirical evidence, all ecologists have come to a consensus that declines in diversity should "accelerate the simplification of ecological communities" (McCann, 2000: 228). Conservation of biodiversity is a very important aspect for the preservation of ecosystem function and health. McCann (2000: 233) suggests that an ecosystem and its component species are to be preserved by proceeding "as if each species is sacred". Also, any species removals (extinctions) or species additions (invasions) "can, and eventually will, invoke major shifts in community structure and dynamics", and the repercussions of these changes are unpredictable (McCann, 2000: 233).

Notable ornithologist, Bridget Stutchbury (2007: 31) stresses the importance of species diversity for human well being and survival and maintains that "the natural 
resources we use directly are supported by tens of thousands of species that we pay little attention to". The well-being of humankind is reliant on the existence of a vigorous level of biodiversity, which promotes ecosystem health. The 2005 United Nations Millennium Ecosystem Assessment (MEA) report estimates that 60 percent of the world's ecosystem services have been degraded or used unsustainably (Millennium Ecosystem Assessment, 2005: 1). Since only about 15 percent of the Earth's biodiversity and the interconnections among them are understood, there is much left to be comprehended (Suzuki in Beazley and Boardman, 2001: vi). A complete knowledge of the repercussions of a continued loss of biodiversity is not known. There is a general consensus that there will be an onslaught of negative ramifications as genetic resources, community attributes, and ecosystem properties are lost forever with the extinction of each individual species (Van Dyke, 2003: 80). In addition, "the impact of losing a species, or set of species, [...], depends on whether their role in the environment can be filled by other animals", and effectively sustain the web of life (Stutchbury, 2007: 31). Relying on other species to fill the void left by extinct species is effectively a gamble. There may not always be species which are as well adapted as the extinct species were at performing the specific ecological role.

\subsubsection{Value of Biodiversity and Species}

The decision to protect biodiversity is defined by two major arguments. It is a debate that takes place on the philosophical and ethical front alongside the ecological and political front. Two major arguments for the protection of biodiversity exist. Proponents of either of these arguments insist that the current biodiversity crisis should be addressed because the variety of life and diversity of species not only provide critical utility to humans and entire ecosystems, they also hold much value in and of themselves. Hence, endangered species can be valued intrinsically or instrumentally (Beazley and Boardman, 2001: 13).

The argument to preserve endangered species based on intrinsic value is essentially a call for conservation based on inherent worth. Each species exists as a product and continual process of evolution. Each holds value in and of itself, regardless

of utility. According to this level of worth, humans have a moral and ethical obligation to 
avoid interference with the right of other species to exist. This is the biocentric, or lifecentred view to preserving endangered species (Beazley and Boardman, 2001: 13).

The anthropocentric, or human-centred, view of conservation regards biodiversity and species in terms of their instrumental value. Endangered species are a portion of the web that sustains life. All species contribute to biodiversity of ecosystems. The survival of humans within these ecosystems relies on the continued existence of biodiversity. With the accelerated disappearance of endangered species from the web of life, the level of biodiversity also decreases. Hence, endangered species hold instrumental value. The anthropocentric view proposes that endangered species should be conserved out of “enlightened self-interest" (Beazley and Boardman, 2001: 13).

The earlier and more dominant views of conservation biology tended to value endangered species based on their inherent worth. Conservationists have long argued and championed the importance of preserving biodiversity based on the intrinsic, religious, and cultural values of organisms. More recently, the United Nations Millennium Ecosystem Assessment of 2005 has brought about a shift in scientific perception of the fundamental role and value of biodiversity. The important role that biodiversity plays in offering ecosystem services and contributing to human well being is now being strongly emphasized (Mosquin, 2000: 108; Millennium Ecosystem Assessment, 2005; Ninan, 2009: 1). Justification of actions to conserve biodiversity and individual species no longer lies mainly within the realm of conservation for solely spiritual and ethical reasons and the right of a species' existence independent of human use. As mentioned earlier, this concept, which encompasses the acknowledgment of value in something in and of itself, irrespective of it utility, is largely referred to as 'intrinsic value'.

Ecosystem services that species, biodiversity, and the web of life provide on the larger scale are presently being emphasized in addition to the intrinsic value argument. People tend to value ecosystems based on consideration of their own benefit and wellbeing in some respects, and based on intrinsic value in other respects (Ninan, 2009: 1). This added facet to the importance of biodiversity protection arises from the interconnections between people, biodiversity, and ecosystems. Anthropogenic activity impacts biodiversity and ecosystems both directly and indirectly. The ecosystem services that they provide to humans are greatly affected, consequently resulting in impacts on 
overall human well-being (ibid). It is imperative to note that other natural factors independent of anthropogenic activity may influence biodiversity and ecosystems, and that other factors not necessarily associated with changes in biodiversity and ecosystems can affect human conditions (Millennium Ecosystem Assessment, 2005: v-viii; Ninan, 2009: 1). Nonetheless, the loss of biodiversity and the corresponding ecosystem services that biodiversity provides is one of the greatest threats to humanity. The argument to promote biodiversity protection is thus supported based on both the case for species' valuable contributions to human needs and survival as well as the ethical case for conservation based on inherent value. As such, conservation of biodiversity must be taken seriously on all fronts, at local, sub-national, national, and global levels (ibid.).

The Millennium Ecosystem Assessment identifies four main facets of ecosystem services that contribute to human well-being. They include provisioning, regulating, cultural, and supporting services. Examples of provisioning services include food, water, timber, and fibre provisioning. Regulating services include the controlling and buffering of climate, floods, disease, wastes, and water quality. Cultural services encompass recreation, aesthetic enjoyment, and spiritual fulfillment. Natural supporting services include soil formation, photosynthesis, and nutrient cycling, to name a few. Human wellbeing as defined by the Millennium Ecosystem Assessment refers to material welfare and livelihoods alongside security, resiliency, social relations, health, and freedom of choice and action. The loss of biodiversity affects the critical ecosystem services that ultimately sustain human life and human well-being (Mosquin, 2000; Millennium Ecosystem Assessment, 2005: v-viii; Ninan, 2009: 2).

In essence, biodiversity is important to humans because it holds ecological, economic, and cultural values. The importance of maintaining biodiversity and theories of the web of life have been thoroughly discussed. Ecologically, human beings rely on healthy levels of biodiversity to sustain food webs and maintain systems of life support. The economic importance of biodiversity is very extensive. Essentially, biodiversity provides humans with the necessities of life and forms the basis for the economy. All that is purchased and sold commercially originates from the natural world. Some examples include medicinal ingredients and remedies, forest products, agricultural products, fishing, and recreational activities. Culturally, humans are biologically attached 
to nature and inspired by its intrinsic beauty. Every culture makes use of natural attributes and species to give symbolic meaning to human tradition and society. For example, the bald eagle is extensively used as a symbol of freedom. A well known example of this is the national significance given to the Bald Eagle in the United States (Mosquin, 2000; Millennium Ecosystem Assessment, 2005: 6-10).

\subsection{The Global Biodiversity Crisis}

Most scientists estimate the total number of species on the planet to range between 10 and 20 million (Wilson, 1992: 132). Only about 1.5 million species have been identified, named, and classified. However, species that have been thoroughly studied, whose detailed biological information is known and whose life history traits are understood are much less in number. Less than 1 percent of all species that have been classified are well understood (Suzuki, 2001: vi; Wilson, 1992: 346). Vertebrates are well-documented organisms when compared to invertebrates and plants and fungi, which compose the vast majority of species on the planet (Cooney and Dickson, 2005: 3).

Although extinction is a natural process and massive extinction events have taken place in the past, the present rate of extinction has reached crisis proportions worldwide (Wilson, 1992: 243-259; Lindenmyer and Burgman, 2005: 154). Scientists have only been able to estimate various predictions of species loss. Some estimates predict a loss of a minimum of 0.25 to 0.50 percent of all species per decade. However, scientists warn that these estimates are conservative, merely due to what little is understood about all the species in existence (Lindenmyer and Burgman, 2005: 156). Evidence suggests that current extinction rates are substantially higher than the "background" rate at which species have disappeared due to natural evolutionary processes in the past (Lindenmyer and Burgman, 2005: 157). High extinction rates, alongside accelerating species invasion rates due to increased globalization in a modern world, place ecosystems under great stress. Thus, it is crucial to understand how the loss of species or the addition of nonnative species influences the stability and function of the ecosystems that humans rely on for survival.

The current extinction crisis is defined by the disappearance of thousands of species from the planet on a daily basis. Scientists are calling this phenomenon "the sixth 
great extinction" because species are going extinct at a faster rate than they have since the dinosaurs disappeared (Suzuki, 2001; Ninan, 2009: xvii).

Although there is much uncertainty as to the number of species that currently exist on the planet as well as the actual current rates of extinction, causes of species extinctions are attributed to anthropogenic actions. Even so, exact causes are difficult to pinpoint. Anthropogenic action is defined in the Canadian Oxford Dictionary as anything that is "caused by human activity", such as anthropogenic environmental damage. While the over-harvesting of organisms, pollution, invasive species, and climate change are all factors that have negatively affected biodiversity worldwide, the alteration, fragmentation, and disappearance of habitat are the primary anthropogenic threats to biodiversity (Wilson, 1988: 3; Wilson, 1992: 253; Sisk et al., 1994; Millennium Ecosystem Assessment, 2005: 1-5; David Suzuki Foundation, 2009b). The latter is a crucial factor in the decline of the four species at risk case studies that are the subject of this thesis.

\subsection{Uncertainty and Precaution in Species at Risk Policy and the Need for Local Solutions}

The biodiversity crisis is occurring on a global scale, across the entire planet (Wilson, 1992). However, it is impossible to attempt to resolve the issue on such a vast scale. The problem can only be tackled effectively at national and subnational, or provincial levels. Localized responses can ultimately be more effective means to protect and manage species at risk. In addition, legal tools apply within a defined jurisdiction. Across jurisdictions, the efforts of other stakeholders such as non-governmental organizations, voluntary stewards, and private landowners are also crucial elements in the effort to protect species at risk.

Since there is a great deal of uncertainty in the actual dimensions of the current biodiversity crisis, and scientists are the most thoroughly informed on the causes of the crisis, it is recommended that scientific knowledge should inform the basis of species at risk policy and law. Science alone cannot protect species at risk because it lacks enforcement powers that have the potential to affect human behaviour. Law, on the other hand, can have an impact on human behaviour via the enforcement of norms, as it is the 
only way to enforce changes in behaviour via legal sanctions. Anthropogenic actions have accelerated extinction rates and human behaviour is linked to species extinctions (Sisk et al., 1994; Millennium Ecosystem Assessment, 2005: 1-5). Since science, by itself, does not have the legal power to effect changes via the enforcement of norms, legal and policy tools are essential.

There is substantial uncertainty among the scientific community as to the potential long-term impacts of losses of particular species on ecosystems (Myers, 1993; Hector et al., 2001: 625). Since there will always be a certain amount of uncertainty present, the precautionary principle is crucially important for addressing problems of endangered species (Hector et al., 2001). The precautionary principle is a fairly recent policy and regulatory instrument. It has emerged as a guide for law, policy, management, and decision-making, where uncertainty is involved.

The precautionary principle encompasses the premise that absolute certainty regarding an environmental harm must not be a prerequisite for taking action to stop it. In other words, if there is no absolute certainty that specific actions will impart heavy burdens on future generations, but there is reason to believe that they may, then the specific action should not take place (Folke et al., 1993: 63). The principle is in direct opposition to the presumption that all activities should take place until there is evidence that the activities are causing harm. The principle also advocates action to anticipate and prevent environmental harm, even in the absence of scientific proof that the action is necessary. The precautionary principle is present in many international environmental treaties, such as the 1992 Convention on Biological Diversity, which is briefly discussed in Chapter 3. It is also present in some Canadian federal and provincial statutes, such as Canada's federal Species at Risk $A c t^{2}$, discussed at length in Chapter 3, which advocates a precautionary approach to protection of species at risk on the basis of Canada's ratification of the Convention on Biological Diversity (Cooney and Dickson, 2005: 4-5, 159).

Justification for the application of the precautionary principle within the realm of biodiversity has been also advocated by Norman Myers (1993). Myers states that the precautionary principle applies to biodiversity more than any other environmental

\footnotetext{
${ }^{2}$ Legal citations for all legislation mentioned in this thesis can be found on page 145.
} 
problem because of serious concerns of adverse repercussions on biological, ecological, economic, and other levels. The possible repercussions of biodiversity degradation warrant the formulation and implementation of policy initiatives that take biodiversity protection into account (Myers, 1993: 74).

\subsection{Importance of Biodiversity in Canada}

Biodiversity is important because it encompasses ecological or indirect utility; economic or direct utility; and cultural values alongside intrinsic value based on inherent worth and the basic right of existence of all life forms. Ecologically, the entire planet relies on the integrity of biodiversity to sustain food webs and maintain systems of life support within ecosystems. In essence, biodiversity also sustains human existence, and human beings extract indirect utility or benefit from the variety of all life forms (Wilson, 1988; Wilson, 1992; Mosquin, 2000; Townsend et al., 2000: 338; Millennium Ecosystem Assessment, 2005: 6-10).

Biodiversity provides indirect benefits to humankind by supplying the necessities of life and it also forms the basis for the economy. Remarkable amounts of goods that are purchased and sold commercially originate from the natural world. Some examples include medicinal ingredients and remedies, forest products, agricultural products, fishing, and recreational activities (Wilson, 1988; Wilson, 1992; Mosquin, 2000; Millennium Ecosystem Assessment, 2005: 6-10).

On the national front, some of the economic development in Canada is reliant upon the biodiversity that is a constituent of the country's natural landscape. The Canadian economy is mainly a staples economy that is mostly driven by natural resource extraction. Although mining, oil and gas extraction, forest fibre extraction, aggregate extraction, and agriculture are not as greatly reliant upon biodiversity, the health of the country's fishing industry is contingent upon the integrity of ecological systems and biodiversity. For instance, over the last three decades marine and other wildlife stocks have declined rapidly (Hessing et al., 2005: 272-273). Forestry related industries and agriculture contribute to the loss of genetic diversity through the promotion of monocultures. Reforestation failures in old-growth stands in British Columbia are rampant, depleting species and habitat diversity (Bocking, 1999: 21). Aquaculture is a 
human activity that is affecting the biodiversity of fish, mostly by the accidental release of unfit fish or non-native strains that hybridize with native populations, decreasing their genetic diversity and vigour (Norris et al., 1999; Redpath Museum, n.d.).

In addition, an indication of the economic importance of recreational activities resulting from biodiversity and affinity with nature in Canada can be noted in the results of a 1991 Statistics Canada survey on the 'Importance of Wildlife to Canadians'. Results from the survey indicate that nearly nineteen million Canadians spent over five billion dollars while partaking in wildlife-related activities (Filion et al., 1994). In 1995, Resource Futures International reported similar amounts (almost $\$ 5.6$ billion). With specific reference to endangered species, it is reported that "net benefit to Canadians of wildlife-related activities involving endangered mammals and birds" could be $\$ 40$ million per year. The amount would be much higher in present circumstances as it would have to be adjusted for inflation. Also, the amount does not account for endangered species other than mammals and birds (RFI, 1995: 24; Gray et al., 2003).

As the Canadian government has not made it a priority to update this data and surveys on the matter have not been conducted since ${ }^{3}$, it can be assumed that the same trends have upheld, with affinity towards nature and wildlife continuing to remain an integral part of the 'Canadian identity' and continuing to be embedded within the Canadian economy. One would expect that since Canadians evidence concern for nature in surveys and public opinion research (Amos et al., 2001: 144-146), Canada would have strong policy tools in place for protecting species at risk. The effectiveness of these tools is a fundamental focus of this thesis.

\subsection{Biodiversity Challenges in Canada}

Habitat loss has been attributed as the number one threat to over 80 percent of Canada's species at risk (Elgie, 2009: 211). Measures of the state of current biodiversity in the country include the condition of genetic and species diversity, ecosystems, and ecological functions and processes (Mosquin, 2000: 59). A survey of Canada's taxonomic biodiversity conducted by Ted Mosquin in the early 1990s, including groups in marine regions, revealed that Canada has an estimated 140,000 species, with only

\footnotetext{
${ }^{3}$ At least none that could be easily accessed through electronic channels, to the knowledge of the author.
} 
70,000 having been identified and known to science (Mosquin, 2000: 63). Of great concern are also the loss of genetic diversity and the pool of unique and rigorous genes among species in Canada. This is especially evident in the agriculture and forest fibre industries, where old-growth forests have been replaced with genetically redundant monocultures (Mosquin, 2000: 61). Negative trends are emerging in biodiversity in Canada.

With regards to species at risk in Canada, as outlined in Table 1.1, as of November 2010, 617 species were considered to be at risk; however, the actual number is thought to be much higher (Suzuki, 2001; Illical and Harrison, 2007: 367; COSEWIC, 2010). Thus, the biodiversity crisis is also very severe on the home front.

Table 1.1: Summary of COSEWIC's assessment results for the "risk" categories (Extirpated, Endangered, Threatened and Special Concern) (617 wildlife species) and for the Extinct category (14 wildlife species).

The results include data up to the November 2010 COSEWIC meeting.

\begin{tabular}{|c|c|c|c|c|c|c|c|c|c|c|c|}
\hline Status & Mammals & Birds & Reptiles & Amphibians & Fishes & Arthropods & Molluscs & s Vascula & rr|Mosses & sLichens & Total \\
\hline & & & & & & & & Plants & & & \\
\hline Extinct & 2 & 3 & 0 & 0 & 7 & 0 & 1 & 0 & 1 & 0 & 14 \\
\hline Extirpated & 3 & 2 & 4 & 1 & 3 & 3 & 2 & 3 & 1 & 0 & 22 \\
\hline Endangered & 20 & 29 & 17 & 9 & 46 & 25 & 18 & 94 & 8 & 4 & 270 \\
\hline Threatened & 17 & 24 & 11 & 4 & 33 & 6 & 3 & 49 & 3 & 3 & 153 \\
\hline $\begin{array}{l}\text { Special } \\
\text { Concern }\end{array}$ & 27 & 20 & 9 & 7 & 49 & 5 & 6 & 39 & 4 & 6 & 172 \\
\hline Total & 69 & 78 & 41 & 21 & 138 & 39 & 30 & 185 & 17 & 13 & 631 \\
\hline
\end{tabular}

[Source: http://www.cosewic.gc.ca/rpts/Full_List_Species.htm, COSEWIC, 2010]

\subsection{Canadian Legal Tools for the Protection of Species at Risk}

Despite the presence of scientific uncertainty in the biodiversity crisis, much information is known about certain species in Canada. Individual species case studies, analyzed in depth in Chapter 5 and Chapter 7, serve to highlight the importance of 
scientific information in the creation and implementation of species at risk policy. This thesis focuses on four specific case studies that have been very well studied in order to conduct an interpretive qualitative evaluation of the legal protection of species at risk in Canada. The motivation behind the focus of case studies for the evaluation of legal species at risk protection in Canada is the present lack of case study literature that focuses on provincial measures in conjunction with federal measures. Canadian lawyer Stewart Elgie has comprehensively analysed the federal jurisdiction with regards to species at risk protection (Elgie, 2003; Elgie, 2009). Case studies that are the subject matter of this thesis highlight legal protection measures at the provincial level of jurisdiction as well as the federal level, with particular consideration of the fact that the provincial jurisdiction plays a very important role in the protection of Canada's species at risk, a matter that will also be discussed in this paper. Case studies are also an effective method of evaluating legal measures for protecting species at risk because the knowledge that exists about certain well-studied species is enough to facilitate the pursuit of effective protection, with the proper legal tools and sufficient political will. In the Canadian context, there are a range of legal tools available for protecting species at risk. These tools include: federal and provincial statutes and regulations; species listing processes; critical habitat identification; and recovery plans.

Chapter 3 outlines the existing legal tools for protecting species at risk at the federal level and their shortcomings. Since jurisdiction is a crucial component for the effective implementation of species at risk protection in Canada, the central contribution of this thesis consists of a comparison of the legal tools provided by the provinces of British Columbia and Ontario. The provinces were selected for study as they are often compared in the legal and policy literatures and they contain the highest identified levels of species at risk among all the regions in Canada. The rationales for the selection of the two provinces are elaborated on in Chapter 2. After setting out the main legal tools for Ontario in Chapter 4, there are two case studies from Ontario in Chapter 5. The main legal tools for British Columbia are addressed in Chapter 6, while two case studies from British Columbia are encompassed in Chapter 7. The rationales for the selection of species at risk case studies are outlined in Chapter 2. Vertebrate species were selected because of access to available data. Also, all species selected for study are indicator 
species whose health and existence are indicators of the health of their habitats and environs.

In the case of the legal tools available in Ontario, where there is dedicated endangered species legislation at the provincial level, the Endangered Species Act, 2007, Environmental Non-governmental Organizations (ENGOs) are pushing for the abolition of exemptions that undermine the provisions of the Act. In British Columbia, ENGOs are pushing for the establishment of dedicated endangered species legislation which should be generally modeled after the Ontario law. Jurisdictions can draw policy lessons from one another on the basis of successful solutions to defined issues.

In essence, there is a requirement for more effective management tools for the problem of biodiversity loss and species at risk. These tools must be rooted in scientific understanding about the specific causes of species decline and the habitat requirements for the recovery of species in decline. Science-based policy, legal, and management tools following a precautionary approach must be implemented at both the federal and provincial levels for more effective management of species at risk in Canada.

The recommendations resulting from the scrutiny of existing legal tools and original legal documents as well as the evaluation of legal inadequacies are elaborated in Chapter 8. Emerging themes include the importance of inter-jurisdictional and intrajurisdictional cooperation for effective species at risk policy; the judicious and scientifically informed use of flexibility instruments such as permits and exemptions to existing law; and the importance of funding private landowner stewardship efforts. Scientific information and the proper definition of critical recovery habitat for species at risk alongside the importance of using a precautionary approach are also discussed.

The research methodology of this thesis is rooted in interpretive qualitative evaluation techniques, via the close scrutiny of legal documents to obtain qualitative data so as to evaluate their effectiveness (Patton, 2002: 4-12). Case studies also served to highlight the qualitative data. Methodologies will now be discussed in Chapter 2. 


\section{Table 1.2: Timeline of Significant Biodiversity Developments}

Significant developments in biodiversity law and policy, situating Canada in the larger global context:

1916: Canada - United States Migratory Birds Convention

1917: Canada enacted the Migratory Birds Convention Act

1930: Canadian Parliament passed first National Parks Act

1966: United States passed Endangered Species Preservation Act, amended in 1969 and replaced in 1973 with the Endangered Species Act.

1971: Ramsar Convention on Wetlands of International Importance; Ontario passed Endangered Species Act

1973: Canada passed the Canada Wildlife Act; New Brunswick passed Endangered Species Act; United States passed revised and comprehensive Endangered Species Act

1978: Committee on the Status of Endangered Wildlife in Canada (COSEWIC) began assessing wildlife species and classifying their chances of survival

1981: Canada adopted the Ramsar convention of 1971

1988: Wildlife Ministers' Council of Canada established the program for Recovery of Nationally Endangered Wildlife (RENEW)

1989: Canadian Parks and Wilderness Society (CPAWS) and World Wildlife Fund (WWF) launched Endangered Spaces Campaign; Manitoba passed Endangered Species Act and Quebec passed An Act Respecting Threatened or Vulnerable Species

1990: Federal government and Wildlife Ministers' Council of Canada developed $A$ Wildlife Policy for Canada

1991: Federal government developed The Federal Policy on Wetland Conservation

1992: In June, Convention on Biological Diversity opened for signature at United Nations Conference on Environment and Development (UNCED), and Canada became a signatory; Council of Canadian Forestry Ministers released Canada Forest Accord

1993: Convention on Biological Diversity entered into force during December; Canada became first industrialized nation to ratify the Convention

1994: Canadian government and Biodiversity Working Group developed Canadian Biodiversity Strategy: Canada's Response to the Convention on Biological Diversity; Revised National Marine Conservation Areas Policy released; Migratory Birds Convention Act amended 
1996: National Accord of the Protection of Species at Risk endorsed by federal, provincial, and territorial governments; Canadian Endangered Species Protection Act introduced in October 1996 and died on the order paper in April 1997 when federal election was called

1998: Parks Canada Agency Act was passed; Nova Scotia passed Endangered Species Act; Prince Edward Island passed Wildlife Conservation Act; Saskatchewan passed Wildlife Act

1999: COSEWIC updated criteria in accordance with criteria developed by International Union for Conservation of Nature (IUCN)

2000: Canada National Parks Act passed by Parliament in June (passed by Senate in October 2000); Species at Risk Act introduced in April 2000 and died on the order paper in October 2000 when federal election was called; Alberta passed Wildlife Act

2001: Species at Risk Act re-introduced after Liberals were re-elected

2002: Species at Risk Act passed by Parliament in June 2002 and came into force during December 2002; Canada National Marine Conservation Areas Act passed

2007: Ontario passed Endangered Species Act, 2007

[Adapted from Greenbaum and Wellington, 2010: 465] 


\section{CHAPTER 2.0 METHODS}

The research method for this thesis was based on an interpretive qualitative evaluative method (Patton, 2002: 10). Patton (2002: 10) describes the particular research method that was used for this thesis as qualitative 'program evaluation'. The effectiveness of policy tools and legal measures, also known as qualitative data, was evaluated based on their ability to achieve the goals of species at risk protection. After close scrutiny and reading of legal documents, the implementation of species at risk protectionist policy goals was analyzed and their effectiveness for the management and preservation of species at risk in Canada were assessed. The policy tools and legal measures available at the federal level have been much studied (Amos et al., 2001; Elgie, 2003; Illical and Harrison, 2007; Elgie, 2009), but there are significant gaps in the literature with respect to the provincial level.

Evaluation case studies are pertinent to the application of interpretive qualitative evaluative research. This method of research emphasizes the integration of case studies. The method is often used in legal evaluation and policy analysis ${ }^{4}$. The purpose of this method is to amass information and generate findings that are useful based on the information. By understanding individual case studies, processes and outcomes of the 'program', or the effectiveness of the legal tools, can be more readily understood. Implementation gaps can be more easily identified when legal tools are evaluated on the basis of their effectiveness at protecting individual species on a case-by-case basis. Recommendations for improvement can be more easily pinpointed and suggested (Patton, 2002: 10).

At the outset of this thesis, a substantial portion of Canadian environmental policy literature was initially consulted ${ }^{5}$. A focus on species at risk policy was emphasized. Case study research is well established in scientific, social science, policy, and legal research. Case studies are a substantial portion of this thesis as well. Some recent examples of case studies illustrating biodiversity and species integrity as a policy challenge within the Canadian context are contained in case study anthologies edited by Gore and Stoett (2009) and VanNijnatten and Boardman (2009). The main biodiversity

\footnotetext{
${ }^{4}$ See the case studies in Gore and Stoett (2009) and VanNijnatten and Boardman (2009), for examples.

${ }^{5}$ Geist and McTaggart-Cowan, 1995; Amos et al., 2001; Illical and Harrison, 2007; Gore and Stoett, 2009; VanNijnatten and Boardman, 2009.
} 
case studies in Gore and Stoett (2009) emphasize local solutions to global problems in biodiversity and only two species case studies are evaluated: polar bears in the Canadian Arctic and salmon aquaculture issues in British Columbia. Bocking (2009: 13-37) identifies the importance of biodiversity in terms of various Canadian values and perspectives, in relation to economic repercussions and the management of resources such as forests and fish all the while protecting the integrity of species and habitats. The only case study in VanNijnatten and Boardman (2009), Elgie (2009: 197-212) analyzes the very long process that was undertaken for the creation of the federal Species at Risk Act, with a very limited portion of the study dedicated to the current policy situation at the federal level of government.

The first portion of the research methodology that is the basis of this thesis encompassed the complete review of original legal documents and existing legal tools for the protection of species at risk in Canada. Documents including provincial and federal statutes and regulations as well as species recovery strategies and management plans were thoroughly scrutinized. A statute is defined in standard dictionary definitions (such as the Canadian Oxford Dictionary) as "a decree or enactment passed by a legislative body, and expressed in a formal document". A regulation is defined in the Canadian Oxford Dictionary as "a prescribed rule or an authoritative direction, often appearing as a subordinate form of legislation that may be established without the necessity of enacting a new statute". Regulations have legal clout yet are different from legislation because they are appendages to existing legislation that essentially modify existing statutes in efforts to avoid enacting entirely new legislation. The statutes and regulations that were closely examined and evaluated are those that specifically address species at risk or that affect species at risk $^{6}$. Press releases, documents, and report cards ${ }^{7}$ published by

\footnotetext{
${ }^{6}$ Statutes examined and evaluated include the federal Species at Risk Act; the Ontario Endangered Species Act, 2007; the BC Wildlife Act, the Forest Practices Code of British Columbia Act, and the BC Forest and Range Practices Act. Regulations evaluated include Ontario Regulation 242/08 under the Endangered Species Act, 2007 and BC Government Actions Regulation 17/04 under the Forest and Range Practices Act. Specific species' recovery strategies were also analyzed.

${ }^{7}$ Documents evaluated include the Environmental Commissioner of Ontario's Report on the Ontario Endangered Species Act, 2007 (February 2009), which is available here:

http://www.eco.on.ca/eng/index.php/pubs/eco-publications/the-last-line-of-defense.php and the Nature Canada report card on the performance of the Species at Risk Act (April 2009), which is available here: http://www.naturecanada.ca/endangered atrisk saraRC2009.asp
} 
prominent Canadian Environmental Non-Governmental Organizations were also evaluated $^{8}$. In addition contemporary textbooks on Canadian environmental law were extensively reviewed ${ }^{9}$ as well as prominent cases that were brought to the Federal Court of Appeal. The most prominent case in the thesis is that of the Spotted Owl, as well as litigation resulting from applications for judicial review of the Species at Risk Act for the Greater Sage-Grouse and the Nooksack Dace ${ }^{10}$.

Since science and policy often intersect in environmental law, scientific literature on biodiversity was also reviewed ${ }^{11}$. An investigation of the current biodiversity crisis led to the realization that a case study approach was required to specifically assess the consequences of current legal measures for species at risk.

The case studies focused on four endangered vertebrate species and include the Eastern Loggerhead Shrike (Lanius ludovicianus migrans), Jefferson Salamander (Ambystoma jeffersonianum), Northern Spotted Owl (Strix occidentalis caurina), and the Vancouver Island Marmot (Marmota vancouverensis). Two species from Ontario and two from British Columbia are token examples of species at risk in Canada. The case studies are highlighted to garner insight into the degree of protection that exists at the level of federal and provincial jurisdictions. They also provide insight into the efficacy of this protection. Each species is analyzed in various contexts. First, differences in species protection based on ecological and life history traits were evaluated. Subsequently, the protection granted to each species allows comparison of two different types of provincial endangered species protection: dedicated endangered species legislation versus legislation that is not specifically dedicated to endangered species yet includes minor provisions to account for endangered species protection. The case studies illustrate how both types of provincial endangered species protection measures work in tandem with the federal level of protection, as well as their effectiveness.

\footnotetext{
${ }^{8}$ Major Canadian ENGOs with reference to species at risk: Ontario Save Our Species Coalition (SOS), Ontario Nature, Canada Nature, Western Wilderness Committee, David Suzuki Foundation, Forest Ethics, Environmental Defence.

${ }^{9}$ Boyd, 2003; Hughes and Lucas, 2003; Benedickson, 2009; Muldoon et al., 2009.

${ }^{10}$ Western Canada Wilderness Committee v. British Columbia (Minister of Forests), 2002 BCSC 1260; Alberta Wilderness Association v. Canada (Environment), 2009 FC 710; Environmental Defence Canada v. Canada (Fisheries and Oceans), 2009 FC 878

${ }^{11}$ Wilson, 1988; Jeffries, 1995; Bocking, 2000; VanDyke, 2003; Cooney and Dickson, 2005; Askins et al., 2008; Dearden and Mitchell, 2009.
} 
The research stresses the importance of the case study approach in light of the interpretive qualitative evaluative method. Legal and policy tools for species at risk protection were reviewed and analytically assessed. For instance, federal tools and the Species at Risk Act are described in Chapter 3, while the Ontario Endangered Species Act, 2007 is discussed in depth in Chapter 4, alongside other important species at risk management and legal tools. Although British Columbia lacks dedicated endangered species legislation, statutes that affect species at risk are described in Chapter 6 along with other legal measures. After evaluating the existing legal measures via the case study method, conclusions were drawn and policy recommendations for changes or reforms are provided on the basis of the analysis. The recommendations are found in Chapter 8 , and stress the importance of inter-jurisdictional and intra-jurisdictional cooperation as well as the benefit of dedicated species at risk legislation at both federal and provincial levels of jurisdiction and private landowner cooperation.

\subsection{Rationale for the Selection of British Columbia and Ontario as Comparator Provinces}

As previously mentioned, a major component of this research investigation is the selection of British Columbia and Ontario as comparator provincial jurisdictions. Two case study species were chosen from each province. Ontario was selected because the Ontario Endangered Species Act, 2007 is considered to be the best example of species at risk legislation in the country. Given the lack of extensive species at risk legal tools and dedicated legislation, British Columbia was also selected as a comparator province.

Both provinces also contain the highest identified levels of species at risk among all the regions in Canada, according to Committee on the Status of Endangered Wildlife in Canada (COSEWIC). Currently there are 617 species identified as being at risk in Canada. British Columbia is home to 202 of these species, while 205 of these species reside in Ontario (COSEWIC, 2010). Similarities in number of species at risk in the two provinces also allow them to be useful comparators in the realm of species at risk policy in Canada. The similarities between the two provinces permit each provincial jurisdiction to draw lessons from the other. It is for these reasons that species from these two provinces were selected for case study in this investigation. 


\subsection{Rationale for the Selection of Case Study Subjects: Vertebrate Species at Risk}

Vertebrates were selected not because they are the most important species in existence with regards to ecosystem contribution, but because there is a greater availability of information which provides access to comparators for research purposes. Charismatic vertebrates are used as comparators because their aesthetic and cultural appeal garners more interest and as a result allows more attention and funding to be diverted toward their study (Wilson, 1993: 49).

The Northern Spotted Owl and Vancouver Island Marmot are both charismatic vertebrate species that were chosen because there is more scientific data and information available on these more aesthetically popular species. These species obtain the greatest amount of funding that can in turn allow for population surveys and species health assessments. Policy research can only be compiled on the basis of availability and accessibility of information. It is for this reason that charismatic vertebrate species that cultivate popular appeal among non-governmental organization (NGO) campaigns, as well as the general public, and in turn appeal to governments, are the subjects of the case studies in this thesis. Both the Eastern Loggerhead Shrike and the Jefferson Salamander have been the subject of minor NGO campaigns and exist as very important indicator species of the health of the sensitive and densely populated southern Ontario and Greenbelt region. Both Ontario cases have some degree of charismatic appeal as they are the subject of public NGO campaigns, albeit not as large a scale as the British Columbia case studies. In addition, the Eastern Loggerhead Shrike is a species that was legally protected under Ontario's first piece of species at risk legislation, the Endangered Species Act, 1971. A comparison of similarities and differences of legal protection in the original Act and the new Act is juxtaposed in this thesis.

As a result of the evaluation of legal tools and selective case study analysis, conclusions were drawn and policy recommendations were made for possible future legal changes and reforms. These recommendations are outlined in Chapter 8. 


\section{CHAPTER 3.0 FEDERAL LEGAL MEASURES FOR SPECIES AT RISK IN CANADA}

Those who wish to ensure the effective protection of species at risk continually turn their attention to legal measures. Legal tools for the protection of biodiversity have the considerable advantage of enforcement measures. In the chapters that follow, the impacts of the presence and absence of legal tools at the provincial level are examined. In this chapter, the central focus is on setting the stage for scrutiny of the provincial tools, by indicating what is available at the federal level and explaining why the tools at the federal level are insufficient. Then, the nature of jurisdiction in Canada and how it affects species at risk protection is briefly described. Legal species at risk protection is not immune to jurisdictional matters. Subsequently, the focus is turned to the influence of international law upon Canadian law, and followed with a discussion of legal tools and of the key federal legal tool, the Species at Risk Act.

The extent of the current biodiversity crisis spans the entire globe. However, it is impossible to attempt to resolve the crisis at such a large scale. Legal tools to mitigate the biodiversity crisis only take effect at the national and subnational level. In the early 1990s, when the biodiversity crisis was acknowledged to be a serious global problem, the international community mobilized to establish international norms. International law exerts influences on federal law, and obligates the federal government to implement legal measures for the protection of endangered and threatened species. The influence of international law led to the creation of the federal Species at Risk Act (SARA) in 2002 (Gore and Stoett, 2009: 20-23; Greenbaum and Wellingon, 2010: 374-378).

However, prior to the passage of the Act, various federal laws for environmental protection were in place. None of those laws was specifically dedicated to species at risk protection, leaving a void in the federal protection of species at risk. Species at risk were acknowledged and listed by way of a decision making process by the Committee on the Status of Endangered Wildlife in Canada (COSEWIC), which was founded in 1978. Prior to the enactment of $S A R A$, the results of the process did not have any legal effect. The Recovery of Nationally Endangered Wildlife (RENEW) committee, established in 1988, was also in existence prior to $S A R A$. Its purpose was to establish recovery strategies for endangered or threatened species as listed under COSEWIC. For many 
years, these policy tools had no legal clout. Canadian endangered species law was in great need of improvement if protectionist measures were to become legally binding, and subject to enforcement measures. Nonetheless, even with the recognition of the urgent need for species at risk legislation at the federal level, conflicting stakeholder interests created challenges and a long time passed before an adequate compromise could be reached (Amos et al., 2001: 139; Elgie, 2009). The main elements of SARA will be discussed in this chapter.

Even though the Species at Risk Act has been in existence for 9 years, its implementation over the previous years has been viewed as insufficient for protecting species at risk. Many environmental non-governmental organizations such as the David Suzuki Foundation, Ecojustice, Environmental Defence, and Nature Canada have been successful in emphasizing its shortcomings (Nature Canada, 2009). Litigation for judicial review has recently played a crucial role in outlining inadequacies in species at risk protection (Valiante, 2009: 44-45). The Act's shortcomings will be described in this chapter alongside recommendations for further reform.

\subsection{The Institutional Composition of Canadian Environmental Law and Policy}

The present responsibility of various levels of government with respect to environmental issues is rooted in the division of jurisdictional powers between the federal and provincial governments that was originally outlined in the British North America Act, 1867 (BNA, 1867). As set out in the Act, provincial governments are responsible for natural resources, public lands and forests, and mines and minerals. Fisheries, aboriginal matters, interprovincial and international transport, as well as regulation of trade and commerce, are under the jurisdiction of the federal government. Although this division of powers was intended to be clear and precise, there is a history of jurisdictional conflict with respect to environmental issues, as the environment is not clearly defined within the constitution. These problems persisted even after the repatriation of the constitution from Britain to Canada in 1982 (the Canada Act, 1982) (Rogers and Wilkinson, 2000: 191).

Jurisdictional responsibilities were originally outlined for the purposes of economic expansion, growth, and development. In an era of concern for sustainable development and biodiversity preservation, jurisdictional conflict exists with regard to 
environmental issues. The reason is that environmental problems flow from one jurisdiction to the other, generating issues that require coordination and consultation among the various branches of government and all the various stakeholders. This results in what has been coined "jurisdictional gridlock" within the Canadian environmental policy process (Rogers and Wilkinson, 2000: 192). In other words, "jurisdictional gridlock" results from conflicting jurisdictional claims between different government jurisdictions, impeding the resolution of problems (ibid.).

Jurisdictional conflict is intrinsic to Canadian law as a result of the distribution of heads of power in the Canadian constitution. Issues pertaining to the environment can be found at every level of jurisdiction. For this reason, environmental policy can be quite messy. The imprecise definition of the environment and the responsibility of jurisdictions within the Canadian constitution has a vast influence on the Canadian environmental policy process, and ultimately, on environmental law within various jurisdictions. The influence of international law upon domestic law is also an important factor in the outcome of environmental law and policy in Canada, specifically at the federal level of jurisdiction. These influences are described in section 3.2.

\subsection{Influences of International Law upon Canadian Law}

International law is influential because it impacts the behaviour of countries at the national level. States respect it and "regard it as law" (Muldoon, 2003: 608). Events and actions in the international system can have a major impact on the activities of domestic states depending on the adoption of international law into domestic law (Hessing et al., 2005: 85). It cannot have any effect unless it is transformed into domestic law. In Canada, this usually occurs in the form of legislation (Currie, 2001: 199-200).

When countries sign international treaties, they commit themselves to enacting domestic legislation to implement the obligations contained in the treaty. In Canada, only the federal government has the authority to enter into treaties, and yet the federal government is limited to passing implementing legislation only within the constitutional limits of its authority. Its authority is not permitted to extend beyond its jurisdiction to the provincial level. Therefore, the federal government cannot implement international law at the level of provincial jurisdiction. 
Examples of important international wildlife and biodiversity treaties that have been ratified by Canada which eventually spurred the creation of federal legislation include the Migratory Birds Protection Convention, leading to the Migratory Birds Convention Act, 1994; the Convention on the International Trade in Endangered Species of Wild Flora and Fauna (CITES), leading to the Wild Animal and Plant Protection and Regulation of International and Interprovincial Trade Act (WAPPRITTA); and the Convention on Biological Diversity, which led to Canada's Species at Risk Act. These are elaborated on below.

Very few worldwide environmental treaties pertaining to species protection had been established prior to the 1970s. The Migratory Birds Protection Convention is a rare case. It was initially established in 1916 as a treaty between the United States and Canada (Great Britain) on the basis that international cooperation is required to protect migratory birds, because their habitat spans more than one country. It was subsequently negotiated for the entire continent of North America: Canada, the United States, and Mexico. The treaty was negotiated to prevent the extinction of migratory birds and to "establish regulations for their cross-boundary protection" (Greenbaum and Wellington, 2010: 91-92; Heritage Canada, n.d.). The Migratory Birds Convention Act, 1994 is the current federal legislation that arose from the international convention. The Act commits Canada to implement the protection of North American migratory bird habitat. The federal government asserts its authority over transboundary species through this Act. Commercialization by hunting and trafficking of migratory birds is prohibited under the Act, while the establishment of Migratory Bird Refuges in sensitive areas of importance is encouraged, in order to protect them from the threat of habitat destruction and overhunting (Greenbaum and Wellington, 2010: 91-92, 386).

All migratory birds fall within federal jurisdiction and their protection is the responsibility of the federal government. However, the Act protects only migratory birds and it does not apply to other species at risk. For this reason, it does not address holistic biodiversity protection, nor is it beneficial to the specific protection of species at risk. Canada ratified the 1973 Convention on the International Trade in Endangered Species of Wild Flora and Fauna, commonly known as CITES, and then followed up with passage of Canada's Wild Animal and Plant Protection and Regulation of International and 
Interprovincial Trade Act (WAPPRIITA). One large drawback to WAPPRIITA is that it only enables the protection of species at risk within the context of trade and commerce. Hence, its protection of biodiversity is extremely limited. Also, the administration of the Act is shared among federal and provincial/territorial agencies, thus relying upon interjurisdictional cooperation (Amos et al., 2001: 139; Greenbaum and Wellington, 2010: $92-$ 93). This may even complicate matters further, since it is always more difficult to achieve a consensus when there are matters of overlapping jurisdiction. Nonetheless, even when the responsibility is distributed among different levels of government, cooperation is further complicated, paving the way for "jurisdictional gridlock", a term that was defined and explained in section 3.1. This concept will be further elaborated in section 3.4.

The Convention on Biological Diversity (CBD) was introduced at the United Nations Conference on Environment and Development of 1992, also known as the Rio Conference, or the Earth Summit. The Convention required that each nation establish measures for conserving biological diversity, insofar as also developing legislation or other regulatory provisions for the protection of threatened species and populations (Amos et al., 2001: 140). It is also one of only a few international agreements on sustainable development that are legally binding, when transformed into law (Greenbaum and Wellington, 2010: 386). The CBD is particularly significant for incorporating the precautionary principle. Recall that the conception behind the principle is that action should be taken to decrease or eliminate environmental hazards even if there is no scientific proof that the suspected hazard is causing harm. Within the context of endangered species preservation, the burden of proof should lie with those whose activities disrupt the environment, endanger species, and cause biodiversity loss, to demonstrate that their actions will not result in damage to species, ecosystems, and the biosphere. If this cannot be proven, it is best to err on the side of caution and thus it is important to preserve as many species as possible. The Convention on Biological Diversity paved the way for the establishment of the Species at Risk Act (SARA). In turn, the precautionary principle is present as a cornerstone of the SARA. It is worth noting that the precautionary principle can be found in other Canadian environmental laws, such as the omnibus Canadian Environmental Protection Act, 1999. The principle has also 
been incorporated into some provincial laws such as the Ontario Endangered Species Act, 2007.

It is readily apparent that international law has quite a bearing on what occurs on the national legal front. It is especially evident that Canada has been slow to enact legislation pertaining to biodiversity protection after signing the CBD. In doing so, Canada has also demonstrated that it lags behind other nations when attempting to legally safeguard biodiversity through legislation. One of the most notorious examples of this is the United States' Endangered Species Act (ESA), which was passed in 1973; twenty nine years before Canada's long awaited SARA (Illical and Harrison, 2007: 367). The main reason for the prolonged time span for enacting $S A R A$ is the difficulty in satisfying all stakeholders and ultimately coming to a consensus in a timely manner. In addition, the Canadian government was able to draw lessons from the United States Act, which incorporates "command and control" and "prohibitive policy", while Canada opted for a persuasive model. The American experience also mobilized Canadian business and agricultural interests to lobby the Canadian government to avoid the costly US direction of conflict and litigation. In doing so, the lobbyists hoped to avoid the burden of financial and non-financial costs due to excessive litigation and intentional killing of endangered species for fear of punishment in the absence of protectionist measures (Greenbaum and Wellington, 2010: 479-481). The United States Act played an important role in the debate over the establishment of the Canadian Species at Risk Act. However, a thorough and detailed discussion of the US Endangered Species Act is beyond the scope of this paper. For further elaboration on the specifics of the United States Endangered Species Act please see Greenbaum and Wellington (2010: 479-481) and Illical and Harrison (2007).

\subsection{Policy Tools and Legal Measures at the Federal Level}

\subsubsection{Before the Species at Risk Act}

Prior to the 1990s, there was not much recognition of the importance of biodiversity and protecting species at risk. Some federal legislation yielding legal authority had been previously enacted that covered some aspects of species at risk. Yet, no one single statute had been dedicated to prioritizing the preservation of endangered 
species. The Canada National Parks Act is only restricted to the protection of species that have a connection to national parks, which, on the grand scope of the entire nation means that it is not necessarily protecting very many endangered species. The Act authorizes penalties for individuals who 'hunt, disturb, confine, or possess threatened or protected species' within the context of Canada's national parks (Amos et al., 2001: 139). The Fisheries Act and the Migratory Birds Convention Act, 1994 both grant the federal government authority and jurisdiction over the protection of species at risk, but neither include provisions that specifically mention "species at risk", nor do they mandate development of strategies to protect them (ibid.). Also, these Acts only give the federal government jurisdiction over the protection of aquatic species and migratory birds respectively.

Mentioned in section 3.2, WAPPRIITA only authorizes the protection of species at risk within the context of trade and commerce, by prohibiting the international or interprovincial transport of endangered species (Amos et al., 2001: 139). The Canada Wildlife Act is potentially the most useful of the legislation that pre-dates the Species at Risk Act, since it gives authority to the federal government to carry out public education and research for wildlife conservation, providing for some means of protecting endangered flora and fauna, while generating public concern. Nonetheless, it is not centrally focused specifically on protecting endangered species (ibid.).

The importance of inter-jurisdictional cooperation to the conservation and protection of species at risk was recognized in October of 1996, when federal, provincial, and territorial wildlife ministers came to an agreement in the Wildlife Ministers Council of Canada. Each jurisdiction committed to pass legislation and programs to protect species at risk and their habitats, endorsing the establishment of the National Accord for the Protection of Species at Risk. The accord delineates basic principles of species conservation and a number of commitments to protect species at risk. The emphasis on governments to play a leadership role in the conservation of species at risk outlines the economic and non-economic importance of biodiversity and species at risk protection nationwide. It is specifically noted within the Accord that provincial cooperation is essential to provide effective protection for species at risk and their habitats throughout the nation. Under the Accord, the Canadian Endangered Species Conservation Council 
(CESCC) was created in 1998 to facilitate cooperation. The Council is composed of federal ministers of Environment, Fisheries and Oceans, and Heritage, as well as the provincial and territorial ministers who are responsible for wildlife species (Amos et al., 2001: 141; Accord for the Protection of Species at Risk Backgrounder, n.d.).

The Accord obligates each jurisdiction to pass endangered species legislation and establish specific minimum requirements such as recovery plans and habitat protection (Elgie, 2003: 518). Yet, presently, only six provinces - Nova Scotia, New Brunswick, Quebec, Ontario, Manitoba, and Newfoundland and Labrador - have enacted legislation that was created specifically for the protection of species at risk. In September of 1998, the ministers reinforced the provisions of the Accord by emphasizing the importance of stewardship in protecting species at risk (Accord for the Protection of Species at Risk Backgrounder, n.d.). Stewardship and voluntary initiatives as policy tools will be further highlighted in the case studies in chapters 5 and 7.

Prior to the development of a specific piece of endangered species legislation in Canada, few legal bodies and tools dedicated to species at risk protection were in existence. Those that did exist were also very limited in scope, in terms of their authority over the protection of species identified as being at risk. Federal government bodies that existed, and continue to exist, had no actual legal authority. Examples include the Committee on the Status of Endangered Wildlife in Canada (COSEWIC), which was established in 1978. Composed of a panel of scientific experts from provincial, territorial, and federal wildlife agencies, alongside non-governmental organizations, its primary function is to issue status reports on species thought to be at risk, and to assign designations to each species.

COSEWIC is specifically composed of members from each provincial and territorial wildlife agency, four federal agencies (Canadian Wildlife Service, Parks Canada, Fisheries and Oceans Canada, and the Federal Biodiversity Information Partnership, chaired by the Canadian Museum of Nature), three non-government science members, and the co-chairs of the Species Specialist and the Aboriginal Traditional Knowledge Subcommittees (Amos et al., 2001: 139). The members of COSEWIC provide advice as specialists in their field, and not as representatives of their individual agencies, in attempts to establish a platform for the convergence of interests of various 
actors holding stakes in species at risk in Canada (ibid.). Currently, COSEWIC is made up of 31 members. The voting membership consists of members from each of the 13 provincial and territorial government wildlife agencies, 4 federal agencies (Canadian Wildlife Service, Parks Canada Agency, Department of Fisheries and Oceans, and the Federal Biodiversity Information Partnership, chaired by the Canadian Museum of Nature), 3 non-government science members, 10 Co-chairs of the Species Specialist Subcommittees (SSCs) and 1 Co-chair from the Aboriginal Traditional Knowledge (ATK) Subcommittee. Members have extensive experience with wildlife and biology, including Aboriginal Traditional Knowledge, ecology, genetics, and management. Members of COSEWIC are university academics, independent experts, Aboriginal people, or government, museum or independent biologists who volunteer their time and efforts (COSEWIC, 2010b).

To this day, COSEWIC has no legal authority, as it only yields the power to designate or list a species, but does not actually have the authority to protect a species that has been listed (Elgie, 2003: 510). The committee is, however, a crucial component of the decision making process which readily intersects with implementation of the policy goal of protecting species at risk. The categories applied by COSEWIC are outlined and defined in Table 3.1 .

\section{Table 3.1: COSEWIC Wildlife Species Definitions and Status Categories}

Wildlife Species: A species, subspecies, variety, or geographically or genetically distinct population of animal, plant or other organism, other than a bacterium or virus, that is wild by nature and is either native to Canada or has extended its range into Canada without human intervention and has been present in Canada for at least 50 years.

Extinct (X): A wildlife species that no longer exists

Extirpated (XT): A wildlife species that no longer exists in the wild in Canada, but exists elsewhere

Endangered (E): A wildlife species facing imminent extirpation or extinction

Threatened (T): A wildlife species that is likely to become Endangered if nothing is done to reverse the factors leading to its extirpation or extinction 
Special Concern (SC): A wildlife species that may become Threatened or Endangered because of a combination of biological characteristics and identified threats

Not at Risk (NAR): A wildlife species that has been evaluated and found to be not at risk of extinction given the current circumstances

Data Deficient (DD): A category that applies when the available information is insufficient (a) to resolve a wildlife species' eligibility for assessment or (b) to permit an assessment of the wildlife species' risk of extinction

[Extracted from the official COSEWIC website: http://www.cosewic.gc.ca/eng/sct0/terms_e.cfm ]

In 1988, the Recovery of Nationally Endangered Wildlife (RENEW) was formed. It is made up of representatives from federal and provincial wildlife agencies. These include three federal departments: Environment Canada, Fisheries and Oceans Canada, and Canadian Heritage. RENEW was also intended as a means of reporting to the public on progress made under the Accord for the Protection of Species at Risk. As such, RENEW is under the general direction of the Canadian Endangered Species Conservation Council (CESCC) (Environment Canada, 2001). The primary responsibility of RENEW is to establish recovery teams for species which are listed as endangered or threatened by COSEWIC. These tend to be vertebrate species. It is notable to mention that RENEW has not established many recovery plans over the duration of its existence. It had only had 21 plans approved by 2003, in 15 years of existence. Also, these recovery plans do not have legal force (Elgie, 2009: 510). In addition, RENEW is heavily reliant upon volunteer effort and is often riddled with inadequate funding (Scudder, 1999: 963).

Academics, scholars, and scientists, many of which are members of COSEWIC and RENEW, understand most causes of species declines in Canada. These individuals directly affect Canada's species at risk by informing policy makers and they are indirectly responsible for maintaining Canada's biodiversity. They take it upon themselves to scientifically inform political decision-makers (Amos et al., 2001: 149). 
Table 3.2: Elements of Recovery of Nationally Endangered Wildlife (RENEW)

\begin{tabular}{|l|l|}
\hline Purpose/Function & $\begin{array}{l}\text { Establish recovery teams for species which are listed as endangered or } \\
\text { threatened by COSEWIC. }\end{array}$ \\
\hline Composition & $\begin{array}{l}\text { Three federal departments (Environment Canada, Fisheries and Oceans } \\
\text { Canada, and Canadian Heritage -- Parks Canada Agency); provincial and } \\
\text { territorial government agencies, wildlife management boards authorized } \\
\text { by a land claim agreement, aboriginal organizations. }\end{array}$ \\
\hline Sources of Funding & $\begin{array}{l}\text { Mainly depends on volunteer effort; often lacks adequate funding. Each } \\
\text { member agency assumes the cost of staff or contract salaries for its } \\
\text { representatives on RENEW. }\end{array}$ \\
\hline
\end{tabular}

Table 3.3: Elements of the Committee on the Status of Endangered Wildlife in Canada (COSEWIC)

\begin{tabular}{|l|l|}
\hline Purpose/Function & $\begin{array}{l}\text { Issues science-based status reports on species thought to be at risk and } \\
\text { assigns designations to each species. }\end{array}$ \\
\hline Composition & $\begin{array}{l}\text { A panel of scientific experts from provincial, territorial, and federal } \\
\text { wildlife agencies, as well as non-governmental organizations. Currently, } \\
\text { it is made up of } 31 \text { members. The voting membership consists of } \\
\text { members from each of the 13 provincial and territorial government } \\
\text { wildlife agencies, 4 federal agencies (Canadian Wildlife Service, Parks } \\
\text { Canada Agency, Department of Fisheries and Oceans, and the Federal } \\
\text { Biodiversity Information Partnership, chaired by the Canadian Museum } \\
\text { of Nature), 3 non-government science members, 10 Co-chairs of the } \\
\text { Species Specialist Subcommittees (SSCs) and 1 Co-chair from the } \\
\text { Aboriginal Traditional Knowledge (ATK) Subcommittee. }\end{array}$ \\
\hline Sources of Funding & $\begin{array}{l}\text { Lacks dedicated budget and depends mainly on funds from the Canadian } \\
\text { Wildlife Service (CWS). Each member agency assumes the cost of staff } \\
\text { or contract salaries for its representatives on the Committee. Status } \\
\text { report preparation is partially funded by provincial or federal agencies } \\
\text { commissioning status reports and by funding arrangements through } \\
\text { national conservation organizations. }\end{array}$ \\
\hline
\end{tabular}

Scientists play a very crucial role in biodiversity protection. Bocking (2004: 1619) maintains that science must accomplish two functions if it is to play an effective role in the resolution of environmental problems such as species at risk conservation. First, the available scientific information must be relevant and credible, as per the scientific method. Second, it must be readily available so that all stakeholders have liberal access to the information they need in order to present and support their views.

The different interests of each stakeholder group has an impact on whether a consensus, or "minimum willing coalition" can be reached to successfully satisfy each stakeholder interest and maintain a delicate balance while guaranteeing adequate protection for Canadian species at risk (Amos et al., 2001: 139). Once a decision is made 
on the formulation of specific policies, there are numerous policy tools that are available for the implementation of policy. With regards to species at risk policy, enabling legislation and regulations are the primary instruments.

Soon after the passage of the National Accord for the Protection of Species at Risk, and after many years of stakeholder consultation, Bill C-65 was introduced. It was intended to become the Canada Endangered Species Protection Act (Amos et al., 2001: 141). The bill was, however, frowned upon by "virtually every stakeholder group industry, landowners, environmentalists, First Nations, and provincial governments" (Amos et al., 2001: 144). Most opposition also arose because of controversies within the United States regarding the US Endangered Species Act of 1973. Stakeholders did not want those same controversies echoed within Canadian borders. Bill C-65 pitted economic interests against environmentalists. Business, agricultural lobbyists, and landowners did not want a regulatory "command-and-control" approach to species protection which places a financial burden on the private sector, similar to the approach in the US, and they emphasized the need for publicly funded voluntary stewardship instead.

Environmentalists stressed the need to preserve the critical habitat of endangered species, as the bill was only proposing "a ban on destruction of a species' 'residence', defined by the bill as its nest or den, [which] would do little to address loss of habitat, which is viewed by the scientific community as the primary threat to biodiversity" (Illical and Harrison, 2007: 377). They claimed that bill C-65 was not sufficient because it did not include mandatory habitat protection for species at risk. At the same time, the provinces feared that their provincial authority over Crown lands for resource and economic exploitation would be compromised by over-arching federal government jurisdiction, creating jurisdictional gridlock (Illical and Harrison, 2007: 377). The provinces claimed that the bill allowed the federal government to overstep jurisdictional boundaries and allowed it too much intervention. First Nations also questioned the authority of the federal government to pursue its proposals (Amos et al., 2001: 140, 144). Among all this controversy, Bill C-65 was left to die on the order paper with the calling of an election in June of 1997 (ibid.). 
The importance of scientific criteria for the selection and listing of species at risk was deemed to be essential. This ultimately would make scientific and not political criteria for designation of utmost significance. The ideal would be to allow COSEWIC to legally list species at risk under the endangered species legislation (Amos et al., 2001: 139). It was hoped that sound scientific information could also be the basis of "nondiscretionary critical habitat protection, recovery plans, and prohibitions on takings of listed species" (Illical and Harrison, 2007: 378).

Prior to the introduction of the Species at Risk Act, there were insufficient legal tools dedicated to specifically target the problem of species at risk. There are serious questions as to whether the Species at Risk Act has adequately filled the void. The Act will now be described and its shortcomings will be highlighted.

\subsubsection{The Federal Species at Risk Act (SARA)}

Designated laws are the main legal tools that all jurisdictions in Canada rely upon for the protection of species and habitat. The centerpiece of policy tools for the preservation of species at risk in all of Canada is the federal Species at Risk Act. As enacted legislation, it is the primary instrument that has been set in place by the federal government. A summary of $S A R A$ is provided in table 3.4 .

\section{Table 3.4: A summary of the Species at Risk Act (Bill C-5)}

- The purposes of this enactment are to prevent Canadian indigenous species, subspecies and distinct populations of wildlife from becoming extirpated or extinct, to provide for the recovery of endangered or threatened species, to encourage the management of other species to prevent them from becoming at risk.

- This enactment establishes the Committee on the Status of Endangered Wildlife in Canada (COSEWIC) as an independent body of experts responsible for assessing and identifying species at risk.

- It provides that COSEWIC's assessments are to be reported to the Minister of the Environment and to the Canadian Endangered Species Conservation Council and it authorizes the Governor in Council to establish by regulation the official list of species at risk based on that process. 
- It creates prohibitions to protect listed threatened and endangered species and their critical habitat.

- It recognizes that compensation may be needed to ensure fairness following the imposition of the critical habitat prohibitions.

- It creates a public registry to assist in making documents under the Act more accessible to the public.

- It is consistent with Aboriginal and treaty rights and respects the authority of other federal ministers and provincial governments.

[Source: Greenbaum and Wellington, 2010: 484]

Within the $S A R A$, a variety of policy instruments are advocated, including recovery strategies, action plans, and management plans. Recovery strategies are mandatory for all listed species. They are "detailed plans that outline short-term objectives and long-term goals for protecting and recovering species at risk" (SARA, Department of Fisheries and Oceans Canada, 2009). Action plans are used to provide a summary of "the projects and activities required to meet recovery strategy objectives and goals" (ibid.). The plans are used to implement projects and activities in order to improve the status of a species (ibid.). Management plans "set goals and objectives for maintaining sustainable population levels of one or more species that are particularly sensitive to environmental factors, but which are not yet considered in danger of becoming extinct" (ibid.).

Offences and punishments are laid out in Section 97 of the Species at Risk Act. They are applied in the event of an infringement of the provisions of the Act or an emergency order. Despite the existence of these punishments, an emphasis is placed on voluntary measures and subsidized stewardship, as outlined in Section 10 of the Act (Illical and Harrison, 2007: 367).

Monetary compensation is also a facet of Canada's endangered species policy, whereby funding is granted to private interests that may be affected by subsequent regulation. The advocacy of such permissive policy tools is a stark contrast to the more adversarial, regulatory, command and control approach of the United States Endangered Species Act (Illical and Harrison, 2007: 367). In essence, the Canadian approach to 
endangered species policy allows species at risk to persist based on the availability and the allocation of state funds.

With regards to policy formulation, decision making, and implementation, administrators acting under statutory authority make most environmental regulatory decisions. They have a responsibility to design regulations and guidelines, interpret statutory terms, apply the interpretations to facts, and use discretion when making decisions on individual cases, often while attempting to balance competing interests (Valiante, 2009: 34). Under some statutes, including the Species at Risk Act, decisions made by administrators can be appealed to specialized tribunals. The court's involvement is usually limited to appeals on a 'question of law' or through judicial review. Judicial review is "a mechanism for ensuring the accountability of administrative decision-makers through the courts, but on limited grounds" (ibid.). Some prominent cases have been appealed under $S A R A$. These cases highlight the inadequacies of the Act, as outlined in section 3.3.4.

The Species at Risk Act outlines specific mandatory criteria that allows for a more delineated discretion and greater opportunities for courts to provide supervision. For instance, the $S A R A$ includes a requirement for the development of recovery strategies addressing particular criteria within a specified deadline for all listed endangered species (Valiante, 2009: 35). Environmental groups have brought judicial review applications for numerous instances of failure to identify critical habitat in recovery strategies (Valiante, 2009: 44, note 37). "Critical habitat" is all habitat that is necessary and essential for the survival or recovery of a listed wildlife species $(S A R A, 2002)$. Two judicial review cases under $S A R A$ are described in section 3.3.4.

The Species at Risk Act is centred on habitat-based species protection and voluntary stewardship with an incorporation of compensation if there would be a need to take over lands as outlined in Sections 10 and 11 of the Act. The SARA was able to quell the concerns of the major stakeholders: environmentalists and scientists, and business and agricultural parties. The Act that came to fruition was essentially a compromise between the environmental and business communities, one that has been called a “minimum willing coalition" by Amos et al. (2001: 139) (Illical and Harrison, 2007: $381)$. 
The goals of the Species at Risk Act incorporate the prevention of the extirpation or extinction of species. The Act also stresses the importance of providing for the recovery of endangered or threatened species via recovery plans, as well as the encouragement of the management of other species in order to prevent them from becoming at risk, as outlined in Sections 37 to 55 of the Act. Sections 14 to 31 of the Act delineate that COSEWIC's species designations are still to be taken into consideration. However, they are to be reported to the Minister of the Environment and to the Canadian Endangered Species Conservation Council. The council then authorizes the Governor in Council to establish an official list of species at risk (Illical and Harrison, 2007: 381). Ultimately, the final decision rests in the hands of the politicians.

Critical habitat of listed threatened and endangered species is protected under prohibitions in the Act. Compensation is granted to parties that are economically impacted by critical habitat prohibitions. The Act encourages public education via the creation of a public registry ${ }^{12}$, making documents under the Act more accessible to the average citizen. In addition, aboriginal and treaty rights are also respected under the Act, as well as the authority of other federal ministers and provincial governments, so as not to over-step federal jurisdictional boundaries, respecting the constitutional division of powers.

With respect to jurisdiction, only "federal species" are afforded protection under SARA. "Federal species" are aquatic species, migratory birds, and species found on federal Crown lands. The patchwork of authorities as outlined by the constitutional division of powers affords different species varying levels of protection.

Migratory birds are treated differently from other "federal" species with respect to habitat protection, in line with Article II of the Migratory Birds Convention. Migratory bird species benefit from an additional layer of protection under the Migratory Birds Convention Act, 1994 (Elgie, 2003: 511). "Non-federal species", or species that fall within provincial jurisdiction, are not directly protected by the SARA.

Accentuating the complexities of varying levels of protection afforded to species at risk under the Act, provisions to protect the critical habitat of species on provincial land exist under Section 61 (3). Under the federal 'safety net' clause, the federal

\footnotetext{
${ }^{12}$ Species at Risk Act (SARA), Public Registry. $<$ http://www.sararegistry.gc.ca/>
} 
environment minister is given the authority to invoke these provisions and make a recommendation to protect the critical habitat of a "non-federal species" that is listed as endangered or threatened, provided it is not adequately protected under provincial or territorial laws. This occurs if the Minister is requested to do so by a provincial or territorial minister, or by the Canadian Endangered Species Conservation Council. If a $S A R A$ listed species is deemed to not be effectively protected under existing provincial or territorial laws, the Minister must recommend that Cabinet order protections under SARA to apply on private, provincial, or territorial lands (Elgie, 2003: 517; Elgie, 2009). Emergency protection for a listed species is also made possible under Section 80 of the Act, allowing the Governor in Council to make an emergency order to protect the listed species upon recommendation by the Minister (ibid.).

\subsubsection{Inadequacies of the Species at Risk Act (SARA)}

Some loopholes and inadequacies of the Species at Risk Act have already been alluded to above. They will be reiterated and discussed further below. Nongovernmental organizations have provided extensive documentation and analysis to demonstrate that $S A R A$ has not lived up to its promise. ${ }^{13}$

The challenges of SARA seem most prominent when it is contrasted with the United States Endangered Species Act of 1973. The approach of the US endangered species law relies primarily upon what is termed as 'command and control' regulation. It has generated considerable controversy due to the costs of protection borne by the private sector. $S A R A$ on the other hand, emphasizes publicly supported, voluntary stewardship. Yet, many environmentalists insist that SARA is too cautious, and simply does not do enough to protect Canada's endangered species (Suzuki, 2001).

The statute was created based on a decentralized approach as a result of the constitutional division of powers. Mary Illical and Kathryn Harrison (2007: 370) eloquently explain the importance of the division of powers with respect to protection of endangered species:

\footnotetext{
${ }^{13}$ David Suzuki Foundation, Ecojustice, Environmental Defence, and Nature Canada collaboration, Report Card on Species at Risk Act. April 2009. 'Canada's Species at Risk Act: Implementation at a Snail's Pace'. $<\underline{\text { http://www.naturecanada.ca/pdf/SpeciesAtRisk_reportApril2009.pdf }}>$.
} 
(...) the constitution grants provincial governments ownership of very extensive Crown resources, with which comes authority to manage species resident on those Crown lands (...) While the provinces have uncontested authority to conserve their own resources as they see fit, provincial governments' defensiveness concerning their natural resource jurisdiction arguably owes more to their desire to exploit those resources as a source of economic development.

The jurisdictional gridlock created by the constitutional division of powers is essentially the root cause of disagreement and litigation. An example of this is illustrated in the lawsuit involving Western Canada Wilderness Committee v. British Columbia. The outcome of the litigation will be discussed further in section 7.1. Two other cases that have been brought to court for judicial review will be discussed in section 3.3.4.

The ultimate decision to list species lies within Cabinet, and not COSEWIC, and members of the environmental community are still very critical of this (Illical and Harrison, 2007: 379). As well, many environmental advocates maintain that the mechanism for listing species should be based on scientific criteria, not political ones (Illical and Harrison, 2007: 378). Also, protection of critical habitat is left to the discretion of Cabinet, which may choose not to actually enforce action. This all depends on the involvement of the provincial government in the protection of the critical habitat. The cooperation between the two levels of government creates yet another situation of jurisdictional gridlock (Illical and Harrison, 2007: 379).

The Act essentially allows for some legitimate measures and options for preserving endangered species. All of them require an adequate amount of resources, be they financial or otherwise. Some options include the purchase of private land for conversion into federal parkland, and providing compensation to private landowners and industry for any economic losses they may incur as a result of voluntarily refraining from critical habitat destruction. Also, the government has a responsibility to recompense industry for economic losses and for licenses that may have been previously granted to extract resources, such as logging and mining, from Crown lands, which are now deemed to be critical habitat. These measures can be very costly and are extremely limited, since 
there are limits to the amount of funds that taxpayers are willing to allocate to endangered species preservation. The same dilemma arises when ordering directives for resource extraction and development, as well as parks and land use planning, once the previously mentioned actions have been taken. These procedures require a great deal of monitoring and enforcement, and hence necessitate adequate funding and personnel training. It is for this reason that voluntary measures and stewardship programs are favoured over all other options, within the realm of the SARA. Through the encouragement of private landowners and industry, as well as the opportunity for financial incentives such as tax exemptions, voluntary measures are hailed as the most cost effective of all available measures of endangered species protection. It remains to be seen if they are truly the best means of species at risk preservation.

An overview of existing legal measures at the provincial level in Ontario and British Columbia and their effect on case study species in conjunction with the federal Species at Risk Act is discussed in the following chapters.

\subsubsection{Litigation for Judicial Review}

Litigation is a policy tool that is available to stakeholders, usually public interest groups, to appeal to the courts to ensure that the provisions of a statute are being properly upheld. With regard to the Species at Risk Act, there have been several important cases brought to Federal Court. Two cases in particular resulted in the setting of important precedents for endangered species with regard to $S A R A$. One concerned the Greater Sage-Grouse (Centrocercus urophasianus) while the other concerned the Nooksack Dace (Rhinichthys cataractae). ${ }^{14}$

\subsubsection{The Greater Sage-Grouse: Alberta Wilderness Association v. Canada (Environment)}

In July 2009, a precedent was set for the use of the Species at Risk Act to compel judicial review of environmental policy (Association of Corporate Counsel, 2009). Working in cooperation, in February 2008, a coalition of ENGOs submitted an application for judicial review of the "Recovery Strategy for the Greater Sage-Grouse".

\footnotetext{
${ }^{14}$ For detailed account of these cases, see Greenbaum and Wellington, 2010: 491-495.
} 
The endangered species was once widespread across the prairies. It is now only found in remote areas in southeastern Alberta and southwestern Saskatchewan. The habitat of the bird has been fragmented due to oil and gas development (Ecojustice, 2009).

Concerning the case of Alberta Wilderness Association v. Canada (Environment), the ENGOs pointed out that the "Recovery Strategy issued by the [Environment] Minister [Jim Prentice] did not identify any critical habitat" (Federal Court Decision, July 2009). Siding with the ENGOs, Federal Court justice Russell Zinn ruled that the Minister of the Environment broke the law because sufficient knowledge exists to identify critical habitat of the species, particularly their breeding grounds (Ecojustice, 2009). The judge maintained that there is no provision of discretion in this matter, and that the requirement to list all critical habitat reflects an application of the precautionary principle. He also held that as long as some critical habitat is identifiable, it must be listed in the Recovery Strategy. This case is of utmost significance for endangered species policy, as the ruling provides a guide on how the Minister must consider critical habitat protection, and thus consider current scientific fact to inform policy.

Scientific knowledge that allows for the identification of the causation of species declines is incorporated into recovery strategies and management plans. As outlined in Section 41(1) of the Species at Risk Act, it is required that critical habitat be identified to the most complete extent possible and that it be based on the best available scientific information. If available knowledge is not taken into consideration, then implementation gaps will occur and critical habitat will not be adequately protected. As a result, a species could continue to suffer declines. Gaps in implementation could lead to serious infringements of policy objectives. Such gaps may result in defeating the purpose of the policy that was initially created to resolve the defined problem.

\subsubsection{The Nooksack Dace: Environmental Defence Canada v. Canada}

Litigation also took place over the endangered Nooksack Dace, a small, freshwater minnow found in four rivers in the Fraser Valley area of British Columbia. A coalition of ENGOs launched an application for judicial review in Federal Court in 2007, claiming that the recovery strategy for the Nooksack Dace did not conform to the 
requirements of the Act because it did not identify critical habitat to the best extent possible.

Adequate scientific information was available that explained the decline of the species, as well as the requirement of the species to sustain a stable population, and to ensure its survival and recovery. The Recovery Team recommended that all suitable habitats be designated as critical. Even though critical habitat had been mapped out and defined, it was not included in the final version of the "Recovery Strategy for the Nooksack Dace". Critical habitat definitions were being left out of recovery strategies in accordance with a "new" $S A R A$ policy directive that ensured that "critical habitat should be removed from all RS [Recovery Strategies in the Pacific Region] in process and for the foreseeable future until a clear policy direction has been provided" (Environmental Defence Canada v. Canada, para. 16). The government stated that this policy directive was introduced because critical habitat information in some recovery strategies had not yet been submitted for peer review. It stated that it wished to conduct scientific peer review in order to ensure that critical habitat identification would be "scientifically defensible" (Environmental Defence v. Canada, para. 18). Other reasons for not listing critical habitat in recovery strategies included the need to consult with all potentially affected parties prior to including the information. In addition, another reason was that the definition of critical habitat in the Fisheries Act and Oceans Act were not consistent with that found in the Species at Risk Act (Environmental Defence Canada v. Canada, para. 16).

However, Federal Court Justice Campbell maintained that neither reason could justify the excising of information that was known about the critical habitat of a listed species, because, as per s. 41 of $S A R A$, the critical habitat information did not need to be subject to peer review, nor did it require consultation with stakeholders who would be affected by the identification of critical habitat. Consultation could wait until the final stages of the process, such as inclusion within the action plan. There was no adequate justification for the exclusion of critical habitat information from recovery strategies.

The focus of the judge's decision was based mainly on the statutory interpretation of $S A R A$. Justice Campbell sided with the ENGOs, insisting that a broad approach to interpretation be applied to fulfill Canada's commitment to applying the principles of the 
Convention on Biological Diversity, and the application of the precautionary principle. The precautionary principle should apply in the preparation of recovery strategies in accordance with s. 38 of SARA. The judge also sided with the ENGOs where he maintained that an expansive definition of "habitat" that includes both location and attributes complies with the values and principles of the $\mathrm{CBD}$, as they comprise what would be necessary to ensure the protection of a species. In addition, the identification of as much critical habitat as possible based on the best available scientific information in accordance with the provisions of s. 41 of SARA are now mandatory, as this precedent was set by Justice Zinn in the case concerning the Greater Sage-Grouse.

Justice Campbell concluded by stating that the case concerning the Nooksack Dace was "absolutely necessary" because the omission of mapping or designation of critical habitat were found to represent 'errors in law'. By approving such a recovery strategy, the Minister failed to "follow the law". The ENGOs were successful in their application for judicial review concerning the Nooksack Dace. In addition, the case set a precedent. Justic Campbell's decision has significant implications for the recovery strategies of all the other listed Pacific Region species. The implementation of the federal policy directive denying identification of critical habitat in recovery strategies for species at risk has also been halted as a result of this case.

Hence, via the possibility for judicial review, ENGOs are making use of the court system in order to establish proper protection for species at risk under the Act because existing instruments are not functioning properly, as acknowledged in the aforementioned case. Both cases also highlight the importance placed upon applying the precautionary principle and updated scientific knowledge to the implementation of laws.

\subsection{Jurisdictional Challenges and Proposals for Reform}

The concept of jurisdictional gridlock was introduced in section 3.1. It is a much lamented fact in Canadian policy circles that the Canadian constitution makes environmental protection especially difficult, due to what has been characterized as jurisdictional gridlock. Well-delineated jurisdictions are often easy to follow in all other ambits of Canadian law and policy. However, the environment, which was never given a clear and apparent place within the Canadian constitution, can be found no place at all, or 
it may arise in every jurisdiction. This is what makes environmental matters so extremely complicated in Canada. Protection of species at risk and biodiversity in Canada is not immune to these issues. These very obstacles are also apparent in the case studies that will be examined further in Chapters 5 and 7.

The Species at Risk Act defers much care and protection of species at risk to the provinces in accordance with the constitutional division of powers. According to The Constitution Act, 1867, all Canadian provinces and territories are granted authority over natural resources and conservation as outlined in Section 92a. The constitutional power that provides the provincial governments with the authority to protect the environment also grants direct authority to exploit natural resources for economic potential, and in order to provide an important source of provincial revenue. Thus, provincial governments are very likely to remain assertive over their constitutional authority. Federal jurisdiction over the environment, on the other hand, is indirect, and it only applies to federal lands (only 4 percent of Canada's land base) (Harrison, 1996: 19). Hence, environmental policy tends to be fragmented among various jurisdictions in Canada. The protection of species at risk does not fall solely in the hands of the federal jurisdiction. By virtue of the constitutional division of powers, most of the responsibility lies at the provincial level of government.

As a consequence of the federal system of government, federal and provincial governments shape the formulation and implementation of public policy, either by fighting to maintain authority over certain issues, or by deferring the responsibility to another level of government. In the context of environmental protection, Kathryn Harrison (1996: 20) maintains that "constitutional ambiguity and overlapping jurisdiction provide an opportunity for either level of government to avoid responsibility for environmental protection by pleading inadequate authority and 'passing the buck' to the other level". In environmental matters, the federal government is most likely to surrender its authorities to the provinces in order to avoid 'electoral blame'. The 'passing of the buck' is also known as 'blame avoidance'. As is evident in the case studies analyzed further in Chapters 5 and 7, the same is true within the realm of species at risk protection. In the case of the critically endangered Spotted Owl in British Columbia, environmentalists argue that the federal government is not taking advantage of 
emergency provisions that are possible under the Species at Risk Act to force the protection of the species' critical habitat. The species is not present on federal lands, nor does it fall specifically within federal jurisdiction. By not allowing the emergency provision, the federal government is 'passing the buck' to the provincial level.

Thus, the issue of blame avoidance highlights the importance of analyzing policy solutions between and among levels of government. In the case of endangered species protection, since most of the burden for their management and protection rests upon the provinces, it is appropriate for the provinces to examine solutions that are currently functioning in other provinces, and pinpointing which solutions might work well in their jurisdiction. The rationale for legal lesson drawing in this paper exists under the same premise. The province of British Columbia, which lacks dedicated legislation for the protection of species at risk, is compared to Ontario, which has recently enacted a new and revised Endangered Species Act, 2007. The province of British Columbia may benefit from gathering ideas and drawing lessons from the Ontario endangered species policy experience, considering that Ontario has had endangered species legislation since 1973. Other examples in the legal literature include the work by Mary Illical and Kathryn Harrison (2007), who incorporate lesson drawing into their analysis of Canada's Species at Risk Act and compare it to the United States Endangered Species Act. Elgie (2009) also discusses the influence of cross-jurisdictional learning in the creation of the Species at Risk Act. A similar method can be used to compare endangered species policy approaches among the two different provincial jurisdictions of British Columbia and Ontario. 


\section{CHAPTER 4.0 PROVINCAL LEGAL MEASURES FOR SPECIES AT RISK IN ONTARIO}

Since most species at risk reside on non-federal lands, the provinces hold the greatest responsibility for the protection of species at risk as outlined by the Canadian Constitution. For this reason, prominent current legal measures at the provincial level in Ontario and British Columbia are evaluated and later compared in Chapter 8. Eighty percent of the province of Ontario is allocated as provincial land (Greenbaum and Wellington, 2010: 480). The province of Ontario has a greater array of legal tools that are dedicated to species at risk protection. Thus, Ontario legal tools are first outlined here, setting the stage as comparator to British Columbia. The legal measures that exist in British Columbia will be discussed in Chapter 6.

This chapter encompasses an overview of all provincial legal measures for species at risk in Ontario. In order to understand the current legal situation in Ontario with regard to species at risk, the chapter begins with a description of legal tools that were in existence prior to the central piece of provincial legislation dedicated to species at risk protection in the province, the Endangered Species Act, 2007. The Act and its key components are also outlined, while the chapter concludes with a description of exemptions and flexibility tools that are intrinsic to the ESA, 2007.

The legal situation that existed prior to the advent of the recent Ontario Endangered Species Act, 2007 indicated that changes were long overdue. The original endangered species legislation that was enacted in 1971 was outdated. Evaluation and assessment of the Endangered Species Act, 1971 and all policy tools pointed to grave inadequacies. The Act was deemed ineffective because science-based designation of species at risk was not mandatory, nor was protection of critical habitat for listed endangered species. Scientists and ENGOs maintained that changes to species at risk policy in Ontario were urgently required. Their push eventually led to legal reform: the Endangered Species Act, 2007. The factors that set the stage for legal reform and the enactment of the recent Act are discussed below. 


\subsection{Before the Ontario Endangered Species Act, 2007}

In Canada, Ontario set the stage for the establishment of legislation designated specifically for the protection of species at risk of extinction. It is significant that in 1971, it was the first province to ever enact endangered species legislation. The Act coincided with the environmental movement of the late 1960s and early 1970s that placed considerable political pressure on the government to put environmental issues on the agenda. The movement gave way to federal statutes such as the Canada Shipping Act, 1970, which prohibits the discharge or dumping of oil or oily waste from ships; the Fisheries Act, 1970, which prohibits the harming of fish habitat and fishing grounds; the Environmental Contaminants Act, 1974, which prohibits the release of toxic substances in excess of pre-determined limits; and the Migratory Birds Convention Act, 1970, which makes it illegal to harm migratory bird habitat and migratory species. Other significant Acts that were concerned with the environment emerged at the provincial level during this period, such as the Ontario Environmental Protection Act, 1971, which is the principal statute in the province that is concerned with enforcing pollution regulation. It is therefore apparent that the environmental movement had a tremendous influence on legal reform during this period.

The Ontario Endangered Species Act, 1971 predated the United States Endangered Species Act of 1973. The Act protected the species listed in regulation as well as their habitats. The Ontario Ministry of Natural Resources was responsible for the Act's enforcement. The protection provided under the Act was discretionary, and the approach to listing species was not science-based. The Act did at least protect 42 species and their habitats. Without the requirement for science-based listing, and covering such a small portion of the species needing protection, it was clear that the Act was in dire need of revision. Reform of the Endangered Species Act, 1971 which eventually led to the creation of the Endangered Species Act, 2007 is discussed in Section 6.2.

Aside from a designated statute specifically dedicated to enforcing species at risk protection, other policy and legal tools have been established in the province of Ontario for the purposes of protecting species at risk of extinction. These are discussed below. The province has a body with no individual legal authority, similar to COSEWIC. Known as the Committee on the Status of Species at Risk in Ontario (COSSARO), it is 
responsible for reviewing documentation on species that may possibly be at risk. The committee is comprised of 11 members. They are appointed by the Lieutenant Governor in Council (i.e., Cabinet), who designates one of the members as chair. Members serve up to a maximum of three years, and are eligible for reappointment. COSSARO is made up of experts originating from various disciplines and backgrounds, such as scientific disciplines or Aboriginal Traditional Knowledge. Presently, the committee consists mainly of scientists with backgrounds in biology, ecology, and zoology. ${ }^{15}$

COSSARO was created by the Ontario Ministry of the Environment in 1995. However, it did not have any legal clout prior to the enactment of the Ontario Endangered Species Act, 2007. The committee evaluates the conservation status of species occurring in Ontario and makes recommendations on the status of species at risk. Based on their expertise, COSSARO will determine when species are at risk. When determined to be so, these species are listed on the Ministry of Natural Resources Species at Risk in Ontario (SARO) list. When a species is classified as being endangered or threatened, it will receive protection under the ESA, 2007 (MNR, 2009).

\section{Table 4.1: COSSARO Wildlife Species Definitions and Status Categories}

The categorization of species at risk under COSSARO is as follows:

Extinct: A species that no longer lives anywhere in the world.

Extirpated: A species that lives somewhere in the world, and at one time lived in the wild in Ontario, but no longer lives in the wild in Ontario.

Endangered: A species that lives in the wild in Ontario but is facing imminent extinction or extirpation.

Threatened: A species that lives in the wild in Ontario, is not endangered, but is likely to become endangered if steps are not taken to address factors threatening it.

Special concern: A species that lives in the wild in Ontario, is not endangered or threatened, but may become threatened or endangered due to a combination of biological characteristics and identified threats.

[Extracted from the COSSARO web site]

\footnotetext{
${ }^{15}$ A description of COSSARO Agency members biographies is available here:

$<$ https://www.pas.gov.on.ca/scripts/en/bios.asp?minID=59\&boardID=141880\&persID=145966\#1>
} 
COSSARO designations are similar to COSEWIC designations, which were discussed in Chapter 4. However, there are fewer categories available under COSSARO with respect to COSEWIC. COSSARO lacks the Not at Risk and Data Deficient categories that are available under COSEWIC.

Table 4.2: Elements of the Committee on the Status of Species at Risk in Ontario
(COSSARO)
\begin{tabular}{|l|l|}
\hline Purpose/Function & $\begin{array}{l}\text { Issue science-based status reports on species thought to be at risk and to } \\
\text { assign designations to each species. Reports classifications to the } \\
\text { Minister of Natural Resources. Has only become a legally recognized } \\
\text { committee after the enactment of the Endangered Species Act, } 2007 .\end{array}$ \\
\hline Composition & $\begin{array}{l}\text { A panel of 11 members appointed by the Lieutenant Governor in } \\
\text { Council, who designates one of the members as chair. Members are } \\
\text { experts in the following areas: conservation biology, population } \\
\text { dynamics, taxonomy, systematics or genetics; or Aboriginal Traditional } \\
\text { Knowledge (ATK). Expert knowledge of species in a particular region of } \\
\text { Ontario or in a specific taxonomic group, as well as a reasonably broad } \\
\text { knowledge of Ontario's flora and fauna is also required. }\end{array}$ \\
\hline Sources of Funding & Ontario Ministry of Natural Resources \\
\hline
\end{tabular}

The Endangered Species Act, 1971 was very outdated. Over the years, changes in land and resource use, planning processes, and increasing threats to native species had taken place. The species listing approach was a major element of weakness that required great revision. The full spectrum of categories of species at risk was not adequately protected. The 1971 Act left much room for interpretation and limited protection to species listed in the "endangered" category. Hence, species that fall within any other categories, such as the "threatened" and "special concern" categories, would not have had the benefit of protection.

The discretionary approach under the 1971 Act did not provide for a sciencebased process for including species on the endangered list. Once a species appeared on the discretionary list, there were no mandatory programs to protect species deemed to be at risk nor were there programs to aid in recovery. In addition, the Act did not take into consideration the critically important roles of private landowners and voluntary stewardship in the protection and restoration of species and their habitats, nor did it take indigenous knowledge into consideration. As a result of these combined factors, it was evident that Ontario was in urgent need of new endangered species legislation, and legal reform (MNR, 2006: 1-2). The Ontario Endangered Species Act, 1971 was eventually revised and rewritten. It is now called the Endangered Species Act, 2007. 


\subsection{The Ontario Endangered Species Act, 2007}

The current Endangered Species Act, 2007 (ESA, 2007) was passed in May of 2007 and came into full force on June 30, 2008. See table 4.3 for a detailed explanation of the Act. The ESA, 2007 was hailed as the best piece of endangered species legislation in the entire country by a multitude of ENGOs and environmentalists. ${ }^{16}$ The Act is the first in Canada to include science-based listing in combination with mandatory protection for threatened and endangered species and their habitats. It offers mechanisms such as permits and agreements in order to encourage stewardship. The permits and agreements also allow for land use that would prove not to harm threatened and endangered species, or the recovery of these species. The new Act is significantly better at addressing species at risk issues in comparison to the previous Act because it follows an independent, scientific and timely process for listing and protecting all species at risk, with the help of COSSARO. The new legislation also includes a mandatory requirement to prepare and carry out recovery plans for threatened and endangered species as well as management plans for species of special concern. It provides for the allocation of funds for species at risk programs (MNR, 2007).

\subsubsection{Recovery and Management Plans}

Recovery of species encompasses attempts to prevent further loss of a species at risk. Recovery efforts are performed in order to reduce threats or remove them altogether. Once a species is deemed to be at risk by COSSARO, the government is responsible for outlining the steps that will be taken towards the recovery of the species. The ESA, 2007 requires that "recovery strategies" be prepared for endangered and threatened species, while "management plans" are to be organized for species of special concern. The plans and strategies are organized, science-based plans that outline advice for the government and recommend steps for recovering species at risk. Recovery strategies include information that is pertinent for the consideration of a species'

\footnotetext{
${ }^{16}$ The Endangered Species Act, 2007 was hailed and endorsed by David Suzuki Foundation < http://www.davidsuzuki.org/issues/wildlife-habitat/science/endangered-species-legislation/ontario/ >; Environmental Defence, Ecojustice (formerly Sierra Legal Defence Fund), CPAWS Wildlands League, and Ontario Nature:

$<$ http://www.ecojustice.ca/media-centre/press-releases/ontario-passes-best-endangered-species-act-in-thecountry $>$.
} 
recovery. These elements include habitat needs, existing threats to the species or ecosystem, recommended actions for protecting and recovering species and their habitats, and the defined area that is considered to be a species' habitat. The ESA, 2007 has a mandate for strict timelines for the preparation of recovery and management plans. For species listed as endangered, a recovery strategy must be set in place within one year of its listing on the SARO. For threatened species, a recovery strategy must be in existence within two years of listing. Species of special concern must have an established management plan within five years of listing on the SARO, unless a plan is already in place or in preparation by the federal government (MNR, 2010).

Recovery strategies are most often prepared by recovery teams. These teams are comprised of organized groups of experts usually including scientists and academic researchers. The teams are responsible for using the most relevant and best available scientific, community, and 'Aboriginal Ecological Knowledge', or traditional knowledge, in order to recommend the best possible actions for preventing the decline of species listed as being at risk in the province of Ontario. The Ontario Ministry of Natural Resources is currently working with partners on recovery projects all across Ontario. Some partners include ENGOs, educational institutions such as universities, private entities and donors, in conjunction with the Ontario MNR and funding from the Endangered Species Recovery Fund, launched by WWF-Canada and Environment Canada in 1988. Approximately 80 recovery teams are working to help curb the decline of endangered and threatened species in the province (MNR, 2010). Some examples of recovery efforts include the recovery teams organized for the Redside Dace, the Woodland Caribou, the Ontario Badger, the Butternut, the Loggerhead Shrike, and the Jefferson Salamander. The latter two will be discussed in the Ontario case studies described in Chapter 5.

Once a recovery strategy or a management plan is in place, the government is required to respond within 9 months of the completion of the documents. The response will provide a summary of actions that the government will take in order to accomplish each strategy or plan. At this point, the government must prioritize its impending actions. Similar to the $S A R A$, public participation is incorporated in the $E S A, 2007$. The Act encourages public education and dissemination of information as responses to recovery 
strategies and action plans are posted on the internet and made available for public review and comment. The responses are made available on the Ontario MNR website as well as the Environmental Registry ${ }^{17}$. All recovery strategies and management plans are also made public and posted on the registry (MNR, 2010).

\subsubsection{Stewardship Programs}

One of the main goals of the ESA, 2007 aside from the use of science-based listing of species at risk and the protection of species at risk and their habitats, is the promotion of "stewardship activities to assist in the protection and recovery of species that are at risk" (ESA, 2007, c. 6, s. 1.). This is a major element upon which the ESA, 2007 places a high priority, which was greatly lacking in the previous legislation. The Species at Risk Stewardship Program was created to fulfill the high priority stewardship component of the Act. The program encourages all citizens of Ontario to uphold a responsibility for the conservation of biodiversity and the protection and recovery of species at risk. The stewardship program includes education and outreach components, private landowner incentive programs, and funding for stewardship actions.

Private landowner support is a vital component of the protection of species at risk, considering that a vast proportion exist on private lands. Hence, voluntary conservation efforts are imperative to species at risk recovery. The Ontario Species at Risk Stewardship fund provides a total of $\$ 18$ million to eligible stewardship projects, composed of mostly protection and recovery activities. These funds are guaranteed over four years, from 2007 to 2011. The Stewardship Fund is available to individuals and groups across the province, including landowners, farmers, aboriginals, academic institutions, conservation organizations, industries, municipalities, and stewardship councils. Examples of some projects that have received funding include: mapping tallgrass prairie habitat, restoring of habitat by an aggregates company, and designing a wireless system to track at risk turtle species (MNR, 2010).

Stakeholders have expressed concern over the selection of fund recipients in the 2007-2008 and 2008-2009 fiscal years, because not enough time was allocated to the

\footnotetext{
${ }^{17}$ Ontario Ministry of Natural Resources. Species at Risk Environmental Registry. $<\underline{\text { http://www.mnr.gov.on.ca/en/Business/Species/2ColumnSubPage/241718.html }>}$
} 
consideration of applications for funding. Recovery teams responsible for specific species at risk were also not consulted during the application process. In addition, the majority of funded projects are not directly linked to existing recovery plans. Future funding applicants are being encouraged to consult with MNR staff and species experts in order to maximize fund allotments (Miller, 2009: 53).

Farmers play an especially important role in the conservation of species at risk in Ontario. With this understanding, the MNR established the Species at Risk Farm Incentive Program (SARFIP) in 2008. SARFIP is a cost-share program that is funded by the Ontario MNR. The program specifically targets Ontario farms that are registered under the Canada-Ontario Environmental Farm Plan, so as to promote and encourage the protection and conservation of habitat for species at risk (MNR, 2010).

Landowner stewardship is also being encouraged via the Conservation Land Tax Incentive Program (CLTIP). It is a program that recognizes and supports the private stewardship of provincially significant conservation lands in Ontario. The strategy of the program encompasses the granting of property tax relief to private landowners who agree to protect the integrity of natural heritage that is present on the land. Presently, the program is offering a $100 \%$ tax exemption on eligible areas of property. The landowners benefit from retaining ownership of the land as the CLTIP is not a land acquisition program. The program encourages the participation of private landowners while instilling stewardship values and cooperation for the preservation of Ontario's natural heritage and species at risk (MNR, 2010). However, the MNR reserves participation to landowners with only endangered species inhabiting their land. There are no incentives that exist for habitats of threatened species, or other species at risk. Not all stakeholders are benefitting from the program. As of 2009 , only 60 properties across Ontario actually were recipients of tax relief for the habitat of endangered species under the CLTIP (Miller, 2009: 54).

At the outset, the new Ontario Endangered Species Act, 2007 received many accolades and much praise from numerous environmental organizations and academics. However, due to the application of numerous exemptions, the Act has been the target of much recent criticism. 
Table 4.3: Bill 184, [Ontario] Endangered Species Act, 2007 Explanatory Note

\begin{tabular}{|c|c|}
\hline \multirow[t]{3}{*}{ PURPOSES of the BILL } & $\begin{array}{l}\text { 1. To identify species at risk based on the best available scientific information, } \\
\text { including information obtained from community knowledge and aboriginal } \\
\text { traditional knowledge. }\end{array}$ \\
\hline & $\begin{array}{l}\text { 2. To protect species that are at risk and their habitats, and to promote the } \\
\text { recovery of species that are at risk. }\end{array}$ \\
\hline & $\begin{array}{l}\text { 3. To promote stewardship activities to assist in the protection and recovery of } \\
\text { species that are at risk. }\end{array}$ \\
\hline \multirow[t]{2}{*}{$\begin{array}{l}\text { CLASSIFICATION OF } \\
\text { SPECIES }\end{array}$} & $\begin{array}{l}\text { The Committee on the Status of Species at Risk in Ontario (COSSARO) is } \\
\text { continued. Its members must be persons who have relevant expertise drawn } \\
\text { from a scientific discipline or aboriginal traditional knowledge. COSSARO is } \\
\text { required to assess and classify species and to report the classifications to the } \\
\text { responsible Minister. The Bill sets out rules for classifying species as extinct, } \\
\text { extirpated, endangered, threatened or special concern species. Classifications } \\
\text { must be based on the best available scientific information, including } \\
\text { information obtained from community knowledge and aboriginal traditional } \\
\text { knowledge. See sections } 3 \text { to } 6 \text {. }\end{array}$ \\
\hline & $\begin{array}{l}\text { A designated Ministry official is required to make and file a regulation (referred } \\
\text { to in the Bill as the Species at Risk in Ontario List) that lists all the species that } \\
\text { are classified by COSSARO as extirpated, endangered, threatened or special } \\
\text { concern species. When new information is reported to the Minister by } \\
\text { COSSARO, the Ministry official must amend the regulation to accurately } \\
\text { reflect the new information... See section } 7 \text { and Schedules } 1 \text { to } 5 \text {. }\end{array}$ \\
\hline \multirow[t]{3}{*}{$\begin{array}{l}\text { PROTECTION AND } \\
\text { RECOVERY OF } \\
\text { SPECIES }\end{array}$} & $\begin{array}{l}\text { If a species is listed on the Species at Risk in Ontario List as an extirpated, } \\
\text { endangered or threatened species, the Bill prohibits killing, harming, harassing, } \\
\text { capturing, taking, possessing, transporting, collecting, buying, selling, leasing, } \\
\text { trading or offering to buy, sell, lease or trade a member of the species, or } \\
\text { selling, leasing, trading or offering to sell, lease or trade anything that is } \\
\text { represented to be a member of the species... See Section } 9 \text {. }\end{array}$ \\
\hline & $\begin{array}{l}\text { If a species is listed on the Species at Risk in Ontario List as an endangered or } \\
\text { threatened species, the Bill prohibits damaging or destroying the habitat of the } \\
\text { species... The regulations may specifically prescribe an area as the habitat of a } \\
\text { species but, if no habitat regulation is in force with respect to a species, } \\
\text { "habitat" is defined to mean an area on which the species depends, directly or } \\
\text { indirectly, to carry on its life processes... See Section } 10 \text { and } 2 \text { (definitions). }\end{array}$ \\
\hline & $\begin{array}{l}\text { The Minister is required to ensure that a recovery strategy is prepared for each } \\
\text { species that is listed on the Species at Risk in Ontario List as an endangered or } \\
\text { threatened species.... See Sections } 11 \text { to } 15 \text {. }\end{array}$ \\
\hline \multirow[t]{2}{*}{$\begin{array}{l}\text { AGREEMENTS, } \\
\text { PERMITS and OTHER } \\
\text { INSTRUMENTS }\end{array}$} & $\begin{array}{l}\text { The Minister may enter into agreements for the purpose of assisting in the } \\
\text { protection or recovery of species that are listed on the Species at Risk in } \\
\text { Ontario List. Such an agreement may authorize a person to engage in an } \\
\text { activity that would otherwise be prohibited. See section } 16 \text {. }\end{array}$ \\
\hline & The Minister may also issue a permit that authorizes a person to engage in an \\
\hline
\end{tabular}




\begin{tabular}{|c|c|}
\hline & $\begin{array}{l}\text { activity that would otherwise be prohibited. These permits may only be issued } \\
\text { in specified circumstances. See section } 17 \text {. }\end{array}$ \\
\hline & $\begin{array}{l}\text { If specified conditions are met, instruments issued under other Acts that } \\
\text { authorize a person to engage in an activity have the same effect as a permit } \\
\text { issued by the Minister under the Bill. See section } 18 \text {. }\end{array}$ \\
\hline & $\begin{array}{l}\text { Special provisions govern agreements and permits relating to aboriginal } \\
\text { people. See section } 19 \text {. }\end{array}$ \\
\hline & $\begin{array}{l}\text { Permits issued by the Minister under the Bill may be amended or revoked in } \\
\text { specified circumstances. If the Minister intends to amend or revoke a permit } \\
\text { without the consent of the holder of the permit, notice must be given and the } \\
\text { holder of the permit may require that a hearing be held before the Minister } \\
\text { makes a decision. See section } 20 \text {. }\end{array}$ \\
\hline ENFORCEMENT & $\begin{array}{l}\text { The Bill contains a number of provisions relating to enforcement. These } \\
\text { include provisions designating enforcement officers and, in specified } \\
\text { circumstances, authorizing them to conduct inspections and searches. Orders } \\
\text { may be made in specified circumstances. A person against whom an order is } \\
\text { made may require that a hearing be held and, after a hearing is held, the } \\
\text { Minister may confirm, amend or revoke the order. See sections } 21 \text { to } 35 \text {. }\end{array}$ \\
\hline $\begin{array}{l}\text { OFFENCES AND } \\
\text { PENALTIES }\end{array}$ & $\begin{array}{l}\text { A contravention of specified provisions of the Bill, or of provisions of } \\
\text { agreements, permits or orders under the Bill, is an offence. A person cannot be } \\
\text { convicted of an offence if the person establishes that the person exercised all } \\
\text { due diligence to prevent the commission of the offence, or that the person } \\
\text { honestly and reasonably believed in the existence of facts that, if true, would } \\
\text { render the person's conduct innocent.... See sections } 36 \text { to } 45 \text {. }\end{array}$ \\
\hline $\begin{array}{l}\text { Miscellaneous } \\
\text { Other provisions in the } \\
\text { Bill include the } \\
\text { following: }\end{array}$ & $\begin{array}{l}\text { The Bill makes clear that it does not abrogate or derogate from the protection } \\
\text { provided for the existing aboriginal and treaty rights of the aboriginal peoples } \\
\text { of Canada as recognized and affirmed in section } 35 \text { of the Constitution Act, } \\
\text { 1982. See section } 46 \text {. }\end{array}$ \\
\hline & $\begin{array}{l}\text { The Species at Risk in Ontario Stewardship Program is established. Its purpose } \\
\text { is to promote stewardship activities that relate to species listed on the Species at } \\
\text { Risk in Ontario List... See section } 47 \text {. }\end{array}$ \\
\hline $\begin{array}{l}\text { COMMENCEMENT and } \\
\text { SHORT TITLE }\end{array}$ & $\begin{array}{l}\text { With certain minor exceptions, the Bill comes into force on June } 30,2008 \text { or } \\
\text { such earlier day as may be named by proclamation of the Lieutenant Governor. } \\
\text { The short title of the Bill is the Endangered Species Act, 2007. See sections } 63 \\
\text { and } 64 \text {. }\end{array}$ \\
\hline
\end{tabular}

ADAPTED from Government of Ontario, "Explanatory Note" for Bill 184

[Extracted from Allan Greenbaum and Alex Wellington, Environmental Law and Policy in the Canadian

Context (Captus Press, 2010), Figure 13.2] 


\subsection{Exemptions and Flexibility Tools in the Ontario Endangered Species Act, 2007}

Although it was to be considered the strongest legislation of its kind in Canada, the Endangered Species Act, 2007 allows for some forms of flexibility via exceptions and exemptions. These are referred to as "flexibility" tools by the MNR. These options allow for the legal killing of species at risk or the destruction of their habitat under special circumstances. Permits, agreements, and other instruments may be legally granted under the Act, while exemptions may be created by regulation. The legislation allows for the establishment of stewardship agreements "for the purpose of assisting in the protection or recovery of a species" (ESA, 2007 c. 6, s. $16(1))$. Such agreements would allow for activities to occur that would otherwise be prohibited under the Act, but would be deemed permissible based on long term recovery goals. Correspondingly, permits allow activities to occur that would otherwise be prohibited by the Act.

A permit would be granted at the Minister's discretion if the main purpose of the activity is to ultimately assist in the protection or recovery of a species at risk, or if the Minister decides that action is required for the benefit of human health and safety. Similarly, permits may be issued to allow otherwise prohibited activities to occur. For instance, a permit may be granted if the Minister is of the opinion that the main purpose of the permit is not related to the protection or recovery of a species at risk, but the permit meets the following tests:

- an overall benefit to the species will be achieved within a reasonable time; and,

- reasonable alternatives have been considered, including alternatives that would not adversely affect the species, and the best alternative has been adopted; and,

- reasonable steps to minimize any adverse affect are required as conditions of the permit (Miller, 2009: 34-35).

A permit would also be granted if it were required to assist in the recovery or protection of a species at risk, such as stewardship agreements with conservation organizations. An example would be a permit granted to allow an organization to carry out a prescribed burn in order to restore habitat of a species at risk. Also, a permit may be granted where an activity "will result in significant social and economic benefit to Ontario" (ESA, 2007 c. 6, s. $16(1))$. In all cases, the Minister must use discretion to 
ensure that the ultimate recovery and survival of a species will not be compromised. Information regarding permit proposals and granted permits is posted on the Environmental Registry. ${ }^{18}$

Once granted, exemptions via instruments such as permits or approvals can be granted if instruments were previously granted under other statutes. Prohibited activities may be allowed to occur if such an instrument has already been granted under other existing provincial or federal statutes. All of the above exemption instruments occur on a case-by-case basis and take place at the discretion and scrutiny of the Minister (Miller, 2009: 34-35).

In July of 2008, soon after the Act came into force, some blanket exemptions to the provisions of the Act were approved. These exemptions can be granted through regulation at the discretion of Cabinet. They can apply to a category or activity, or in relation to specific species. Ontario Regulation 242/08 was filed in June of 2008 so as to coincide with the coming into force of the ESA, 2007. The regulation allowed for 23 exemptions from the provisions established in the Act. The exemptions fall into three major categories. These include exemptions for numerous major industrial and development sectors; exemptions for specific activities that the MNR deems are not harmful to species at risk; and exemptions for emergency response, public safety, and law enforcement. As outlined by the regulation, particular exemptions apply to several specific activities on an ongoing basis, as in the case of field cultivation of American ginseng for instance. The regulation also contains a limited, predetermined transition period. Within this time, activities are exempted from the provisions of the Act. Once the time has elapsed, the activities will apply and be prohibited. An example of this occurs in the exemption granted to the commercial forestry industry (Miller, 2009: 38).

The regulation also facilitates the creation of agreements to exempt activities for an undetermined amount of time. These agreements apply to infrastructure and development. Agreements made under the regulation are different than stewardship agreements as instruments under the Act. Regulated agreements allow the complete circumvention of key components of the Act. They do not need to exist specifically for the protection and recovery of species at risk. Rather, they only require that reasonable

\footnotetext{
${ }^{18}$ Ontario Environmental Registry: < http://www.ebr.gov.on.ca/ERS-WEB-External/ >
} 
steps be taken to ensure the minimization of adverse effects on species at risk, that survival or recovery is not made vulnerable, and that the agreements are not in conflict with any means that the Minister of Natural Resources intends to take to protect a species (Miller, 2009: 39).

Specific exemptions that will negatively affect the vast majority of species at risk that are slated to be protected under the Act include the exemption for commercial forestry on Crown lands, the exemptions for development and infrastructure, for pits and quarries, and for hydro-electric generating stations (Miller, 2009: 39-40). For this reason, they are considered the most severe and intrusive of the exemptions. The exemptions have the potential to undermine the purpose of the Act, while weakening protective measures.

The commercial forestry industry was granted a one year exemption to the Act, until June 30, 2009, after which compliance with the legislation was expected. The exemption allowed commercial timber harvesting on Crown lands, essentially permitting the industry to disregard the prohibitions of the Act associated with the destruction of habitat and the killing of species at risk until that date. However, there is a lack of current information on the expiry of this exemption, nor on a possible extension. It is assumed that the forestry industry is allowed to continue conducting business as usual. Presently, no public information is available on the status of extended exemptions beyond June 30, 2009. The industry continues to lobby intensely for a blanket exemption with no expiry date (Kryzanowski, 2009). The MNR has stated that "it is committed to working with the forestry industry to harmonize its existing processes with the new Act" (Miller, 2009: 39). There are 59 species at risk inhabiting the areas of Crown lands zoned for commercial forestry (ibid.).

Developers were granted a two year exemption, until June 30, 2010. If an approval was completed prior to the coming into force of the ESA, 2007, the exemptions to certain types of development and infrastructure apply until the expiry date. Various approvals under other Acts are eligible for such exemptions. Some examples of these acts include the Planning Act, 1990, the Building Code Act, 1992, the Condominium Act, 1998, the Ontario Energy Board Act, 1998, the Drainage Act, 1990 and the Environmental Assessment Act, 1990. The exemptions for development and 
infrastructure also apply to certain class environmental assessments as well as regulations established under the Environmental Assessment Act, 1990 (Miller, 2009: 40).

Exemptions for aggregate extractors apply to all pits and quarries that obtained a license prior to the coming into force of the ESA, 2007. The exemptions are valid until June 30, 2010. The need for expiry dates or renewal has not yet been addressed in this case (Miller, 2009: 40).

Ontario Regulation 242/08 permits the exemption of hydro-electric facilities from the prohibitions outlined in the Act. The prohibitions are not applicable until the third year after a target species is listed on the SARO or the third year after the date that the species is shown to exist at the facility. The exemption is only applicable if the construction of the facility began before the three year anniversary date, or if required approvals were acquired before this date. For this sector, there is no exact deadline to obtain an agreement as with the other sectors regulated under O. Reg. 242/08, and the need for an expiry date and renewal is not specified (Miller, 2009: 40-41). This particular exemption applicable to the hydro-electric sector will severely affect endangered species in central and southern Ontario, where the majority of hydro-electric facilities are situated (Ontario Nature, 2008).

A very broad exemption exists within the regulation that potentially permits the killing of species at risk or the destruction of their habitats where actions are permissible if a person "reasonably" feels that there is an imminent risk to the safety or health of a human being or animal (ibid.). For instance, in the event that a listed species at risk attacks a human being, endangering his or her life, the person is entitled to justifiably hurt or kill the animal, sacrificing the species at risk in order to ensure their safety.

All exemptions are ultimately at the discretion of the Minister of Natural Resources. For information on all 23 exemptions, refer to the Ontario Endangered Species Act, 2007 O. Reg. 242/08 ${ }^{19}$. The previously discussed industry exemptions have weakened the provisions of the Act and are undermining its purpose. Under the previous ESA, 1971, 42 species at risk of extinction and their habitats were fully protected. As a result of the exemptions, these same 42 species and their habitats are no longer fully

\footnotetext{
${ }^{19}$ Ontario Regulation 242/08 made under the Endangered Species Act, 2007. Available $<$ http://www.elaws.gov.on.ca/html/source/regs/english/2008/elaws_src_regs_r08242_e.htm>.
} 
protected under the $E S A, 2007$. This is because the exemptions now apply to the original 42 species listed under the outdated Act, which have been relisted under the ESA, 2007. The previous Act did not include such exemptions, and provided full protection to each of the 42 listed species. The exemptions are essentially allowing the clock to be turned back on endangered species protection in Ontario as protection of the 42 species has been weakened by the exemptions, rather than fortified.

Municipal jurisdictions also play an active role in endangered species protection in the province of Ontario. Land use planning by each municipality decides the future outlook of a community, as certain areas are allocated for development and others are slated for conservation. Official plans provide broad instructions for community planning and land use for 10-20 years. They usually include natural heritage policies governing features such as wildlife habitat, wetlands, woodlands, and rare species or species at risk. Under the Planning Act, $1990^{20}$, the Provincial Policy Statement provides a guide for the development of Official Plans and other planning documents. Consequentially, municipalities are guided in the development of private lands via zoning by-laws, site plan control, subdivision plans, severances, and other land use decisions. The Provincial Policy Statement issued under Section 3 of the Planning Act, $1990^{21}$ provides direction on ensuring species at risk and their habitats are considered in municipal land-use planning and that they are protected when areas are developed. Section 2.1.3 of the Provincial Policy Statement indicates that "development and site alteration shall not be permitted in significant habitat of endangered species and threatened species". This is significant as it is in line with the provisions of the ESA, 2007. In addition, the Provincial Policy Statement goes beyond many stewardship incentive programs under the $E S A, 2007$ which only guarantee funding for owners of land that consists of habitat of 'endangered' species. The Provincial Policy Statement also stresses the importance of preserving the habitat of 'threatened' species. Hence, the significance of attempting to protect species when they are threatened is highlighted.

\footnotetext{
${ }^{20}$ Ontario Planning Act, 1990. Available < http://www.elaws.gov.on.ca/html/statutes/english/elaws_statutes_90p13_e.htm $>$.

${ }^{21}$ Provincial Policy Statement under the Ontario Planning $\bar{A} c t, 1990$. 2005. Available < http://www.mah.gov.on.ca/Asset1421.aspx $>$
} 
Protective measures at this stage may prevent these species from becoming 'endangered' in the future.

Now that all existing legal and policy instruments in Ontario that are dedicated to the protection of species at risk have been reviewed, two individual case studies of species at risk in Ontario are analyzed in Chapter 5. The effectiveness of existing legal tools and the importance of scientific fact as an informative framework for these tools are also evaluated. 


\section{CHAPTER 5.0 ONTARIO SPECIES AT RISK: TWO CASE STUDIES}

Case studies of two specific Ontario species at risk were evaluated to discover if existing protectionist measures and legal tools, as well as proposed reforms in the Ontario Endangered Species Act, 2007 are sufficient for protecting species at risk.

Two cases of endangered species in Ontario are analyzed individually: the Eastern Loggerhead Shrike and the Jefferson Salamander. They are both listed as endangered on the $S A R A$ public registry and are important indicators of environmental health. The decline of these species denotes environmental and ecosystem deterioration. In particular, the Eastern Loggerhead Shrike was also selected for study because it is one of the original 42 species listed for protection under the Endangered Species Act, 1971.

\subsection{The Eastern Loggerhead Shrike}

\subsubsection{A Songbird on the Precipice of Extinction: Indicator of Southern Ontario Landscape Health}

The Eastern Loggerhead Shrike (Lanius ludovicianus migrans) is an indicator of the health of open field savanna grassland, tallgrass prairie, and alvars, as it nests and survives in these locales (Yosef, 1996: 279; Ontario Biodiversity Council, 2008: 9). Over the years, and with an increase in the size and density of the human population in southern and central Ontario, much development and urbanization has consequently taken place, vastly degrading these ecosystems. The presence and health of the Eastern Loggerhead Shrike provides a signpost for the fate of the remaining fragile and sensitive areas of prairie, savanna, and alvars in southern Ontario. However, the species tends to be mostly found within alvars, as areas of tallgrass prairie and savanna have disappeared, with few areas remaining, consisting of less than three percent of their original range (Ontario Biodiversity Council, 2008: 9). Preservation efforts that allow for the recovery of this endangered species can be extrapolated to other species that occupy the last remaining tracts. It is thus beneficial to conduct a focused case study on an indicator species that is representative of a disappearing ecosystem and the other species that rely on the same habitat for survival. Any conclusions and policy recommendations will be applicable to many other species at risk. This case study focuses on the status of the 
Eastern Loggerhead shrike as an indication of the effectiveness of existing policy tools, and the reliability and availability of scientific information to inform these instruments.

\subsubsection{Ecological Traits and Habitat Requirements}

The Loggerhead Shrike (Lanius ludovicianus) has suffered a very severe decline over the last 50 years. There are eleven subspecies of Loggerhead Shrike in existence in North America. Two subspecies currently exist and breed in Canada: the Prairie Loggerhead Shrike (Lanius ludovicianus excubitorides) and the Eastern Loggerhead Shrike (Lanius ludovicianus migrans) (Chabot et al., 2001; Telfer, 2010). The Eastern Loggerhead Shrike ${ }^{22}$ has suffered the most severe declines of the two. It is endemic to very small pockets of Manitoba and is found mostly in Ontario. A very unique subspecies, it is the only predatory songbird, or passerine, that exists in Ontario. As such, it is an important top predator in the food web and it holds individual ecosystem importance. It hunts for prey, and its diet consists of larger insects as well as mice, small snakes, and other small birds. It consumes large quantities of major agricultural pests such as grasshoppers, field mice, and meadow voles (ibid.). It is also known as the "butcher bird" because of its hunting instincts, whereby it impales its prey on sharp thorns and barbed wire to assist in tearing the food apart before consumption.

The Eastern Loggerhead Shrike was once a very common subspecies in southern Canada. Its range spanned from southeastern Manitoba, across southern Ontario and Quebec, and into the Maritime provinces. It now only nests in some pockets of southern Ontario and southeastern Manitoba. In Ontario, persistent habitat loss has forced the shrike to nest in limestone plains at the southern edge of the Canadian Shield (Chabot et al., 2001; Royal Ontario Museum, 2008). Specifically, these core areas of the Canadian Shield are the Carden Plain, northeast of Lake Simcoe; the Napanee Plain, just north of Lake Ontario in the Kingston area; and the Smith's Falls Plain, in eastern Ontario (ibid.). Figure 5.1 below shows the approximate locations of these three core areas within the shrike's historic breeding range in Ontario (Bird Studies Canada, n.d.).

\footnotetext{
${ }^{22}$ Information on the Eastern Loggerhead Shrike is available under the $S A R A$ s public registry: Species at Risk Act (SARA), Registry. June 2008. Eastern Loggerhead Shrike. < http://www.sararegistry.gc.ca/species/speciesDetails e.cfm?sid=26 >.
} 


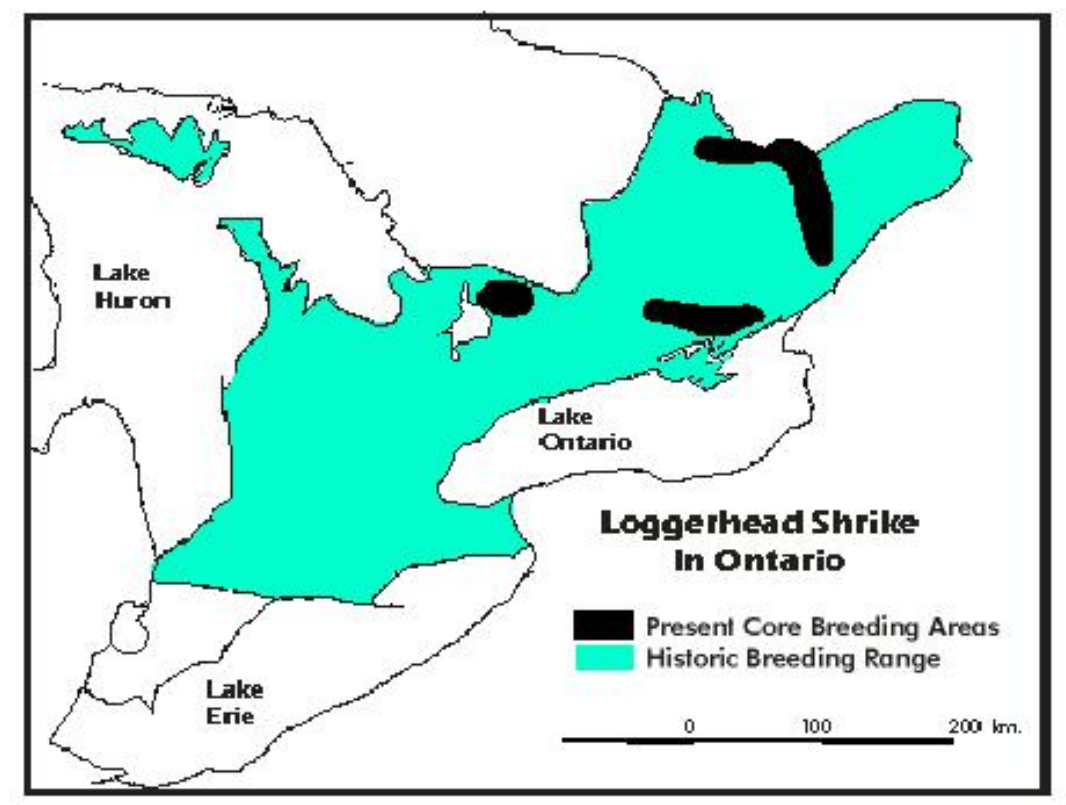

Figure 5.1: Eastern Loggerhead Shrike Historic and Present Breeding Ranges [Source: Bird Studies Canada, n.d.]

\subsubsection{Current Status and Causes of Decline}

Of all North American songbirds, grassland species like the Loggerhead Shrike are undergoing the most drastic decline in numbers (Chabot et al., 2001; Stutchbury, 2007: 115). The decline of grassland birds is more pronounced than that of forest songbirds. Native grasslands are among the most endangered ecosystems in North America because they are easily converted into land for agricultural purposes or slated for development. More than 90 percent of tallgrass prairie and savanna has been lost, correlating with the local extinctions of Loggerhead Shrike all across the Canadian and American western prairies. With the disappearance of native grasslands, songbirds that were originally adapted to the native landscape have been forced to adapt to an assortment of habitat types.

Presently, with the disappearance of all but tiny fragments of native grasslands, birds such as the Loggerhead Shrike are forced to survive on agricultural lands. There, the habitat is poorer in quality and severely altered by heavy grazing and mowing. May and June are trying months for the survival of young nestlings. This is when hayfields 
are mowed, obliterating the nests of grassland birds such as the shrike (Stutchbury, 2007: 183-184).

The Eastern Loggerhead Shrike is declining in number faster than any other grassland bird in North America. The exact reason for the decline of the Loggerhead Shrike is unknown. However, it has been suggested that a combination of various factors including habitat loss, pesticide exposure, increased predation, and car strikes have contributed to the decline. Scientists have not yet been able to determine the exact number or reasons why the birds suffer fatalities at the hatchling stage, preventing them from reaching maturity (Telfer, 2010).

Habitat loss is a major threat to the Eastern Loggerhead Shrike and it poses the greatest danger. Over the second half of the last century, intensive farming and conversion of grasslands to farmland, natural succession, reforestation, and development have all drastically reduced the amount of habitat available to the species. Younger and inexperienced shrikes are also susceptible to car strikes, particularly when they are nesting and breeding in roadside fields and edges. When they swoop across roadways to catch prey, they are also susceptible to being killed by vehicles (Nature Conservancy of Canada, 2006; Wildlife Preservation Canada, 2008).

Chemicals such as pesticides can infiltrate the bird's food sources. This is because shrikes forage and breed near agricultural fields where chemicals are often applied to control pests. The Loggerhead Shrike is a species that prefers to dwell in grasslands, but is forced to thrive in and around farmland, as grasslands are being converted to agricultural lands and residential lands at alarming rates (Stutchbury, 2007: 117).

Poisoned birds are more susceptible to dying from collisions with buildings, fences, or other objects, and are more easily hit by passing cars (Stuchbury, 2007: 119). Many modern pesticides are hormone disruptors that can negatively affect fertility and reproduction. All possible sub-lethal effects of pesticides are not entirely known, but some are thought to impede normal embryonic development and cause thinning of eggshells (Bartuszevige et al., 2002; Stuchbury, 2007: 121, 123).

In conjunction with habitat loss and car strikes, high levels of predation on Loggerhead Shrike young have also placed the population in peril. Nest predation tends 
to be very high in open grasslands. Birds that prefer to nest in grasslands, like the Loggerhead Shrike, are easier prey. Subsequently, birds that nest in smaller grassland patches are more readily preyed upon than those that nest in more optimal, larger areas of grassland (Friesen et al., 1999; Winter and Faaborg, 1999; Burke and Nol, 2000; Stutchbury, 2007: 183-184). This was confirmed by a large-scale study of remaining native grassland fragments in the 1990s. The study focused on four common grassland birds and looked at more than three thousand nests in thirty-nine grassland fragments ranging in size from a tiny 24 hectare to 40000 hectare preserves. It was concluded that nest predation was vastly higher in the smaller fragments where four out of every five nests were destroyed (ibid.).

Loggerhead Shrikes are not only easily accessible to natural predators in the wild; they are also susceptible to attacks by domestic and feral cats. Felines that prowl grasslands in search of mice, hunt in the same habitat where shrikes live, nest, and hunt. Domestic cats that are permitted outdoors are a major predator of birds that nest in suburban and rural agricultural areas. One particular study observed that every domestic cat kills on average one bird per week (Stutchbury, 2007: 174-175). Considering the vast numbers of domestic and feral cats in Ontario, the number of dead songbirds is unimaginable, and may possibly number in the millions. Although cats only follow their natural hunting instincts, their predation on birds is not a natural part of the ecosystem, and they have never been a natural part of the food chain in Canada. They were introduced to North America with the arrival of the Europeans and became popular in the 1800s (CWS, 2009a; Stutchbury, 2007: 174-175).

The combination of pressures on Eastern Loggerhead Shrike populations has led to significant declines in numbers. At present, the Eastern Loggerhead Shrike is considered to be critically endangered in Canada under COSEWIC and it is also listed under the federal Species at Risk Act (Telfer, 2010). The species is also listed as endangered on the SARO and under the Ontario ESA, 2007. As of 2009, there were approximately only 31 breeding pairs remaining in the wild in Ontario. This is an encouraging number considering that 28 breeding pairs were counted in the wild in the preceding year, and only 19 the year before that. However, as illustrated in Figure 5.2, 
healthy populations are yet to stabilize and numbers of breeding pairs remain dangerously low (Nature Conservancy of Canada, 2006; Wildlife Preservation Canada, 2008).

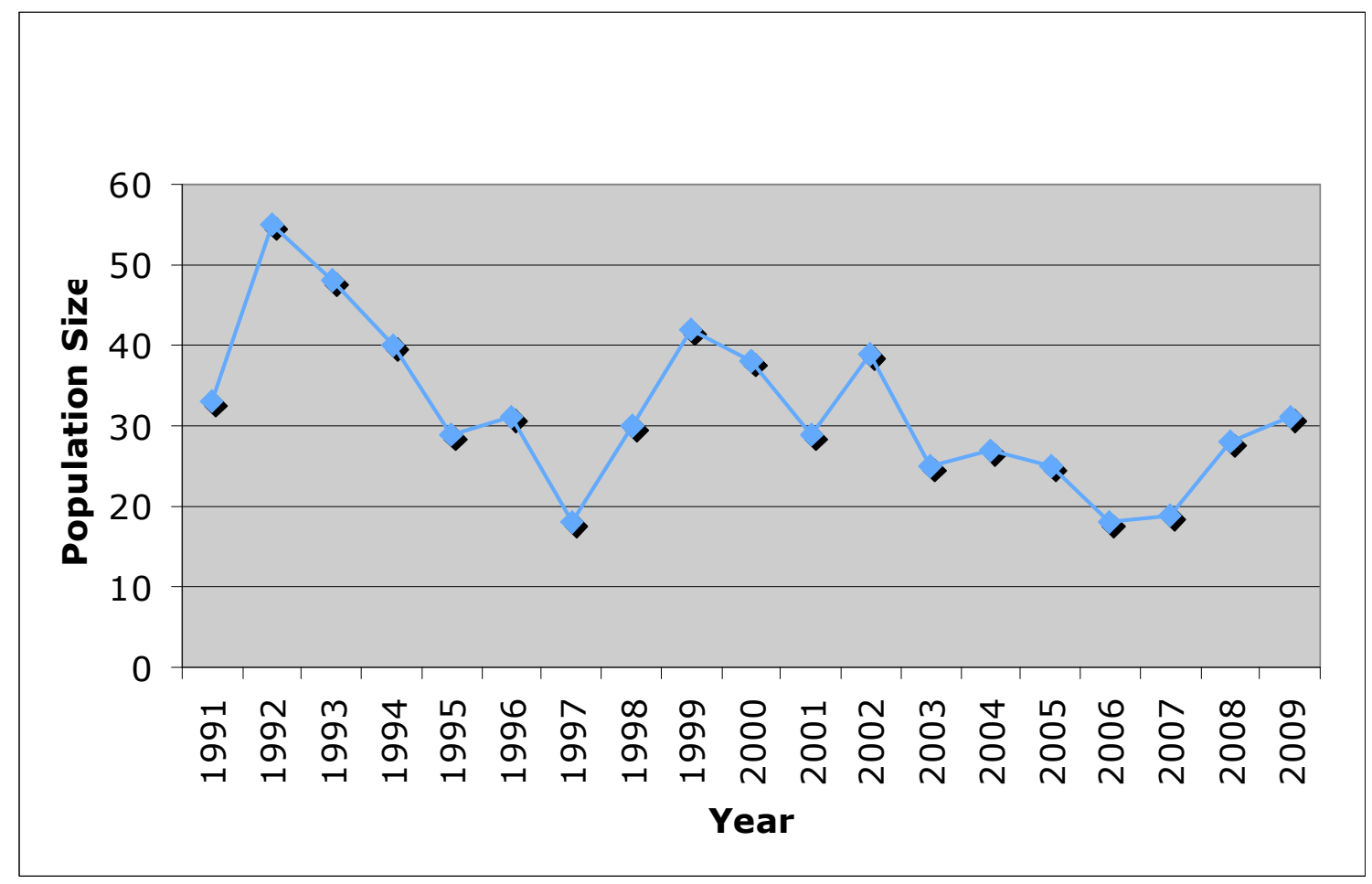

Figure 5.2: Population Monitoring of Eastern Loggerhead Shrike Breeding Pairs (Population Size is determined in numbers of breeding pairs).

[Source: Wildlife Preservation Canada, 2010]

The Eastern Loggerhead Shrike is an attractive charismatic subspecies that has a large amount of public appeal. As such, there has been a great deal of mobilization over the last decade to attempt to protect the species. Considering the few breeding pairs remaining in Ontario, there is evidence that the efforts have not been successful thus far (Wildlife Preservation Canada, 2008). Taking into consideration that habitat loss is the primary cause of the disappearance of the species, some efforts have been made to protect existing habitat and plans to establish new habitat for the Loggerhead Shrike are in existence (ibid.).

Monitoring of Eastern Loggerhead Shrike population numbers in the wild has been occurring since 1991. In 1993, a national Loggerhead Shrike Recovery Team was established. It later branched into two groups, one responsible for the Eastern 
Loggerhead Shrike Recovery Program and the other for the Prairie Loggerhead Shrike Recovery Program. Members of the groups include representatives from the Canadian Wildlife Service, provincial wildlife agencies, environmental non-governmental organizations (ENGOs), the Canadian Cattlemen's Association, some provincial cattlemen's associations, a few universities, and the Toronto Zoo, as well as a number of private landowners (Telfer, 2010). The ultimate goal of the Eastern Loggerhead Shrike Recovery Strategy is to increase the population nesting in Eastern Canada to a self sustaining number of a minimum of 500 breeding pairs (WPC, 2005).

Much research on Eastern Loggerhead Shrike populations continues, including population monitoring, bird banding, DNA studies, and the establishment of captive breeding programs. A fundamental portion of the recovery strategy involves the formation of various Recovery Action Groups (RAGs) for each of the six core existing areas of shrike habitat. Each group concerns itself with coordinating shrike recovery in its area. Some examples of RAG activities include the organization of habitat stewardship programs, outreach and education programs, community groups, farming organizations, and naturalist clubs (Eastern Loggerhead Shrike Recovery, n.d.). In essence, the primary goal of the Loggerhead Shrike Recovery Action Groups is to coordinate landowner stewardship efforts. This is extremely important because almost every breeding pair in Ontario is found on private property. Government support, subsidization, and funding for private land stewardship are imperative for the promotion of Loggerhead Shrike conservation and recovery. There is a constant need for additional support from governments, groups, and individuals for the protection of existing habitat, and for the establishment of new habitat, if the Eastern Loggerhead Shrike is to overcome the looming possibility of extinction (Telfer, 2010).

A captive breeding program for the bird is currently in existence. The Eastern Loggerhead Shrike captive breeding program was started by Environment Canada in 1997. Forty-three nestlings were captured in 1997 and 1998 in order to establish two breeding populations located at the Toronto Zoo and at the Avian Science and Conservation Centre at McGill University in Montreal. The captive population now numbers more than 100 . The goal of the program is to use captive populations to reestablish populations in the wild, once actual causes of species decline are identified, and 
in turn become manageable. Since 2001, 221 captive-bred shrikes were released into the wild. Two females that were released the previous year were found to successfully breed in the wild the following year, proving that captive-bred birds can migrate, over-winter, and return to breed. However, not enough captive-bred shrikes have had this success in the wild. More must be understood about the factors and dynamics that affect the interactions between captive-bred and wild shrikes alongside the interaction of causes of the decline of wild populations (Eastern Loggerhead Shrike Recovery, n.d.). Also, many scientists question the genetic viability of captive-bred animals. ${ }^{23}$ Thus, the plight of the Easter Loggerhead Shrike is still riddled with much scientific uncertainty.

In addition, there are other biodiversity issues with regards to species at risk. A population numbering in small sizes, as is often the case with species at risk, endangered species, and captive-bred populations, can encounter genetic diversity issues. Such populations are susceptible to genetic drift, or the "random fluctuation in gene frequencies that occur as a result of nonrepresentative combinations of gametes created during breeding." Drift can lead to the loss of genetic variation and diversity (Berry, 1971; Van Dyke, 2003: 115). Small populations are also susceptible to increased rates of inbreeding due to a greater probability of individuals of above-average relatedness interbreeding (Franklin, 1980; Frankel and Soulé, 1981; Van Dyke, 2003: 116). These problems eventually lead to a population bottleneck. Once a bottleneck takes place in a small population, "the remaining individuals represent only a sample of the original source population." They are no longer an adequate genetic representation of the original source, accounting for a loss in genetic variation and diversity (Frankel and Soulé, 1981; Van Dyke, 2003: 115).

As is evident from population censuses that have been occurring since 1991, populations had been steadily declining, and have recently become unstable, increasing slightly some years and decreasing other years (See Figure 5.2). This instability indicates that populations are not yet fully recovering, and there is still a long way to go. Hence, the Eastern Loggerhead Shrike is still likely susceptible to extinction. Efforts to restore wild populations that have been taking place since monitoring began are not deemed to

\footnotetext{
${ }^{23}$ A discussion of existing research on the genetic viability of captive-bred individuals is beyond the scope of this research paper. For more information please see Lynch and O’Hely. 2001.
} 
be successful as the ultimate goal of 500 breeding pairs in the wild is still far from attainment.

The Eastern Loggerhead Shrike Recovery Program has been funded mostly at the federal level by Environment Canada, with funds destined for habitat stewardship programs. The Ontario Species at Risk Stewardship Fund and private donations have also fuelled the recovery program throughout its years of existence. In 2007, however, federal funds to the program were cut, which placed the program in a predicament to continue with a greater reliance on private donations.

\subsubsection{Existing Legal Measures for the Protection of the Eastern Loggerhead Shrike}

The Eastern Loggerhead Shrike is fully protected under the federal Migratory Birds Convention Act, 1994, the Species at Risk Act, and the recently enacted Ontario Endangered Species Act, 2007. Shrike nesting habitat is protected under the Ontario Planning Act, 1990 whereby it is noted in the natural heritage portion of the Provincial Policy Statement associated with the Act that a municipality must not allow the alteration of "significant habitat of endangered and threatened species" ${ }^{24}$. Based on the Policy Statement, a 400 metre radius wherein development is not permitted has been applied by the Ontario MNR around any Loggerhead Shrike nest site (Stauffer, 2007).

The shrike has the benefit of being protected under two acts that were specifically created to target species at risk issues at both the provincial and federal levels. Hence, it is legally protected by multiple jurisdictions (Telfer, 2010). Unfortunately, the extra layers of protection it should receive from the various jurisdictions are not having a very positive effect on existing populations (see fluctuations in Figure 5.2).

Under the SARA, every year, the federal Habitat Stewardship Program for Species at Risk (HSP) provides funding to support species recovery nationwide. Annually, the federal HSP provides approximately $\$ 2$ million for species recovery in Ontario. In order to be eligible for funding, the amount must be matched, either financially or "in kind" by the recipient organization. HSP projects are established to aid in the recovery of species at risk by supporting actions outlined in recovery strategies, action plans, and

\footnotetext{
${ }^{24}$ Provincial Policy Statement under the Ontario Planning Act, 1990. 2005. Available < http://www.mah.gov.on.ca/Asset1421.aspx >
} 
management plans prepared under the SARA (Environment Canada, 2007). The SARA provides support and funding to the Loggerhead Shrike Recovery Program via the HSP. The HSP grants funding to Wildlife Preservation Canada, which is responsible for the implementation of the recovery strategy, including monitoring, captive breeding and releasing, habitat mapping, stewardship and restoration, and public education. Federal funds are being allocated towards habitat stewardship and enhancement, landowner contact, communication, and outreach. Environment Canada has also confirmed that it will provide some financial support for the captive breeding program and for the maintenance of the captive population (Wildlife Preservation Canada, 2008).

In 2008, the Ontario Ministry of Natural Resources' Species at Risk Stewardship fund granted $\$ 83,500.00$ to shrike recovery. These funds were allocated from the Species at Risk Stewardship Fund. Provincial funds are being allotted towards wild population monitoring and habitat stewardship projects (Wildlife Preservation Canada, 2008).

Apart from support for shrike recovery from Environment Canada and the federal and provincial stewardship funds, most of the support received by Wildlife Preservation Canada for the Eastern Loggerhead Shrike Recovery Strategy originates from private donors. Shrike recovery efforts would not be possible without private donations (Wildlife Preservation Canada, 2008). In order for population numbers to increase, the recovery program must be allowed to continue, and it may only do so via adequate funding.

Although the Ontario Endangered Species Act, 2007 was originally applauded as one of the strongest pieces of endangered species legislation in existence, the twenty three exemptions approved in July of 2008 undermine its effectiveness. The exemptions for forestry, aggregate extraction, hydro, and development affect species like the Loggerhead Shrike, that were initially afforded complete scientifically-based habitat protection under the ESA, 2007 prior to the introduction of O. Reg. 242/08. Specifically, the exemptions for aggregate and hydro industries as well as development have the potential to severely affect endangered species in southern and central Ontario.

Under the Endangered Species Act, 1971, 42 species were listed and their habitats were to be fully protected. Although there was no scientific basis for listing species as endangered under this Act, once a species was listed it was fully protected without 
subjection to exemptions. The exemptions to the ESA, 2007 no longer grant these 42 species the same degree of protection they originally had under the outdated Act. The Eastern Loggerhead Shrike is one of these 42 species. The legislation is taking one step in reverse, to its detriment, instead of moving forward to improve endangered species protection. Hence, Eastern Loggerhead Shrike habitat is subject to certain exemptions, placing its ultimate survival in the wild in danger (Ontario Nature, 2008).

\subsubsection{Implementation Gaps}

As the Eastern Loggerhead Shrike is a migratory bird, the responsibility for its legal protection falls well within federal jurisdiction as well as provincial jurisdiction. At the federal level, the most important piece of legislation with specific regard to species at risk is the Species at Risk Act. Its influence extends only to species located on federal lands, or to aquatic species and those protected under the Migratory Birds Convention Act, 1994 (SARA, 2002 34(2)). In the case of the Loggerhead Shrike, there are so few individuals remaining in the wild, that the possibility of individuals residing on federal Crown, or public, territory is very slim. Most of the remaining populations reside on private lands held by private landowners.

In October of 1996, all jurisdictions in Canada ratified a national approach for the protection of the country's species at risk. The agreement, known as the National Accord for the Protection of Species at Risk, was sanctioned by the federal, provincial, and territorial governments in a commitment to preserve Canada's species at risk. In the accord, a great emphasis is placed on the importance of stewardship in combating the plight of species at risk (The Accord for the Protection of Species at Risk Backgrounder, n.d.). As outlined in the Species at Risk Act, the federal Minister of the Environment can "enter into a conservation agreement with any government in Canada, organization or person to benefit a species at risk or enhance its survival in the wild." (SARA, 2002 11(1)). Under the Act, and resulting from the National Accord, there is much cooperation and overlap between the various jurisdictions with regard to species at risk policy instruments. As specified in the Act, the federal government is required to allocate funding for the recovery of endangered species from the federal Habitat Stewardship Fund. 
In the fall of 2007, Federal Environment Minister John Baird announced that funds were to be cut in the budget of Environment Canada. The programs affected include the Canadian Wildlife Service along with the Migratory Bird Program, whose budget was cut by fifty percent. The budget allocated for National Wildlife Areas, a program that protects significant wildlife habitats, has been completely eliminated, dropping from $\$ 1.9$ million to zero (CBC, 2007). In the case of the Eastern Loggerhead Shrike, these funding cuts affected the 2008-2009 and 2009-2010 recovery effort field seasons, with even greater repercussions to possibly occur in the future. No reasons were given to justify the funding cutbacks except that the office of the Environment Minster indicated that funding was to be siphoned to priorities in climate change initiatives (ibid.). In essence, shrike recovery is being made possible mostly as a result of private donations, underlining the increasing reliance on external private sources to aid this endangered species, and emphasizing the decrease in government funding. In fact, the 2009-2010 field seasons for the Eastern Loggerhead Shrike recovery efforts are only being permitted to continue mainly due to private "bridge funding" from a major corporate donor (Hess, 2009: 32). Hence, the federal budget cuts jeopardize the future of the Eastern Loggerhead Shrike, and many other endangered species in Canada (Wildlife Preservation Canada, 2007).

The federal government is reneging on its obligation to aid in the best possible manner in the recovery of species at risk, as outlined in SARA. In the case of the shrike, without adequate funding from the Habitat Stewardship Fund, the Eastern Loggerhead Shrike recovery effort faces an uncertain future, essentially placing the survival of the species in dire circumstances (Canadian Association of Zoos in Ontario, 2009).

The federal government also has a responsibility for protecting all Canadian migratory birds, including the Eastern Loggerhead Shrike, under the Migratory Birds Convention Act, 1994. Although the Act strictly prohibits the harming of migratory birds and the disturbance or destruction of their nests and eggs, these actions may still occur unintentionally via commercial activities. Such activities include mining, forestry and agriculture, electrical generation and transmission, fishing, infrastructure management, and urban development. Destruction resulting from these activities is referred to as 
"incidental take". This form of destruction is illegal in accordance with the $M B C A, 1994$ (CWS, 2009b).

Where some activities are illegal at the level of federal jurisdiction, they may be deemed to be legal under provincial jurisdiction. This is when jurisdictional overlap becomes a major implementation gap. In this case, a federal Act prohibits certain activities while a provincial Act, the ESA, 2007, via permit and regulation, may allow such activities and facilitate the action of "incidental take". For instance, the exemptions to the ESA, 2007 under Ontario Regulation 242/08 that were previously mentioned above allow for the legal conduct of many activities where "incidental take" is possible. For example, pits and quarries had been exempted until June 30, 2010 from the prohibitions of the ESA, 2007 relating to the destruction of habitat and the killing of species at risk. The ESA, 2007 exemptions facilitate the possibility of committing a prohibited act according to the $M B C A, 1994$. In this case, the two jurisdictions confound one another. This scenario is but one example of the problems that may arise in the Canadian political system that is founded on the premise of separation of powers as directed by the constitution.

Jurisdiction is a major obstacle to implementation of policy; however, many obstacles are present within the same jurisdiction as well. For instance, some statutes in the province of Ontario may authorize activities that may be prohibited under other Ontario statutes. A case in point is evident where the Endangered Species Act, 2007 allows for the occurrence of prohibited activities if an instrument, such as a permit or approval, has been issued under other provincial or federal statutes, and prescribed general conditions have been met. These conditions are the same as those that apply to permits issued directly under the ESA, 2007: that an overall benefit to a species will be achieved, reasonable alternatives have been considered and the best alternative has been adopted, and reasonable steps to minimize adverse affects are required as conditions of the permit. For all instruments that are applicable under other legislation, the Minister must be of the opinion that these conditions were met at the time the instrument was issued or approved. The problem with this method of approval is that other Acts do not take conservation and preservation into consideration in the same manner as the ESA, 2007 does (Miller, 2009: 36). Hence, any habitat destruction that may legally take place 
under, for instance, the Ontario Aggregate Resources Act, 1990, will not necessarily take into consideration the conservation of a species at risk when undertaking the lawful destruction of their habitat in the same manner as such an exemption or permit would allow under the ESA, 2007.

Implementation gaps are also evident within single pieces of legislation and policy. For instance, the recent exemptions to the Ontario Endangered Species Act, 2007 will prove damaging to the preservation of species and will specifically harm the recovery effort for the Eastern Loggerhead Shrike. Defeating the purpose of the revisions to the statute, the Act will no longer grant full protection towards the habitats of species at risk, one of the defining elements that represented the laudable nature of the new legislation. Industries that qualify for the exemptions are no longer required to explore all available options to justify their activities. The exemptions allow business to operate as usual, in complete disregard for endangered species. Permits and other instruments were created to enable activities that would not otherwise be permitted under the Act, and guarantee that the activities would still foster stewardship, protection, or rehabilitation of a species. When exemptions are permitted without the requirement of such instruments, the purpose of their creation is undermined. For instance, permits give industries higher standards for conducting business while protecting a species. Exemptions facilitate the process of allowing certain industries to ignore endangered species.

Even the use of permits can pose implementation gaps if extreme care and caution are not taken. It is imperative to ensure that flexibility tools such as permits and agreements do not become loopholes for business to function as usual within the framework of the legislation. The Environmental Commissioner of Ontario also warns of taking extreme caution in authorizing the limited use of these flexibility tools and exceptions while ensuring that the purpose of the ESA, 2007, the protection and recovery of species at risk, is not undermined (Miller, 2009: 35). Hence, it is crucial that the law does not become too permissive in favour of economic interests. This could ultimately undermine the purpose of the legislation (Illical and Harrison, 2007).

A major obstacle to the implementation of policy and legislation is the willingness to cooperate on behalf of a significant actor: the private landowner. The Endangered Species Act, 1971 did not include any stewardship incentives for the protection of species 
deemed to be at risk under the Act. No flexibility tools, recovery strategies, or stewardship support existed. The only options for conservation of species listed as being at risk were along the lines of command and control, such as the enforcement of strict fines, as opposed to more permissive voluntary stewardship initiatives and flexibility instruments, such as permits and regulations. Thus, a culture has flourished among some private landowners to rid their properties of endangered species so as not to deal with the consequences. These actions are often coined as "shoot, shovel, and shut-up" (Helferty, 2007).

The new Endangered Species Act, 2007 attempts to stimulate more involvement in species protection on behalf of the private landowner and includes a voluntary stewardship element, relying less on harsh command and control with punitive elements, as was the case under the old Act. Even so, if an endangered species such as the Eastern Loggerhead Shrike establishes habitat and nests on private land, Ontario municipal law states that a 400 metre radius must be preserved wherein interference with the endangered species is not permitted, as previously stated above (Stauffer, 2007). As such, some private landowners are still spurred to "shoot, shovel, and shut-up" rather than deal with all the consequences of having an endangered species making its home on their land. This is of particular importance when considering that some fines have been increased with the passing of the new ESA, 2007. For instance, if a species is harmed within its buffer nesting area and critical habitat, the penalty is a daily fine of $\$ 250,000$, or $\$ 1,000,000$ for a corporation, or time spent in jail (ESA, 2007, 40(1)). This fine has been increased from the previous $\$ 50000$ per day (MNR, 2010). Increases in such fines may ultimately result in the undermining of voluntary stewardship and continue to facilitate the "shoot, shovel, and shut-up" culture that was already prevalent in farming communities and among many other types of private landowners prior to the passing of the ESA, 2007. Ridding the property of the species altogether reduces the effort and financial impact that an endangered species would incur to a private landowner.

The existence of adequate habitat stewardship initiatives and incentives provide measures with which to cooperate with private landowners to ensure more effective protection. In November 2008, it was publicly announced that the MNR was allocating $\$ 800,000$ on a yearly basis to partake in the costs of existing programs in order to reduce 
some of the financial burden to private landowners. An example of an existing program that is subsidized by the MNR is the Species at Risk Farm Incentive Program (SARFIP), where up to $\$ 20,000$ is granted per farm, for all eligible projects. For all other private landowners, the Conservation Land Tax Incentive Program (CLTIP) encourages and grants support for long-term stewardship of various categories of conservation land by granting property owners tax relief in exchange for the protection of natural heritage features on their property. However, landowners and farmers are only allowed to participate in stewardship programs, and they are only eligible for property tax relief if an endangered species is known to presently inhabit the land. There are no incentives in existence for the habitats of threatened species or other species at risk (Miller, 2009: 54).

The implementation gaps present in Ontario affect all species at risk. A second case study on the Jefferson Salamander also attempts to highlight weaknesses in current species at risk legal protectionist measures in Ontario. Most weaknesses and implementation gaps encountered in the case of the Eastern Loggerhead Shrike also arise in the subsequent case.

\subsection{The Jefferson Salamander}

\subsubsection{Shining the Spotlight on the Jefferson Salamander}

The case of the Jefferson Salamander (Ambystoma jeffersonianum) serves as a key illustration of the importance of indicator species. Understanding the ecology of a species is a crucial component of establishing policies for protection. Since it is an amphibian, the salamander is extremely vulnerable to negative environmental change. The salamander's life cycle consists of both an aquatic and terrestrial stage; hence, it is often exposed to a wider variety of pollutants throughout its entire life history in comparison to other organisms that live out their life cycles in one main type of habitat. Its moist, permeable skin adsorbs chemicals from the surrounding environment.

The Jefferson Salamander is a very important indicator species for Ontario's Greenbelt, a protected area of green space found within densely populated and highly urbanized areas of southern Ontario. As there is much scientific uncertainty in the face of massive urbanization, the species also provides a telling illustration of the challenges of species protection in the context of significant scientific uncertainty. The salamander, as 
elaborated below, is hard to identify, and its members live secretive lives, making habitat protection difficult. Initiatives taken to protect the species can very likely be extrapolated to other less sensitive species at risk that reside within the area.

\subsubsection{Ecological Traits and Habitat Requirements}

The Jefferson Salamander ${ }^{25}$ (Ambystoma jeffersonianum) is a fairly large grey to brownish-grey salamander. The amphibian reproduces by amalgamating its eggs into gelatinous masses, that are subsequently attached to sticks and plant stems. Each egg mass typically contains 16 to 40 eggs. The eggs contain a dark brown or black pigment, and they are protected by a layer of gel. These elements, along with the presence of dissolved organic matter in the breeding pond, serve to protect developing embryos from damage due to exposure to ultraviolet $-\mathrm{B}$ radiation (Licht, 2003: 551; Jefferson Salamander Recovery Team, 2010: 1). Highly dependent on water temperature, eggs complete their development in two to four weeks. In July and August, juvenile salamanders begin to move out of the breeding pond and search for shelter amid the forest litter (Jefferson Salamander Recovery Team, 2010: 1).

The Jefferson Salamander is a unique species that exhibits unusual reproductive biology and genetics. It is widely known to coexist with the Blue-spotted Salamander (Ambystoma laterale). These polyploid individuals tend to be $A$. laterale females, which are unable to reproduce successfully without the contribution of male gametes from $A$. jeffersonianum. Since these polyploid populations cannot exist alone, they cannot be defined as a separate species. Most of the polyploids are triploid, having three sets of chromosomes, with a predominance of $A$. jeffersonianum chromosomes. These Jeffersonianum-dominated individuals are referred to as members of the A. lateralejeffersonianum complex. Since these individuals cannot be distinguished from pure $A$. jeffersonianum individuals by habitat or by morphology, often genetic analysis is the only method of determination. This makes the delineation of the A. jeffersonianum species range a rather difficult task. Essentially, this also presents challenges for the protection

\footnotetext{
${ }^{25}$ Information on the Jefferson Salamander is available under the $S A R A$ s public registry: Species at Risk Act (SARA), Registry. June 2008. Jefferson Salamander. < http://www.sararegistry.gc.ca/species/speciesDetails e.cfm?sid=642 $>$.
} 
and recovery of the species. Individuals of the A. laterale-jeffersonianum complex occur at greater abundance, typically encompassing a staggering $90-95 \%$ of local Ontario populations (Lowcock et al., 1987; Lowcock et al., 1991; Noël et al., 2008).

Thus, from a policy perspective, the elements of the existing recovery strategy should apply to both types of individuals (Jefferson Salamander Recovery Team, 2010: 2-3). Figure 5.3 illustrates documented occurrences of the Jefferson Salamander, which makes up the Canadian range of the species. The Ontario population inhabits the northern limit of the species' North American range (Jefferson Salmander Recovery Team, 2010: 5-6).

The Jefferson Salamander has very specific breeding and habitat requirements. Its survival is dependent on the limited availability of ideal habitat, such as the presence of fishless vernal pools and wetlands, within or in close proximity to woodland, so the species can successfully breed and burrow. Thus, in addition to being an indicator species of the health of the local woodland environment and high quality vernal pools, the Jefferson Salamander plays a crucial role in channeling nutrients between the aquatic environment and the upland wooded environment, due to it carrying out its life history in both aquatic and terrestrial environments (Jefferson Salmander Recovery Team, 2010: 3).

Since it is an amphibian, the Jefferson Salamander is dependant upon water for breeding and survival. Breeding takes place during the first spring rains in March and April, usually in temporary vernal pools and wetlands. Breeding ponds are typically vernal pools that are sourced by groundwater, snowmelt, or surface waters. These vernal pools will tend to disappear and desiccate in mid to late summer. Some other types of breeding areas may include wetlands that may also have permanent or semi-permanent water stands. Breeding ponds tend to be located within a woodland, or in very close proximity to a woodland. The Jefferson Salamander has a tendency to return to the same breeding pond in subsequent years. A key factor for breeding success is the availability of low shrubs, twigs, fallen tree branches, or other forms of vegetation, which are required for the attachment of egg masses (Jefferson Salamander Recovery Team, 2010: 9). Food items must be readily available. These are typically small aquatic invertebrates and amphibian larvae. Essential to the breeding success of the species is the absence of fish predators within breeding ponds (ibid.). 


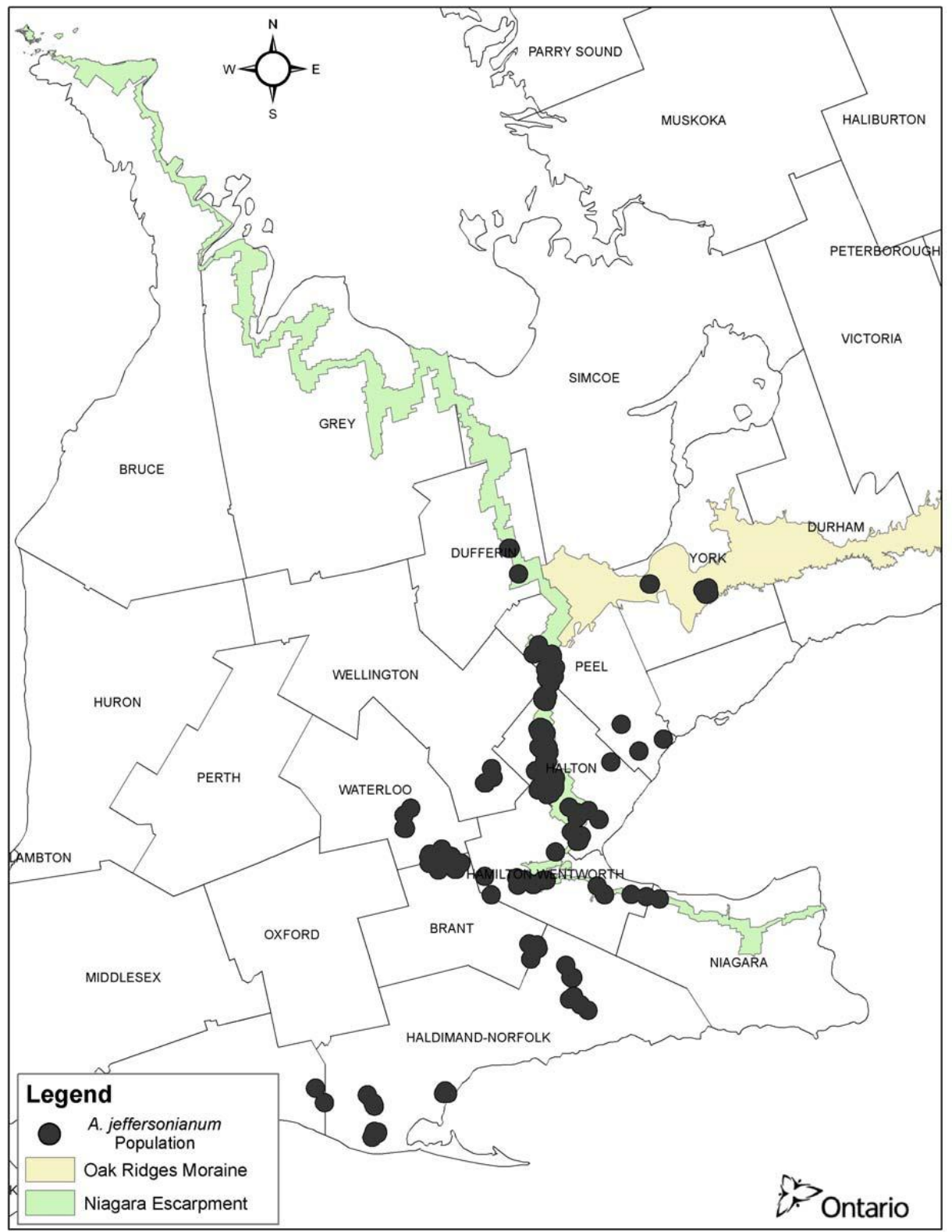

Figure 5.3: Documented individual occurrences of Ambystoma jeffersonianum in Ontario [Jefferson Salmander Recovery Team, 2010: 7]

Adding to the specificity of the species' breeding grounds and habitat, the Jefferson Salamander also makes use of moist soils that are prevalent in deciduous or mixed woodlands. This terrestrial habitat is absolutely essential for the survival of the species as it is used during all portions of its life cycle: migration to and from breeding grounds, summer and fall movement and foraging, and overwintering. The habitat must contain moist microhabitat, such as leaf litter, fallen branches, tree stumps, rock fissures, 
and rodent burrows. It is in this locale that the Jefferson Salamander resides when it is not migrating or breeding. Migratory movements can range from distances of $300 \mathrm{~m}$ up to $1 \mathrm{~km}$ from the breeding pond to surrounding habitat. The species is fairly mobile for its size (Jefferson Salamander Recovery Team, 2010: 10).

\subsubsection{Current Status and Causes of Decline}

The distribution of the Jefferson Salamander is not entirely known. The most recent data suggest that it exists within a total of 13 localities in three main areas of southern Ontario. As of October 2008, distribution of the species is restricted to 328 breeding ponds, representing 27 populations (Jefferson Salamander Recovery Team, 2010: 6). However, population size is unknown. Such population estimates are difficult to obtain due to the secretive nature of the species and the presence of triploid females of the A. laterale-jeffersonianum complex that carry three copies of each chromosome: two copies from the Jefferson Salamander species and one copy from the Blue-spotted Salamander species.

Furthermore, it is very likely that the species is in a state of continual decline, especially considering its limited habitat located within the Greater Toronto Area and the surrounding Greenbelt, the most densely populated area of Ontario. COSEWIC and COSSARO have both designated the species as being "threatened". Historically, prior to the clearing of forests for agriculture, the Jefferson Salamander was most likely more widespread throughout southwestern and south-central Ontario (Jefferson Salamander Recovery Team, 2010: 6).

Habitat loss is considered to be the greatest threat to the species. The Jefferson Salamander inhabits deciduous forests that contain non-permanent ephemeral bodies of water, which it uses for breeding. Examples include limestone sinkhole ponds and kettle ponds fed by spring runoff, groundwater, or natural springs. Presently, suitable habitat is available only on fragmented deciduous woodlots of agricultural land (SARA Public Registry, 2010). Anthropogenic activities linked to urbanization, aggregate extraction, and resource development, are the greatest threat to the species in southern Ontario. The development of roads, linked to urbanization, can establish barriers to dispersal and migration, and result in habitat fragmentation. Individuals have been killed by vehicles 
while attempting to migrate across roads, and curbs and catch basins may pose as barriers and traps. Climate change and anthropogenic development is linked to the drying and filling of vernal pools, and may also contribute to the modification of the timing of the breeding season. Habitat destruction also takes a toll on the breeding success of the species. Particularly, considering the pond fidelity of the species, if breeding ponds are destroyed from year to year, once they migrate to their previously existing breeding grounds, breeding individuals will not have the ability to successfully reproduce. It will prove laborious to find new breeding grounds, or they may be non-existent (Jefferson Salamander Recovery Team, 2010: 11-12).

\subsubsection{Existing Legal Measures for the Protection of the Jefferson Salamander}

The Jefferson Salamander is protected at the federal level under the federal Species at Risk Act. It is also protected at the provincial level by the Ontario Fish and Wildlife Conservation Act, 1997 which prohibits the killing, harassment, or capture of the species. The species also receives protection under the Ontario Endangered Species Act, 2007 (SARA Public Registry, 2010). As required under c. 6, s. 9 of the Ontario Endangered Species Act, 2007, a recovery strategy has recently been compiled which explicitly outlines strategies for the protection and recovery of the species.

A regulation to protect the habitat of the Jefferson Salamander under the Endangered Species Act, 2007 came into force on February 18, 2010. The salamander is one of nine species that is the subject of a specific habitat regulation as outlined under $\mathrm{c}$. 6, s. 56 of the $E S A, 2007$. A "habitat regulation is a legal instrument that prescribes an area that will be protected as the habitat of the species" (Jefferson Salamander Recovery Team, 2010: 21). Since the species is typically found along the Niagara Escarpment, the habitat regulation is limited to the City of Hamilton, the counties of Brant, Dufferin, Elgin, Grey, Haldimand, Norfolk and Wellington and the regional municipalities of Halton, Niagara, Peel, Waterloo and York.

The regulated habitat for the Jefferson Salamander protects wetlands, pools and ponds that are being used by individuals or that were used in the past 5 years. The area within $300 \mathrm{~m}$ of these wetlands is also protected as habitat. In addition, suitable breeding areas to which Jefferson Salamanders may disperse, up to $1 \mathrm{~km}$ away from protected 
breeding ponds, are protected (MNR, 2010b). These limits have been set in place because it has been discovered that the species is very mobile for its size, as it can migrate from $300 \mathrm{~m}$ up to $1 \mathrm{~km}$ from breeding ponds to habitat (Jefferson Salamander Recovery Team, 2010: 10).

\subsubsection{Implementation Gaps}

Implementation gaps exist for data and for action, particularly when compared to the Eastern Loggerhead Shrike. There has previously been little information available with regards to recovery efforts and there is currently no breeding program for the Jefferson Salamander. Only recently, with the advent of the Ontario Endangered Species Act, 2007 has a recovery strategy been set in place. Perhaps this could be attributed to the more recent media attention given to the plight of the species.

The public perception of species at risk is greatly influenced by the availability of information that is mainstream and accessible. In recent years, the Jefferson Salamander has been featured in a number of media stories and newspaper articles (for instance, Kyonka, 2008), giving the species a significantly higher level of media exposure than the Eastern Loggerhead Shrike. Both species are ecologically important, and each play different roles in the ecosystem.

As noted above, the Jefferson Salamander is particularly important for the identification of adversely impacted ecosystems. It would be wise to protect these organisms, because they are as helpful as they are important within the food web. Dr. Jim Bogart, chair of the Jefferson Salamander Recovery Team stresses the importance of protecting the species, and notes that "the goal is to know exactly where these salamanders are living [...] then we can justify legislation to protect these areas" (Edmonson, 2003). In accordance with a habitat regulation under the ESA, 2007 specifically outlined for the Jefferson Salamander, a strong recovery strategy has been composed for the species, having recently been completed in March of this year. ENGOs such as the Save Ontario Species Coalition (S.O.S) are applauding the strategy as setting a precedent by following science-based ecological recommendations based on the species' life history traits to enable the protection of breeding, migrating, and overwintering grounds (Richmond Hill Naturalists, 2009). 
Indeed, the greatest obstacle for the protection of the salamander is the species' own characteristic traits and preference for obscurity. Although the ecology of the species is very well known in comparison to other species at risk in Ontario due to extensive study based on its unique genetic traits, widespread habitat protection is crucial to its protection. Since the species is obscure and populations are difficult to delineate, the selection of appropriate habitat slated for protection in accordance with the recovery strategy is extremely important, as well as the impetus for applying a precautionary approach to habitat protection. Obstacles to the implementation of the habitat regulation also arise in the physical limitations that impede adequate monitoring and enforcement. It may also prove to be a trying task in terms of the allocation of funds and personnel to specifically enforce the implementation of the habitat regulation that was recently brought into force. For instance, habitat regulations do not restrict all land uses. Instead, the regulation is in place to identify the areas where the MNR has jurisdiction to regulate any harmful activities. Any activities deemed not to harm habitat are allowed to continue, while those deemed to harm habitat are only allowed to proceed by permit (Richmond Hill Naturalists, 2009). However, all such activities are difficult to monitor as it is impossible for personnel to be present at all locales for a continued period of time, particularly during an economic recession, where governments usually opt to cut funding and personnel.

In addition, the S.O.S. coalition continues to voice its concern for the species. There is a hope that the regulation will allow the Jefferson Salamander to survive amidst constant development pressures within its habitat, and a great stress is placed on the importance of applying as precautionary an approach as possible. Nonetheless, it is too early to determine the impacts of the regulation (Richmond Hill Naturalists, 2009).

Other gaps in implementation may arise since most research on the Jefferson Salamander has primarily focused on the biology and genetics of the species, and research that is specifically focused on natural and anthropogenic threats to the species is very scarce. Hence, it is difficult to quantify and evaluate all elements that are responsible for the decline of the species. Lack of information on all possible threats to the species will pose barriers in mitigation of species declines (Jefferson Salamander Recovery Team, 2010: 13). 
The case of the Jefferson Salamander brings to light the potential benefits of legal protection that is based on sound scientific knowledge and on ecological importance and sensitivity. Furthermore, it illustrates the importance of obtaining this knowledge for obscure species, by performing scientific research so as to better understand their preference for certain habitats as well as comprehending life history strategies. Lack of scientific knowledge and foresight could lead to difficulties in protecting obscure and understudied species. Ecology of species must be well understood in order to create and subsequently implement recovery strategies.

With specific reference to the Jefferson Salamander recovery strategy, although recovery objectives and goals are explicitly outlined and prioritized by level of importance and urgency, an outline of the time required to implement the objectives and fulfill the goals is lacking (Jefferson Salamander Recovery Team, 2010: 18-20). Hence, a significant barrier to implementation is the lack of specific timelines for the recovery of the species.

Dedicated legislation and policy tools within multiple jurisdictions are in place to protect Ontario species at both the federal and provincial levels. Yet, both Jefferson Salamander and Eastern Loggerhead Shrike populations remain in dire shape. It is important to consider the plight of species at risk in a province which does not have designated endangered species legislation, such as British Columbia. The legal and policy tools available for species at risk in $\mathrm{BC}$ will now be examined, with two $\mathrm{BC}$ case studies to follow. 


\section{CHAPTER 6.0 PROVINCIAL LEGAL MEASURES FOR SPECIES AT RISK IN BRITISH COLUMBIA}

Most wildlife species and species at risk reside on provincial land. Therefore the provinces wield the largest responsibility for the protection of species at risk. Ninety percent of the province of British Columbia falls under provincial jurisdiction (Greenbaum and Wellington, 2010: 480). Thus, the biodiversity crisis is best addressed at the provincial level. With this knowledge, all available legal tools for the protection of species at risk in the province of British Columbia at the provincial level of government are evaluated in this chapter. This has been done in the previous chapter for the province of Ontario, and the efficacy of available tools in both provinces is compared in Chapter 8, in addition to recommendations for future reforms.

British Columbia is one of the most diverse provinces in all of Canada, both geographically and biologically. The BC Ministry of Environment's website substantiates the province's crucial contributions to Canada's overall biodiversity: B.C. is home to more than 1138 species of vertebrates, including 488 bird species, 142 mammal species, 18 reptile species, 22 amphibian species, 83 freshwater fish species and 368 saltwater fish species. ${ }^{26}$ The highest number of native species in all of Canada resides in British Columbia. Three quarters of Canada's birds and mammals inhabit the province, with 24 species endemic to the province. The province houses 76 percent of the country's bird species, 70 percent of its freshwater fish, and 60 percent of its evergreen trees (Pojar, 2010: 9). Alongside Ontario, British Columbia has the highest number of at risk species in the nation, with $43 \%$ of its species at risk of disappearing, $86 \%$ of which are in danger due to habitat loss and degradation (Austin et al., 2008).

The BC government states that 152 wildlife species and subspecies are considered candidates for endangered, threatened, or vulnerable status. Scientists have indicated that over 1300 species and their habitats are at risk in the province (Western Canada Wilderness Committee, 2008). It is remarkable that of these numbers, only three species are legally designated by the provincial government as endangered in $\mathrm{BC}$; these are the Burrowing Owl (Speotyto cunicularia), the American White Pelican (Pelecanus

\footnotetext{
${ }^{26}$ British Columbia Ministry of the Environment website, "Wildlife in BC": < http://www.env.gov.bc.ca/fw/wildlife/>
} 
erythrorhynchos) and the Vancouver Island Marmot (Marmota vancouverensis). The Sea Otter (Enhydra lutris) has been designated a threatened species and there are other species under consideration for future listing. ${ }^{27}$

While urban and agricultural development is a key cause of species declines, much of the biodiversity loss in British Columbia is due to industrial logging. Almost all logging in Canada is done in old-growth forests by government-sanctioned clear-cut logging. Under the BC Timber Sales Program (formerly known as the BC Small Business Program), which was established in 2002 to strengthen the provincial economy, planners are employed to select cutblocks, or areas where logging will take place. All at the expense of the government, road builders construct logging routes and the rights to $\log$ the areas are auctioned off to the highest bidder. The contractor logs the trees, specifically using the clearcut method where entire expanses of forest are obliterated. Once the trees are logged, they are transported to a mill. The lumber is often sold under another company's logo. Many consumers are uninformed about the BC Timber Sales Program and how it functions. In this manner, and via provincial government sanction, every day in British Columbia, pristine old growth coastal temperate rainforests, among the worlds' rarest ecotypes, are being logged (WCWC, 2005).

In $\mathrm{BC}$, of species that rely on forests for survival, $31 \%$ of freshwater fish are at risk, as are $25 \%$ of amphibians, $5 \%$ of mammals, and $8 \%$ of birds. Just over one quarter (27\%) of BC's endangered species rely on the province's forests for existence (Canadian Council of Forest Ministers, 2005).

There are only two provincial statutes that govern wildlife and logging practices in British Columbia: the Wildlife Act, 1996 and the Forest Practices Code of British Columbia Act, 1996. Neither of these was designed to specifically address species at risk or the loss of biodiversity. They do not include endangered species as a central focus. These statutes only contain brief provisions that mention endangered and threatened species. As such, British Columbia is one of several provinces that have no stand-alone provincial endangered species legislation.

\footnotetext{
${ }^{27}$ British Columbia Ministry of the Environment website, "Wildlife in BC": < http://www.env.gov.bc.ca/fw/wildlife/>
} 
The Wildlife Act, 1996 contains provisions that are solely discretionary based on a decision by the Lieutenant Governor in Council (i.e. Cabinet) (see Table 6.1 for details). However, the Forest Practices Code of British Columbia Act, 1996 has been mostly repealed. In essence, the statute has been supplanted by the Forest and Range Practices Act, 2002. This more recent Act contains a regulation that was enacted specifically for the purposes of addressing species at risk. The Government Actions Regulation, also known as the British Columbia Regulation 17/04, which was enacted under the Forest and Range Practices Act, 2002, contains discretionary clauses under Section 13 that essentially leave the listing and designation of COSEWIC listed species at risk to the same minister that is responsible for the Wildlife Act, 1996. Protectionist measures are not clearly outlined or defined. Once the Minister decides to assign protection to COSEWIC listed species, discretionary protection by way of a management planning process would ensue. However, there are no mandatory recovery plans or critical habitat protection under the regulation.

There is also a category of species at risk in British Columbia that has been established by order under section 11(1) of the Government Actions Regulation (BC Reg. 17/04) of the Forest and Range Practices Act, 2002. According to the BC Ministry of Environment website, "this category of species at risk represents those species that may be affected by forest or range management on Crown land and are listed by the Committee on the Status of Endangered Wildlife in Canada (COSEWIC). ${ }^{, 28}$ There are presently 85 species at risk by order under this category. ${ }^{29}$ These listed species are the core of the Identified Wildlife Management Strategy (IWMS), as directed under provisions of the Forest and Range Practices Act, 2002. According to the BC Ministry of Environment website, "the IWMS provides direction, policy, procedures and guidelines for managing Identified Wildlife. The goals of the Strategy are to minimize the effects of forest and range practices on Identified Wildlife situated on Crown land and to maintain their limiting habitats throughout their current ranges and, where appropriate,

\footnotetext{
${ }^{28}$ BC Ministry of Environment. Environmental Stewardship Division. Ecosystems Branch. Categories of Species: http://www.env.gov.bc.ca/wld/frpa/species.html

${ }^{29}$ Categories of species at risk by order. Refer to: http://www.env.gov.bc.ca/wld/documents/identified/approved sar order list.pdf; http://www.env.gov.bc.ca/wld/documents/identified/NSWO-CatergorySAR 30.05.05.pdf; http://www.env.gov.bc.ca/wld/documents/identified/2006Jun CatSAR.pdf
} 
their historic ranges" ${ }^{30}$. However, the goals only include management initiatives, and do not include recovery strategies, nor do they mandate habitat protection. The goals only discuss the maintenance of their 'limiting habitats'.

In correspondence with federal government actions, the only instance of recovery planning in $\mathrm{BC}$ occurs in accordance with the Canada-British Columbia Agreement on Species at Risk ${ }^{31}$, under the Accord for the Protection of Species at Risk in Canada. Although it is mentioned, recovery planning is by no means a mandatory action, as explicitly illustrated under Section 2.10 of the accord. This section states that "cooperative, voluntary measures are the first approach to securing the protection and recovery of species at risk". Voluntary measures are never intended to be mandatory.

The importance of valid factual information is also stressed in Section 8.1 of the accord, where it is stated that "the parties will provide their best available information to [COSEWIC]." Nonetheless, the validity of the information is left to discretion, as there is no mention of a method of substantiating the information. With respect to recovery planning, implementation of recovery plans is not explicitly mandated. This is noted in Section 11.1 of the accord, where the preparation of a two step recovery process is discussed very briefly. The two step process includes the creation of a technically and biologically feasible recovery strategy and that of an action plan which outlines the socioeconomic costs of recovery and implementation. A specific mandate and instructions for implementation of these policy tools is not mentioned. Hence, as discussed in the entirety of Section 11.0, a recovery process for listed species at risk in British Columbia is minimal, vague, and highly discretionary.

In essence, British Columbia is taking the opposite approach to Ontario, a province that has stand-alone species at risk legislation. $\mathrm{BC}$ has opted to address species at risk issues within statutes that are not specifically dedicated to the issue, or within vague regulations that have been established specifically to attempt to address the issue. However, the entire process is completely discretionary.

\footnotetext{
${ }^{30}$ BC Ministry of Environment. IWMS: http://www.env.gov.bc.ca/wld/frpa/iwms/

${ }^{31}$ Canada-British Columbia Agreement on Species at Risk: http://www.llbc.leg.bc.ca/public/pubdocs/bcdocs/419585/aa canadabritish columbia agreement on species at risk 0805 e.pdf
} 
British Columbia is in urgent need of legislation that is tailored to the requirements of species at risk. In order to better address the problem of biodiversity loss within the province, species that reside on provincial Crown lands and private lands must be protected by legislation within the provincial jurisdiction, as the federal Act does not apply within these areas. As a result, "non-federal" species at risk of extinction are not granted any specific protection tailored to address their conservation.

The province is required to prepare recovery strategies in order to fulfill its commitments to recover species at risk under the Accord for the Protection of Species at Risk in Canada, and the Canada-British Columbia Agreement on Species at Risk. Both the accord and agreement emphasize the importance of inter-jurisdictional collaboration, among the provincial jurisdictions and at the federal and provincial levels.

Despite its commitment to the accord and the agreement, the province of British Columbia has not created dedicated endangered species legislation to date. It has the advantage of having many lessons to draw from various examples of provincial endangered species statutes that have already been in existence for a number of years. The most notable example is the newly revised Ontario Endangered Species Act, 2007, which was discussed in Chapter 4. In fact, a coalition of environmental groups in British Columbia comprised of the David Suzuki Foundation, EcoJustice, ForestEthics, Sierra Club BC and Western Canada Wilderness Committee have started a campaign entitled "The Last Place on Earth Without an Endangered Species Law". The title is intended as a play on words for the BC government's tourism advertisement campaign entitled "The Best Place on Earth". 32

The Liberal Party was returned to power in the spring of 2009, under the leadership of Gordon Campbell. The BC government throne speech in August 2009 inaugurated the formation of a Species at Risk Task Force (Ecojustice, 2009b). ENGOs are pushing the direction of the Task Force to follow in the footsteps of the Ontario model for endangered species legislation; one which includes an expert panel, science-based listing, and mandatory habitat protection to enable species recovery and survival (ibid.).

\footnotetext{
${ }^{32}$ Website for "The Last Place on Earth Without An Endangered Species Law". Available < http://www.protectbiodiversity.ca/homepage/>
} 
The province of Ontario was selected for comparison in this study so as to outline the benefits of specific species at risk protection under two jurisdictions, at the provincial and federal levels, in contrast to dedicated species at risk protection solely at the federal level, as is the case in British Columbia to date. Although it does contain many aspects that will require some improvement, the Ontario ESA, 2007 currently maintains its reputation as the strongest provincial endangered species legislation in the country.

The two case studies of endangered species in British Columbia that follow in Chapter 7 are intended to accumulate evidence of the inadequacies of the existing legal measures of species at risk in the province, as well as at the level of federal jurisdiction. The importance of the validity and timeliness of scientific, biological, and ecological information for the development of protectionist policies is also highlighted. Recommendations for further reforms are found in Chapter 8.

Table 6.1: Selected Provisions of Environmental Laws in British Columbia Relevant for Species Protection

\begin{tabular}{|l|l|}
\hline \multicolumn{1}{|c|}{ Law } & \multicolumn{1}{|c|}{ Provisions } \\
\hline Wildlife Act, R.S.B.C. 1996, c. 488 & $\begin{array}{l}\mathbf{1}(\mathbf{1}) \text { Definitions } \\
\text { "endangered species" means a species of animal } \\
\text { that is designated as an endangered species, but } \\
\text { does not include a controlled alien species }\end{array}$ \\
\hline Wildlife Act, R.S.B.C. 1996, c. 488 & $\begin{array}{l}\mathbf{1}(\mathbf{1}) \text { Definitions } \\
\text { "critical wildlife area" means land in a wildlife } \\
\text { management area that is designated as a critical } \\
\text { wildlife area }\end{array}$ \\
\hline Wildlife Act, R.S.B.C. 1996, c. 488 & $\begin{array}{l}\text { Critical wildlife areas and wildlife sanctuaries } \\
\mathbf{5} \text { (1) If the minister requires land for habitat for a } \\
\text { species of wildlife designated as an endangered } \\
\text { species or threatened species, the minister may, by } \\
\text { regulation, designate land in a wildlife management } \\
\text { area as a critical wildlife area. } \\
\text { (2) The minister may, by regulation, designate land } \\
\text { in a wildlife management area as a wildlife } \\
\text { sanctuary. }\end{array}$ \\
\hline
\end{tabular}




\begin{tabular}{|c|c|}
\hline Wildlife Act, R.S.B.C. 1996, c. 488 & $\begin{array}{l}\text { Endangered and Threatened Species } \\
\mathbf{6} \text { (1) If the Lieutenant Governor in Council } \\
\text { considers that a species of wildlife is threatened } \\
\text { with imminent extinction throughout all or a } \\
\text { significant portion of its range in British Columbia } \\
\text { because of the action of humans, the Lieutenant } \\
\text { Governor in Council may, by regulation, designate } \\
\text { the species as an endangered species. } \\
\text { (2) If the Lieutenant Governor in Council considers } \\
\text { that a species of wildlife is likely to become } \\
\text { endangered in British Columbia if the factors } \\
\text { affecting its vulnerability are not reversed, the } \\
\text { Lieutenant Governor in Council may, by } \\
\text { regulation, designate the species as a threatened } \\
\text { species. }\end{array}$ \\
\hline $\begin{array}{l}\text { Forest and Range Practices Act, } \\
\text { S.B.C. } 2002, \text { c. } 69\end{array}$ & $\begin{array}{l}\text { 1 (1) Definitions } \\
\text { "wildlife" means } \\
\text { (a) vertebrates that are mammals, birds, reptiles or } \\
\text { amphibians and are prescribed as wildlife under the } \\
\text { Wildlife Act, } \\
\text { (b) fish from or in the non-tidal waters of British } \\
\text { Columbia, including } \\
\text { (i) vertebrates of the order Petromyzoniformes } \\
\text { (lampreys) or class Osteichthyes (bony fishes), or } \\
\text { (ii) invertebrates of the subphylum Crustacea } \\
\text { (crustaceans) or phylum Mollusca (mollusks), and } \\
\text { (c) invertebrates or plants listed by the minister } \\
\text { responsible for the administration of the Wildlife } \\
\text { Act as endangered, threatened or vulnerable } \\
\text { species, and includes the eggs and juvenile stages } \\
\text { of these vertebrates, invertebrates and plants. }\end{array}$ \\
\hline
\end{tabular}


Government Actions Regulation, B.C. Reg. 17/ 04, enacted under the Forest and Range Practices Act

\section{Species at risk, regionally important wildlife and ungulate species}

13 (1) The minister responsible for the Wildlife Act by order may establish one or more categories identifying species of wildlife as species at risk if satisfied that the species are endangered, threatened or vulnerable.

(2) The minister responsible for the Wildlife Act by order may establish one or more categories identifying species of wildlife as regionally important wildlife if satisfied that the species

(a) are important to a region of British Columbia, (b) rely on habitat that requires special management that is not otherwise provided for in this regulation or another enactment, and

(c) may be adversely impacted by forest practices or range practices.

(3) The minister responsible for the Wildlife Act by order may establish one or more categories identifying ungulate species for which an ungulate winter range is required if satisfied that the range is necessary for the winter survival of the identified species. 


\section{CHAPTER 7.0 BRITISH COLUMBIA SPECIES AT RISK: TWO CASE STUDIES}

The case study approach is intended to highlight inadequacies in the existing provincial and federal legal measures for the protection of species at risk, and shine a light on possible areas of improvement to aid in the revision of existing policies and the creation of new ones. Thus far, the focus has been on species at risk policy in Ontario and the highlighting of inadequacies and implementation gaps in the existing legal measures via two different case studies. Ontario is a province that reaps the benefits of the existence of combined dedicated species at risk legislation at both provincial and federal levels. As discussed in Chapter 6, it is evident that British Columbia, on the other hand, lacks dedicated species at risk legislation and relies on other legal measures alongside existing federal legislation to address species at risk issues. Two British Columbia case studies are evaluated to analyze the effects of existing legal tools on two different species at risk: the Northern Spotted Owl and the Vancouver Island Marmot. Both species are listed as endangered on the $S A R A$ public registry. Like both Ontario case studies, these two species are also important indicators of ecological health where their alarming decline is a signpost for environmental and ecosystem deterioration. The accumulation of evidence in the two cases is intended to determine if existing measures are sufficient for protecting species at risk in $\mathrm{BC}$, and to conclude with recommendations for change and reform.

\subsection{The Northern Spotted Owl}

\subsubsection{Canada's Most Endangered Bird and Indicator of West Coast Forest Health}

The Northern Spotted Owl (Strix occidentalis caurina) is Canada's most endangered bird, and British Columbia's most endangered species. It is also an indicator species that represents the health of an extremely important Canadian ecosystem: Canada's last remaining old-growth forests. These forests contain a vast amount of biodiversity. The loss of the Spotted Owl presents a warning sign that the extensive logging which is currently taking place will disrupt natural processes that millennia of forest growth have facilitated: food web development; prevention of soil erosion, floods, and landslides; nutrient enrichment of soil; and reducing the greenhouse effect, to name but a few. The Spotted Owl is also an indicator and possible future predictor of the fate 
of the 71 vertebrate species that occupy the same habitat as the bird (Stone and Reid, 1997: 80).

\subsubsection{Ecological Traits and Habitat Requirements}

The Northern Spotted Owl ${ }^{33}$ (Strix occidentalis caurina) is one of Canada's largest owl species. It is endemic to a very small pocket of coastal Pacific forest in British Columbia. Like all other owl species, the Spotted Owl has adapted a capability to hunt for prey at night. It possesses the characteristic traits of light, fluffy plumage, which facilitates soundless flight; sharp talons and a hooked bill to allow for the catching and tearing apart of prey; eyes that are adapted for night vision; and very sharp hearing. These characteristics allow the owl to hunt unsuspectingly during the night. Approximately 95 percent of the species' diet is composed of small mammals such as the Deer Mouse, woodrats, voles, moles, and hares. The remainder of its diet is composed of birds, large insects, and reptiles (BC MOE, 1998).

Studies of radio-tagged Northern Spotted Owls have produced evidence that the owl prefers to forage in old-growth stands of forest. Hence, its preferred foraging and nesting habitat is very limited to old-growth forest (BC MOE, 1998). The owl requires more than 100 acres (or 40.5 hectares) of old growth low elevation coniferous forests to breed, forage, and raise young. It gives preference to trees over 200 years of age (ForestEthics, 2002; Payton, 2006). The owl does not nest above 1,200 metres, and roughly 70 percent of Spotted Owl habitat has already been logged.

\subsubsection{Current Status and Causes of Decline}

The logging of old-growth forests in British Columbia is negatively affecting many species at risk. Logging is especially damaging for the remaining population of Northern Spotted Owls. The species was declared to be endangered by COSEWIC in 1986. The bird has been documented to be declining by $8-10 \%$ annually, or by about $84 \%$ over the last decade (David Suzuki Foundation, 2005). This is an appalling rate,

\footnotetext{
${ }^{33}$ Information on the Northern Spotted Owl is available under the $S A R A$ s public registry: Species at Risk Act (SARA), Registry. May 2006. Spotted Owl.

$<\underline{\text { http://www.speciesatrisk.gc.ca/search/speciesDetails e.cfm?SpeciesID }=33}>$
} 
considering that it is thought that about 150 years ago, over 1,000 spotted owls lived in the old-growth forests of southwest British Columbia. Presently, less than twenty birds remain. In 2005, only four breeding pairs could be tracked in the wild. Only six owls currently exist in the wild, while ten are being held in captivity for the purposes of captive breeding, in hopes of eventually contributing to a population recovery (WCWC, 2010). Two owls are slated for removal into captivity, leaving only two independently breeding pairs in the wild (ibid.). The biggest threat to the remaining birds, or to the future existence of released captive-bred birds, is the fragmentation of their precious habitat due to commercial logging, or the disappearance of their habitat altogether.

\subsubsection{Existing Legal Measures for the Protection of the Spotted Owl}

The Northern Spotted Owl is only protected under the Species at Risk Act at the federal level. As the owl is not a migratory bird, it does not have the benefit of being protected by the Migratory Bird Convention Act, 1994. Although British Columbia does not have any provincial statutes that dedicate specific protection to species at risk, the owl is somewhat protected under the Forest Practices Code of British Columbia Act, 1996, Forest and Range Practices Act, 2002, and the Wildlife Act, 1996. Of these statutes, the Wildlife Act, 1996 includes the most protective measures for the owl. The Act encompasses provisions that prohibit the harming of owls and their nests (Wildlife Act, 1996 c.48 s.34). ${ }^{34}$ The other Acts refer to the overall health of forests and do not mention protection of owl species to a specific degree.

The Northern Spotted Owl was recognized to be endangered in Canada by COSEWIC in 1986. In 1990, a Canadian Spotted Owl Recovery Team (SORT) was established, which was comprised of professional biologists and professional foresters. SORT provided the British Columbia government with a report on management options in December 1994. In 1997, the British Columbia government sought to attempt to prevent the extirpation of the owl by establishing the Spotted Owl Management Plan (SOMP). The goal of the Plan was stated in the following terms: "to achieve a reasonable level of probability that owl populations will stabilize, and possibly improve,

\footnotetext{
${ }^{34}$ BC Wildlife Act, 1996. Available: http://www.bclaws.ca/Recon/document/freeside/--o20W\%20-/Wildlife\%20Act\%20\%20RSBC\%201996\%20\%20c.\%20488/00 96488 01.xml\#section34
} 
over the longer term without significant short-term impacts on timber supply and forestry employment" ${ }^{\prime 35}$. In approving the Spotted Owl Management Plan, the British Columbia Cabinet accepted a " 60 percent probability that spotted owl populations will stabilize and possibly improve over the long term, ${ }^{36}$. It is notable that the BC government has accepted quite a low level of probability of population stability.

The SOMP was created with the goal of balancing environmental and socioeconomic objectives while encouraging innovative forest management practices. The SOMP covers 21 areas totaling approximately 363,000 hectares in the Chiliwack and Squamish forest districts, Northeast of Vancouver. The complete area includes 159,000 hectares of protected areas and approximately 204,000 hectares of Crown forested land. Areas called Special Resource Management Zones (SRMZs) were created in order to "integrate" spotted owl management and forest management objectives. Within each SRMZ, 67 percent was to be held as suitable owl habitat over the longer term while 33 percent was made available for clearcut harvesting. There are 18 SRMZs, each located about $15 \mathrm{~km}$ apart on average ${ }^{37}$ (Blackburn and Godwin, 2004: 9-10).

A drawback to the SOMP is that it permits clear-cut logging in one third of forests situated within Spotted Owl critical habitat. However, it encourages other methods of harvesting that "might" have less impact on owls and their habitat. Nonetheless, clearcut logging is the most widely used method of logging in this area (Payton, 2006). In the SOMP, the BC government claims that it attempts to "balance Spotted Owl requirements with social and economic concerns." The Plan turned out to be a "self-described compromise between economics and conservation which may or may not save the Spotted Owl" (ibid.). Hence, ecologists and environmentalists have criticized the SOMP for not being adequately precautionary, mainly because it still allows for too much logging within Spotted Owl critical habitat.

\footnotetext{
${ }^{35}$ Spotted Owl Management Plan, quoted in Western Canada Wilderness Committee v. British Columbia (Ministry of Forests), 1 Admin. L.R. (4th) 167; (2003), 15 B.C.L.R. (4th) 229; 2003 BCCA 403, 2003), at para. 24.

${ }^{36}$ Spotted Owl Management Plan, page 10, quoted in ibid., at para. 24 and para. 66. < http://www.canlii.org/en/bc/bcca/doc/2003/2003bcca403/2003bcca403.htmll

${ }^{37}$ Spotted Owl Management Plan, quoted in ibid., at para. 65.
} 
The SOMP has also been criticized by scientists as described in the report entitled Population Assessment of the Northern Spotted Owl in British Columbia 1992-2001. ${ }^{38}$ The report makes use of existing science as a critique for current legal tools. Essentially, scientists predicted the demise of the species based on the SOMP. The study consisted of the monitoring of Spotted Owls within 40 survey areas located inside and outside SRMZs between 1992 and 2001. Actual population declines documented between 1992 and 2001 were compared with expected declines based on the implementation of the SOMP. A simulation model was used to predict expected population numbers resulting from the implementation of the SOMP, and based on SOMP goals. Researchers discovered that the Spotted Owl population declined by 49\% within the survey areas between 1992 and 2001. This rate amounted to an average annual rate of decline of $7.2 \%$. This rate of decline is 4.8 times faster than the rate predicted by the model. Despite protective measures for suitable owl habitat in the survey areas and SMRZs from 1997 to 2001, populations were declining at a significantly greater rate than that expected by following and implementing the SOMP. Further declines were predicted over the next few decades. Based on the results of the study, the SOMP was deemed to be inadequate at achieving the intended goals of stabilizing the owl population. Scientists urgently recommended that additional management actions take place in order to prevent the extirpation of the Spotted Owl from the wild. Thus, the SOMP has been criticized by scientists and environmentalists for not being adequately precautionary, and for allowing too much logging.

The heated debate between the BC government and environmentalists has resulted in litigation for judicial review concerning the Spotted Owl. ENGOs sought to make use of this legal tool to attempt to mandate the protection of species at risk. More recent examples of judicial review were mentioned in Chapter 3, in the cases concerning the Greater Sage-Grouse and the Nooksack Dace.

\footnotetext{
${ }^{38}$ The report is authored by Ian Blackburn, Alton Harestad, James Smith, Stephen Goodwin, Reid Hentze, and Carla Lenihan. It is available at: $<$ http://www.env.gov.bc.ca/wld/documents/spowtrend 1992 2001.pdf $>$
} 


\subsubsection{The Plight of the Spotted Owl in the Courts: \\ Western Canada Wilderness Committee v. BC (Ministry of Forests)}

The plight of the Spotted Owl has prompted litigation, but the outcome of the case did not improve the species' chances of survival. The context in which the case arose involves complex matters of environmental management and also concerns logging approvals. Logging can take place in $\mathrm{BC}$ only in accordance with a Forest Development Plan approved by the forest District Manager ${ }^{39}$. The content of a Forest Development Plan (FDP) is stipulated in the Forest Practices Code of British Columbia Act and the accompanying regulation entitled the Operational Planning Regulation ${ }^{40}$. The Forest Practices Code of British Columbia Act, section 41, provides that a District Manager must approve a Forest Development Plan (FDP) if it was prepared in accordance with the laws and regulations and the DM is satisfied that forest resources will be adequately managed and conserved. The definition of "forest resources" found in the Act includes wildlife, and thus includes endangered species.

Cattermole Timber applied to log four cutblocks of forest which had been classified as "type A old growth owl habitat" in the Chilliwack Forest District, the area within which the "forest resource" of the Spotted Owl resides. Logging was initially approved at all four sites. The Western Canada Wilderness Committee applied for judicial review of that decision. A judge's order directed a different District Manager, Cindy Stern, to revisit the information and reconsider the decision to grant approval for the proposed logging. District Manager Stern decided that for three of the requested cutblocks, the FDP did not adequately manage and conserve the spotted owl, whereas for one of them (Cutblock 37-1) the FDP was adequate. The one cutblock approved for logging was the smallest of the four, covering 88 hectares and calling for removal of 33 percent of the timber. Cattermole Timber was to use new techniques of patch, strip and selective cutting on the site. DM Stern acknowledged that the FDP for that site would pose some risk to the owls, but in her judgment the risk was small, and moreover, it was

\footnotetext{
${ }^{39}$ The Forest Act, divides the province of British Columbia into forest districts (FD), each of which has a District Manager (DM) in accordance with the Ministry of Forests Act. The latter law has been renamed the Ministry of Forests and Range Acts through the Forests and Range Statutes Amendment Act, 2006, s. 27. ${ }^{40}$ Forest Practices Code of British Columbia Act; Operational Planning Regulation, B.C. Reg. 107/ 98, enacted under the Forest Practices Code of British Columbia Act.
} 
outweighed by the benefit of obtaining comparative information for monitoring (i.e., information comparing the owls' use of selectively logged versus unlogged forests) ${ }^{41}$.

The WCWC applied for judicial review of DM Stern's decision, on the grounds that the DM had "erred" in her interpretation of the relevant section of the law, and that she had failed to apply the precautionary principle. The claim was inherent in the following terms: "because of the scientific uncertainty surrounding Cattermole's proposed method of harvesting and the endangered status of the spotted owl, the precautionary principle would operate to foreclose all harvesting in the cutblocks under consideration" $" 2$.

The British Columbia Court of Appeal found that the government had intended there to be a considerable amount of reverence to forestry officials on factual matters, given their specific expertise. The key issue at stake was the application of the law to the facts. Given the phrasing of the relevant provision of the Act, to ensure "adequate" management and conservation, and the factual information considered, the decision made by the District Manager had a rational basis. The Court held that although the District Manager may not have given full effect to the precautionary principle, her decision "reflects a degree of caution akin to that reflected in the precautionary principle". The NGOs appeal to the court to have the logging approval overturned was unsuccessful ${ }^{43}$.

The Spotted Owl has been listed under SARA since 2003. The BC government continued to approve logging inside the habitat of the Spotted Owl, as a result of its Timber Sales Program. The program is described in section 7.1.6 below. In 2004, a coalition of five ENGOs including the Sierra Legal Defence Fund (now known as Ecojustice), the Western Canada Wilderness Committee, ForestEthics, the David Suzuki Foundation, and the Sierra Club Canada, submitted a petition to ask then Environment Minister David Anderson to impel an emergency order under the safety net provisions of the federal Species at Risk Act to protect the remaining owls. The request failed as successive federal Environment Ministers were not responsive to invoking the safety net provisions of SARA (Page, 2007; Payton, 2006; Plotkin, 2007). The provincial

\footnotetext{
${ }^{41}$ Western Canada Wilderness Committee v. British Columbia (Ministry of Forests), 1 Admin. L.R. (4th) 167; (2003), 15 B.C.L.R. (4th) 229; 2003 BCCA 403, para. 31

${ }^{42}$ Ibid., para. 76

${ }^{43}$ Ibid., paras. $79-80$
} 
government has not yet reversed its decision to allow logging in Spotted Owl critical habitat. In fact, provincial Environment Minister Barry Penner suggested in 2005 that "some logging in old-growth forests may benefit the Spotted Owls because it opens [up] their hunting territory" ${ }^{44}$.

In December of 2005, a federal court challenge was launched by the combined forces of the Sierra Legal Defence Fund (now known as Ecojustice), representing the Western Canada Wilderness Committee, ForestEthics, the David Suzuki Foundation, and Environmental Defence ${ }^{45}$ (Page, 2007; Plotkin, 2007). The lawsuit demanded that the federal government intercede on behalf of the Spotted Owl in British Columbia. The lawsuit represented the first legal action of its kind under the Species at Risk Act.

The Western Canada Wilderness Committee reports that the lawsuit was avoided because the BC government promised "to protect Spotted Owl sites", in critical habitat areas such as Fire Mountain (WCWC, 2008b). In October 2008, Western Canada Wilderness Committee set up a protest camp where activists protested against logging which had been continuing on Fire Mountain, and organized a rally, demanding an end to old-growth logging on Vancouver Island and the Lower Mainland of BC (WCWC, 2008b). Seven Spotted Owls were counted in 2009, and only six individuals are thought to currently exist (David Suzuki Foundation, 2010). The species appears to be en route to extirpation (ibid.). Thus, the province is failing to implement its plan to protect the species by not adequately protecting "even limited habitat areas" (Plotkin, 2007).

\subsubsection{Implementation Gaps}

As of 2002, two of the province's largest logging companies, and largest loggers of Spotted Owl habitat, International Forest Products (Interfor) and Canadian Forest Products (Canfor), have voluntarily stopped logging in Spotted Owl habitat. Ironically, the provincial government has continued to be the largest logger of Spotted Owl habitat via its $\mathrm{BC}$ Timber Sales program. The program is a Crown corporation that was established in 2002 to bolster the provincial economy. It plans and logs "cut-blocks", and

\footnotetext{
${ }^{44}$ Canadian Press, "Environmentalists Go to Court to Protect BC's Spotted Owl”, December 6, 2005 $<$ http://www.wildernesscommitteevictoria.org/index.php?action=fullnews\&showcomments=1\&id=269 $>$
} 
then auctions the timber in order to institute market prices (Payton, 2006). The entity defines itself as: "An independent organization within the BC Ministry of Forests created to develop Crown timber for auction to establish market price and capture the value of the asset for the public" (Forest Practices Board, 2005). The province has actually intensified logging in Spotted Owl habitat since 2002 (Payton, 2006).

More recently, promising to better protect Spotted Owl habitat, the BC government, under approval from Environment Minister Barry Penner, has allowed logging to continue in one of the last active Spotted Owl sites in the province. The site is located on Fire Mountain in the Lillooet Valley of northern British Columbia. It is the best remaining recovery habitat for the Spotted Owl. Habitat for recovery of the species will not remain if logging is allowed to continue. Pristine habitat is being fragmented into sections by the day, and the owls will not forage and breed in non-contiguous areas of old-growth forest. Alongside clear-cutting projects, the environment minister has also approved the construction of hydro-electric projects in the Lillooet Valley, which will also prove to be damaging to the recovery habitat (Western Wilderness Committee, 2009).

In May of 2007, the BC government released plans for a captive breeding program for the Spotted Owl. Environmentalists disagree with the plan because they see it as an excuse to continue logging prized timber within the owl's habitat, while eliminating a major obstacle: the owl (Envirolinks, 2007). The government has already moved forward with its plan, which essentially signifies the extinction of the owl in the wild. Indeed, some ENGOs have been blaming the BC government, alleging that the Spotted Owl captive breeding program is presently being used as a scapegoat to keep owls as captive zoo specimens, destined to never return to the wild again, and to allow timber harvesting to continue unscathed.

Only six owls are thought to currently remain in the wild in British Columbia. The rest were captured for the captive breeding program that was established by the BC government in 2007 (Western Wilderness Committee, 2007; Nature Canada, 2009; Western Wilderness Committee, 2009; David Suzuki Foundation, 2010; WCWC, 2010).

\footnotetext{
${ }^{45}$ David Suzuki Foundation, "Environmental Groups Launch Federal Court Case in Historic Bid to Save Spotted Owl", Press Release, December 6, $2005<$

http://www.davidsuzuki.org?WOL/News Releases/web of life12060501.asp
} 
The captive breeding program continues to be highly contentious. The BC Minister of the Environment is refusing to halt clear-cut logging practices in critical Spotted Owl habitat that would be imperative for the existence and recovery of Spotted Owl populations, including those individuals that would eventually be slated for release from captivity.

Implementation gaps and legal inadequacies also occur at the federal level, as evident in the case of the Spotted Owl. Recall that the SARA applies only to federal lands, which only include post offices, national parks, airports and RCMP detachments. Most public (Crown) lands in Canada are under provincial jurisdiction. This means that only a tiny fraction of Canada is under the SARAs direct protection (Illical and Harrison, 2007: 384). In the case of the Spotted Owl, the remaining few individuals exist on private land. Hence, the species is not adequately protected under.

Correspondingly, the $\mathrm{BC}$ government has been discussing opting out of caring for numerous endangered species, including the Spotted Owl, for years. The Species at Risk Act does contain special provisions that can protect areas that are normally under provincial jurisdiction, but these apply only under special circumstances, and at the discretion of government officials. In addition, since the Spotted Owl is not classified as a migratory bird, federal jurisdiction over its protection is limited, and it does not qualify for protection under the Migratory Birds Convention Act, 1994.

The Species at Risk Act contains a federal "safety net" clause. The clause contains provisions which require the federal minister to take action if a jurisdiction is not providing adequate and effective protection. It is essentially "a requirement for federal action in the face of provincial or territorial inaction" (Gau et al., 2007). The federal minister must recommend to the Cabinet that federal prohibitions and protection must apply to a threatened or endangered species. This is to be done if the competent minister feels that a province or territory is failing the task of protecting listed species or their critical habitat (Gau et al., 2007). The Spotted Owl litigation was initiated to attempt to invoke the federal "safety net", to no avail, despite the fact that all requisites to invoke it were in place. The $\mathrm{BC}$ government was failing the severely endangered species, yet the federal government failed to use the provisions outlined in the SARA accordingly. In 
2004, when the request to enable the emergency provisions was made, there were 20 Spotted Owls in the wild.

Had the WCWC won its 2005 case, the provisions could have taken Spotted Owl protection into consideration, based on the fact that the owl severely risks extirpation as a result of inaction (Plotkin, 2007). Therefore, in order for the $S A R A$ to be efficient, it must allow the federal government to strongly assert jurisdiction for the protection of any severely endangered species, regardless of where its habitat is located. Hence, the failure to invoke the emergency provisions thus far constitutes a severe implementation gap within the framework of the Act. Some implementation gaps and inadequacies of policy tools that were highlighted in this case study also arise in the case that follows.

\subsection{The Vancouver Island Marmot}

\subsubsection{Canada's Most Endangered Species}

The Vancouver Island Marmot (Marmota vancouverensis) deserves special attention for many reasons. In 1978, the species was the first ever to be listed as endangered by COSEWIC. The Vancouver Island Marmot is one of the most studied mammals in its home province of British Columbia, and its life history traits are well understood. The species is an indicator of the forest health on Vancouver Island. Since the marmot thrives best in the presence of contiguous forest containing high quality corridors, the decline of the species is an indicator of fragmentation and lower quality forest parcels on the island. The species is a charismatic mammal that has a huge public appeal, as evidenced by its choice as a mascot for the 2010 Vancouver Olympic Winter Games. In addition, it is an important choice for a case study because there have been substantial amounts of resources dedicated to marmot preservation and recovery efforts.

\subsubsection{Ecological Traits and Habitat Requirements}

The Vancouver Island Marmot ${ }^{46}$ (Marmota vancouverensis) is a ground squirrel that is endemic and unique to the mountains of Vancouver Island, British Columbia. It is

\footnotetext{
${ }^{46}$ Information on the Vancouver Island Marmot is available under the $S A R A$ s public registry: Species at Risk Act (SARA), Registry. June 2008. Vancouver Island Marmot. < http://www.sararegistry.gc.ca/species/speciesDetails e.cfm?sid=136>.
} 
one of 14 existing marmot species worldwide. Like all other marmot species, its habitat consists of burrows. It is restricted to habitat in subalpine meadows. Foraging predominantly on grasses and herbaceous flowering plants, the species hibernates during the winter.

The Vancouver Island Marmot survives in small colonies, which on average contain fewer than five adults (COSEWIC, 2000: v). The species depends upon dispersal from one colony to another in order to avoid inbreeding. The marmot thrives within many small colonies so as to sustain a healthy existence for the species. This phenomenon is known as the 'metapopulation' theory. Dispersal of occasional migrants among the colonies is a very important function in the marmot's life history and enables marmot communities to remain viable and healthy (COSEWIC, 2000: v; Vancouver Island Marmot Recovery Foundation, 2007).

\subsubsection{Current Status and Causes of Decline}

The Vancouver Island Marmot is the rarest of the 14 species of marmots that are in existence worldwide (COSEWIC, 2000). Steep declines in population occurred during the mid-1980s and throughout the 1990s. ${ }^{47}$ The species was nearly extinct in the wild by 2003 (Janz et al., 2000).

The decline of the Vancouver Island Marmot has occurred as a result of a number of factors, including a decrease of survival rates and subsequent increase of highmortality episodes. The species' most common predators include wolves, cougars, and golden eagles, which are highly abundant on Vancouver Island. Their predation on the marmot is partly responsible for significant losses at some marmot colonies. On the other hand, no evidence has been uncovered to suggest that declining reproduction rates contributed to species declines (Vancouver Island Marmot Recovery Foundation, 2007).

The predominant factor that has been attributed to the decline of the marmot is the extensive logging on Vancouver Island. Logging practices have caused fragmentation of habitat and as such have resulted in the creation of man-made islands. The fragmentation has led to the isolation of the population in concentrated pockets, subsequently increasing

\footnotetext{
${ }^{47}$ The marmot experienced a pronounced temporary increase in population numbers in the 1980s and 1990s due to the temporary availability of new man-made habitats resulting from clearcut logging and forestry activities. Ultimately, the population declined in the long term (Janz et al., 2000).
} 
the risk of mortality from predation and reducing survival rates. Logging has also served to disrupt the 'metapopulation' model that sustains viable marmot populations by cutting off access to dispersal corridors. The landscape surrounding natural habitat patches has been extensively altered by years of logging activities (Hebda et al., n.d.). In the past, hunting and collecting for scientific purposes were most likely important factors; however, they are negligible factors at present (UNEP, 2002).

Marmots are loyal to colony sites. Studies have found that colonies that had previously been isolated were unlikely to be recolonized, even if the habitat remained suitable. Other studies have also suggested that colonies that had been recently occupied by marmots, yet had been abandoned for several marmot generations, had been connected at some point via between-mountain dispersal movements. Inbreeding may therefore pose a long-term threat in isolated colonies (UNEP, 2002; Vancouver Island Marmot Recovery Team, 2008: 10-11). Figure 7.2 illustrates active and inactive (or isolated) Vancouver Island Marmot colonies.

As of 2003, fewer than 30 mature wild-born marmot individuals were present in the wild and 74 existed in captivity, indicating that the population of marmots totaled less than 100 individuals. Successful reintroductions via the captive breeding program have increased the total number of individuals in the "wild" to 160, while 240 remain in captivity, for a total of 400 overall (Vancouver Island Marmot Recovery Team, 2008). The species is very sensitive to stochastic events and it is especially vulnerable to predation. Predation continues to threaten the future viability of the species in the wild. The species is also at risk from the negative impacts of climate change and inbreeding depression (ibid.). Even with captive-bred marmots continuing to shore up the numbers of the species with their releases, the pressures arising from anthropogenic habitat disturbance remain a serious concern. 


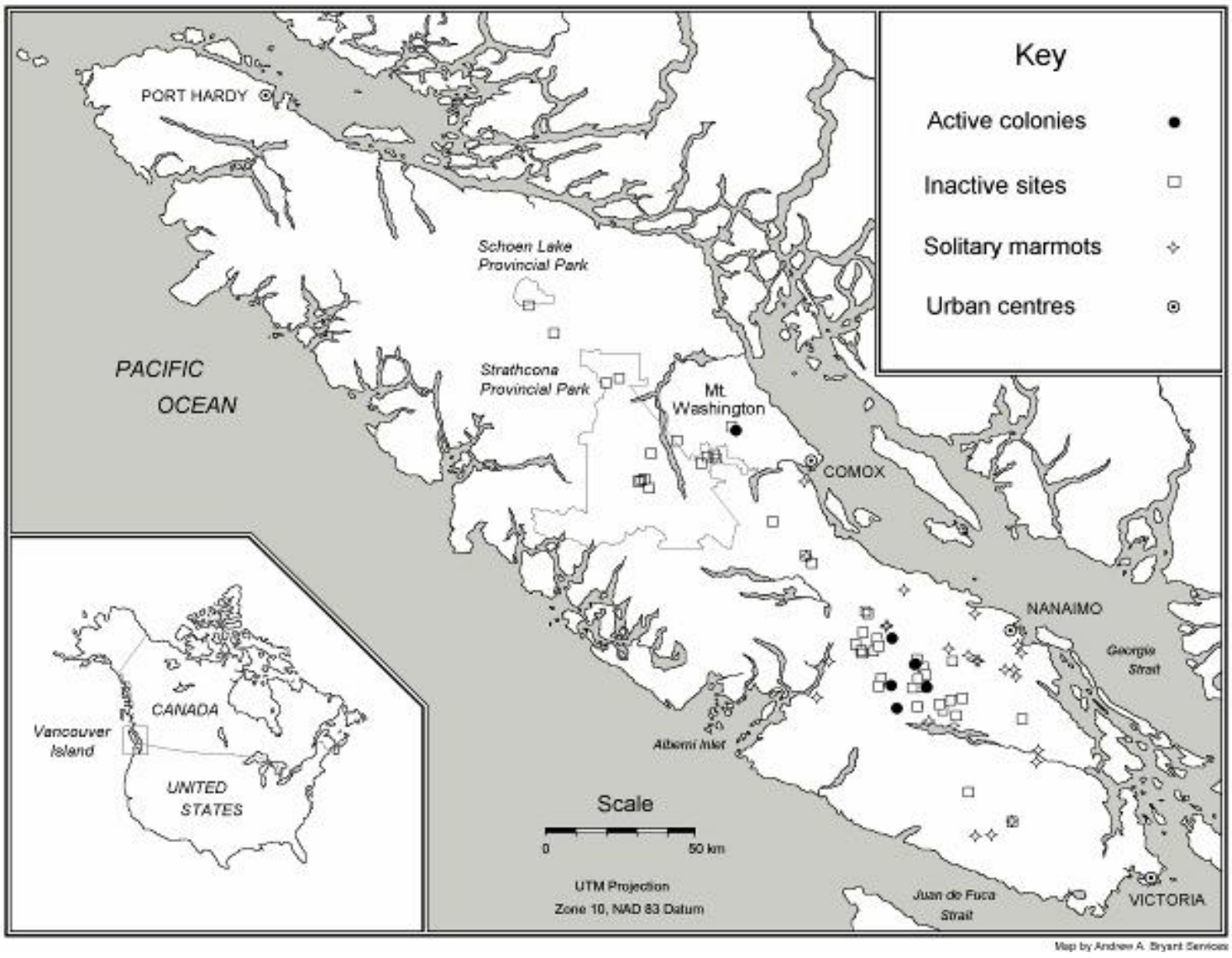

Figure 7.2: Distribution of active (as of 2005) and inactive (1896-2004) colony locations for the Vancouver Island marmot (Marmota vancouverensis) in Canada. Records of solitary marmots likely represent dispersing individuals [Vancouver Island Marmot Recovery Team, 2008]

\subsubsection{Existing Legal Measures for the Protection of the Vancouver Island Marmot}

In 1978, the Vancouver Island Marmot was one of the first species listed as endangered by COSEWIC. The species is protected under provisions of the Wildlife Act, 1996 in British Columbia and $S A R A$, and is listed as endangered under both Acts. The marmot has mass media appeal as a result of its cute and cuddly appearance as well as its status as the most endangered species in Canada. Sensitivity of public perception and an elevated public profile for the species has been facilitated by dedicated ENGO campaigns that are committed to publicizing the plight of the Vancouver Island Marmot ${ }^{48}$. As mentioned above, the selection of the species for a 2010 Vancouver Olympic Winter

\footnotetext{
${ }^{48}$ The major ENGO that is dedicated to advocating the recovery of the Vancouver Island Marmot is the Marmot Recovery Foundation (www.marmots.org) which partners its recovery efforts with Wildlife Preservation Canada (www.wptc.org). The Western Wilderness Committee (wildernesscommittee.org) is another major ENGO that has contributed to publicizing the importance of marmot recovery.
} 
Games mascot illustrates and reinforces its high public profile. The Olympic campaign has vastly increased worldwide public exposure of the species.

The province has taken on commitments to species at risk, through the Accord for the Protection of Species at Risk in Canada and the Canada-British Columbia Agreement on Species at Risk. A dedicated recovery strategy for the Vancouver Island Marmot has also been developed, which relies upon captive breeding and reintroduction (Vancouver Island Marmot Recovery Team, 2008: 2).

The Vancouver Island Marmot Recovery Team was established in 1988. Recovery plans were published in 1994, 2000, and 2008. In 1998, the non-profit Marmot Recovery Foundation was established in order to aid in raising funds and in the administration of recovery efforts (Vancouver Island Marmot Recovery Team, 2008: iv, 2). As a result of the charismatic and aesthetic appeal of the species and the attention that it has garnered over the years, the recovery effort is the most successful of its kind in Canada, to date.

In 1999, the BC Ministry of Environment acquired 1400 hectares of parkland on Vancouver Island with the intent of preserving key Vancouver Island Marmot habitat. However, since critical habitat for the species has not yet been defined to date, it is difficult to know whether the acquisition will prove to benefit the species in the long term (High Beam Research, January 1999; WWWC, 2009).

\subsubsection{Implementation Gaps}

As highlighted in the case of the Spotted Owl, all species at risk in British Columbia are not fully protected under the federal Species at Risk Act because the Act only applies to lands that fall within federal jurisdiction (Illical and Harrison, 2007: 384). Recall that there are a few minor instances where the Act can apply to other lands outside of federal jurisdiction, with strict limitations on when, where, and how it can apply. These provisions are referred to as a federal 'safety net'.

Since it is an endemic species to British Columbia, and special provisions under the 'safety net' or an emergency order have not been invoked for the species, the Vancouver Island Marmot is not afforded complete protection under the Species at Risk Act. The reason being is that most marmot habitat exists on privately owned forest lands, 
which are owned by Island Timberlands and TimberWest (Vancouver Island Marmot Recovery Team, 2008: 10). A commonly recurring issue in species at risk policy is the applicability of the SARA specifically to public land. There is a difficult challenge to the protection of habitat where laws predominantly apply to public lands, even where provisions exist. Provisions to apply the laws on private lands are only on a case by case basis. Since only $4 \%$ of all land in Canada is federal public land, this poses a problem for those species that reside on privately owned land, and where critical habitat exists on private land.

The federal Species at Risk Act stresses the importance of protecting the critical habitat of endangered species. Recall that a species' only hope of survival lies within the viability of its critical habitat, the habitat that is necessary for the ultimate survival and recovery of a species. The current Vancouver Island Marmot recovery strategy explicitly outlines that critical habitat has yet to be defined and identified, despite the fact that marmot habitat is easily identifiable and there is more than enough scientific knowledge to do so (Vancouver Island Marmot Recovery Team, 2008: 19).

It was discovered that a lack of critical habitat identification is common among many recovery strategies launched by the $\mathrm{BC}$ government as required under $S A R A$. The Wilderness Committee and Ecojustice discovered an internal government memo in 2008 where the $\mathrm{BC}$ government specifically instructed recovery teams to avoid mapping critical habitat. The absence of maps pointing to critical habitat does not allow for its adequate location, and in turn undermines the protection of the species at risk (WWWC, 2009). In addition, a lack of defined critical habitat may pose a problem to the viability and recovery of new introduced populations, and undermine the integrity of reintroductions.

When important scientific and ecological information such as life history traits and the characteristics and location of critical habitat that is available within the planning and management process is not noted or is ignored, it is impossible to implement effective legal protection. Hence, the scientific basis of species at risk policy is crucial to ensuring adequate protection.

The case of the Vancouver Island Marmot is not the only instance where deliberate exclusion of critical habitat information in recovery strategies has occurred in 
Canada. ENGOs have applied for judicial review for other instances of failure to identify critical habitat in recovery strategies (Valiante, 2009: 44, note 37). Recall, as mentioned in Chapter 3, the case of the Greater Sage-Grouse (Section 3.3.4.1) and that of the Nooksack Dace (Section 3.3.4.2). Even though information on critical habitat was available for each species in both instances, inclusion of this crucial information in the corresponding recovery strategies was neglected. In both cases, the judges sided with the ENGOs, agreeing that defining critical habitat and including it within recovery strategies is mandatory as laid out in the Species at Risk Act. Attempts to protect critical habitat is also a precautionary approach to protecting species at risk. As such, it satisfies the requirements of the $\mathrm{CBD}$ and the SARA. In fact, the inclusion of available knowledge on critical habitat location and attributes is now mandatory as the precedent was set in 2009 resulting from the case of the Greater Sage-Grouse. There is no excuse to excising important details and scientific information that would assist in the development of better protectionist regimes and policies.

With regards to the marmot captive breeding program, successful reintroductions leading to a drastic increase in the marmot population as outlined in the recovery strategy could potentially be overshadowed by continuously looming current threats. Since the lands of Vancouver Island are mostly privately owned, and the climate is such that logging is permitted up to high altitudes of mountainous terrain, further development may be facilitated, in the absence of land acquisitions or stewardship agreements. Continued logging would likely pose an incessant threat to the existence of the species. In addition, captive-bred individuals could compromise the genetic integrity of wild populations. Genetic interaction and viability cannot be completely foreshadowed, nor can it be modeled to perfection. Reintroduced populations will be left to stochastic forces (Vancouver Island Marmot Recovery Team, 2008: 7).

Taking these implementation and integrity gaps into consideration, recommendations for adjustments in the policy process based on this case study are provided in Chapter 8 .

Being the first listed endangered species in Canada, the Vancouver Island Marmot, in a sense, set a precedent for species a risk protection and recovery measures in Canada. There are many lessons to be drawn from the species. Due to the species' 
heightened appeal as a charismatic mammal, and it being the subject of intensive scientific study, the presence of implementation gaps and legal inadequacies of protection for such a well studied species indicates that the same gaps are most likely found elsewhere. It could be assumed that a much lesser effort is being applied for protection of more obscure, lesser known species. 


\section{CHAPTER 8.0 POLICY RECOMMENDATIONS}

Current legal measures for the protection of species at risk have been evaluated for the federal level of jurisdiction in Canada (Chapter 3), and for two different provincial jurisdictions: Ontario (Chapter 4) and British Columbia (Chapter 6). Given the crucial importance of biodiversity issues and the challenges posed by species at risk in Canada, there seems to be a substantial need for more case studies, and especially ones that deal with the provincial level of jurisdiction. Furthermore, the scientific and ecological particulars of each case are often not prominent. If they are mentioned, they are not elaborated. Yet, if the policy community is to be scientifically informed to allow for the generation of the most scientifically grounded policy, these particulars should be addressed within case studies.

Thus, four different case studies have been analyzed in this thesis to further understand the impact of the current legal tools on specific species at risk that have been listed under COSEWIC (and COSSARO in Ontario). In doing so, various implementation gaps have been identified and highlighted. In this chapter, recommendations for possible future changes and reforms to existing species at risk policy are provided, as determined from implementation gaps highlighted in the four case studies. Overall, the importance of inter-jurisdictional and intra-jurisdictional cooperation is stressed, as well as the benefit of dedicated species at risk legislation at both federal and provincial levels of jurisdiction. Also, it is recommended that any flexibility instruments, such as permits or exemptions, be used with extreme caution. In addition, the importance of stakeholders such as private landowners in the effort to protect species at risk should not be underestimated, and as such should be cultivated. These recommendations are discussed more thoroughly in this chapter.

\subsection{Species at Risk in Ontario: Federal and Provincial Policy Recommendations 8.1.1 Inter-Jurisdictional and Intra-Jurisdictional Cooperation}

The overarching theme in species at risk policy and legal measures in Canada is the importance of collaboration among different jurisdictions in achieving the goals of species at risk protection. In the National Accord for the Protection of Species at Risk, a 
great emphasis and responsibility for recovery and conservation is placed on voluntary stewardship. This same emphasis is echoed in the Species at Risk Act. However, as illustrated particularly in the case study of the Eastern Loggerhead Shrike, and appearing as a common thread among all species at risk, the federal government is failing to provide adequate funding to support stewardship initiatives. The federal government must ensure the existence of an adequate pool of funds to subsidize stewardship programs, since it has taken the path away from command and control policy in favour of voluntary initiatives. The Habitat Stewardship Program as well as alternative funding sources should be expanded, or at the least maintained, instead of being reduced, as has occurred under Environment Minister John Baird in 2007. Also, access to funds by potential stewards is imperative for the program to function appropriately (Nature Canada, 2006).

Great caution must also be taken to avoid conflict within jurisdictions and in avoidance of jurisdictional overlap between jurisdictions. Better cooperation and communication must take place among the jurisdictions in order to satisfy the terms that were initially laid out in the Accord. Cooperation is imperative for the conservation and protection of species at risk because they occur on federal, but mostly provincial lands. A combination of federal and provincial/territorial legislation, regulations, policies, and programs are crucial to protecting species at risk (Canadian Intergovernmental Conference Secretariat, 1999; SARA Registry, 2010).

With regards to intra-jurisdictional dynamics within the province of Ontario, it is imperative that the MNR exercise care when allowing exceptions for other statutes from the ESA, 2007. When doing so, the MNR should ensure that only branches of government that are renowned for their conservation efforts are given authorization to allow the harming of a species at risk or the destruction of its habitat. Although no statutes have been granted exemptions in this manner as of yet, extreme caution must be taken if such exemptions are to take place in the future (Miller, 2009: 36). It would also be important for the MNR to consult with the public on its agreements with other branches of government, both internally and externally to the MNR, in order to clearly explain how overall species benefit tests of the ESA, 2007 will be met while allowing otherwise prohibited activities to take place. It should also ensure that any records of a 
decision made by the Minister or any other authorized person be made available to the public (ibid.).

Other individual programs can be established at the level of specific jurisdictions. For instance, with regard to the case of the Eastern Loggerhead Shrike, and the threats that exist to all songbirds, the predatory threat of housecats and feral cats can be kept to a minimum by introducing regulations to keep all housecats indoors and applying programs to reduce the feral cat population, either at the provincial or municipal level.

\subsubsection{Flexibility Instruments and Exemptions}

With regards to flexibility instruments within the Act, it is recommended that the MNR should apply the "overall benefit" test outlined in the Endangered Species Act, 2007 , with the inclusion of an assessment of cumulative impacts resulting from otherwise prohibited activities, when examining these activities prior to granting permits or agreements (Miller, 2009: 35). The overall benefit test encompasses the opinion of the Minister that "an overall benefit to the species will be achieved within a reasonable time through requirements imposed by conditions of the permit" or other instrument (ESA, 2007, S.O. 2007, c.6, 17(2)(c)). Caution should still be taken when applying the test because the final opinion of the Minister is discretionary. Perhaps it would be wise to allow a scientific body to approve the decision, allowing it to be less discretionary.

In order for the Ontario Endangered Species Act, 2007 to function appropriately and fully protect all listed species and their habitats, it is imperative that all exemptions granted to industries effectively be reversed, and that no new exemptions should be established. If, indeed, exemptions are to stand, only projects that were approved prior to the introduction of the new Act, and that are not able to meet higher permit standards, should apply.

If permits are to be granted, they should be approved on a project by project basis as opposed to the current blanket exemptions for entire industries. This will ensure that the $E S A, 2007$ is not made ineffective by too many exemptions. In addition, all flexibility instruments do not have mandatory expiry dates. These instruments include agreements and permits as well as all exemptions under O. Reg. 242/08. Neither the Act nor the regulation require expiry dates, review at specific intervals, or predetermined timelines. 
Permits are only susceptible to being amended or revoked by the Minister. The above situation could potentially allow the permissible harming and killing of species at risk for an indefinite amount of time without any 'statute-mandated review'. The Minister is the only individual that can make a decision. Thus, flexibility instruments are discretionary. It is therefore recommended that expiry dates apply to all flexibility instruments so as to allow the evaluation of these instruments in accordance with the ESA, 2007 or its regulation (Miller, 2009: 42).

As also emphasized in the case of the Eastern Loggerhead Shrike, species such as the Jefferson Salamander and the Shrike could potentially be adversely affected by Ontario Regulation 242/08, and exemptions for development and aggregate extractors more specifically, as business is permitted to continue as usual, particularly for those developers and pits and quarries that obtained a license prior to the coming into force of the ESA, 2007. These individuals would not be subject to the provisions of the Act, nor to those in the habitat regulations.

In addition, the exemptions for hydro, pits, and quarries alongside those for development and infrastructure do not require these industries to explore all options to meet higher standards of permits and other instruments. Rather, their activities are allowed blanket exemptions, which severely undermine the scope and the provisions of the $E S A$, 2007. It is recommended that revisions to the Act should take place whereby only projects that were approved prior to the passing of the Act that are not able to meet the higher standards of permits and other instruments are to be exempted.

\subsubsection{Private Landowner Rights and Stewardship}

Since a vast majority of species at risk occur on private land, landowners are considerable stakeholders of species at risk and potentially play a crucial role in stewardship. Concerning the property rights of private landowners, a greater investment must be incorporated into stewardship activities. On a positive note, the MNR increased its operating budget from a stable $\$ 2$ million over the last decade to $\$ 6$ million for the 2008-2009 fiscal year (Miller, 2009: 53). It is unclear whether the budget will be increased further in future years. Support for stewardship initiatives is very important in densely populated southern Ontario, where the majority of the species at risk inhabit 
privately owned land. A prime example is the location of Eastern Loggerhead Shrike territory on private fields. However, it remains to be seen if the current budget will be enough to satisfy the needs of private landowner stewardship and other tasks at hand. It is recommended that a large amount of available funds be allotted to private landowner stewardship initiatives.

Nevertheless, even where stewardship programs are in existence, the scope of some programs exhibits some weakness. For instance, the Species at Risk Farm Incentive Program (SARFIP) is only available to farm owners. Even so, not all farm owners are eligible. Only those registered under the Canada-Ontario Farm Plan can qualify (Miller, 2009: 54). In the same light, the Conservation Land Tax Incentive Program (CLTIP) only grants funding to landowners who own land that contains endangered species habitat. For instance, under the present plan, Jefferson Salamander habitat would not be eligible for the incentive, as it is listed as a threatened species. In fact, only 60 properties in the entire province of Ontario are presently receiving tax relief for endangered species habitat under the CLTIP (Miller, 2009: 54). It is thus recommended that the MNR expand the CLTIP to include private property that contains habitat for a broader spectrum of listed species at risk. These should also be extended to recovery lands in addition to conservation lands.

\subsubsection{Recovery Strategies, the Importance of Current Scientific Information, and Precautionary Policy}

With regard to the 42 species that were originally protected under the ESA, 1971, it is recommended that exemptions to the ESA, 2007 not apply to these particular species. This is recommended because any affected industries have most likely already taken species protection into account as per the ESA, 1971. There is no need to wipe the slate clean and allow business in such industries to turn the clock back and revert to practices that existed prior to the listing of species under the $E S A, 1971$. By applying the $E S A$, 2007 exemptions to the 42 original species, a precautionary approach is not taken.

Furthermore, the case of the Jefferson Salamander, and its recovery strategy, highlights another negative facet of the ESA, 2007. Though the Jefferson Salamander is a threatened species in Ontario with a dedicated recovery strategy, still many species at risk 
lack one. There is a transition period of five years (until June 30,2013) to develop recovery strategies for those species listed as endangered or threatened in the schedule of the ESA, 2007. It is possible that the transition period is further undermining the legislation that is set in place to protect species at risk. The time lag may prove not to be precautionary enough. It is plausible that the lag in time for the creation and implementation, as well as the mobilization of resources for monitoring and enforcement could actually place some species in danger of being pushed even closer to the brink of extinction.

When implementing the ESA, 2007 and creating recovery strategies, it is imperative that research on the conservation biology of species as risk, as well as the elements and interacting factors that cause the decline of a species, be conducted. The case of the Jefferson Salamander highlights the importance of quality of information in the effort to pursue the recovery of species at risk. Scientific information is the basis of all recovery efforts, and is an integral foundation to the development and implementation of species at risk policy. Obscure species are at a disadvantage and the focus of conservation efforts tend to shift to well-studied species. Hence, it is recommended that as much scientific research as possible be conducted on all listed endangered and threatened species. In addition, the MNR should commit to adequate resourcing of research to fill in as many gaps in scientific knowledge as possible in order to monitor species recovery satisfactorily. Best available knowledge should be incorporated into recovery methods so it can be adopted within policy and inform a sound yet precautionary approach. Acting in a precautionary manner is the most opportune way to avoid further species declines, even in the absence of comprehensive scientific information.

Also, all recovery strategies should include integrated timelines to ensure that a well organized and chronological research and monitoring program can be established and implemented. Furthermore, it is recommended that recovery strategies, for all listed species that currently lack one, be established as expeditiously as feasible. With respect to species at risk, time is of the utmost importance. The greater the lag in time for the creation and implementation of a recovery strategy, the further at risk a species may become. 
With respect to habitat regulations, it is imperative that they be as specific and appropriate as possible. Habitat regulations, in a similar light to entire recovery strategies, are only as good as the availability of scientific information. Hence, it is important that the regulations and recovery strategies be compiled based on the most recent and best available information, or their integrity could be compromised. As illustrated in both Ontario cases, range maps and maps displaying documented locations of the species at risk should be an integral part of a habitat regulation. In this manner, it would facilitate the delineation of where the actual regulation would apply.

\subsection{Species at Risk in British Columbia: Federal and Provincial Policy Recommendations}

\subsubsection{Importance of Federal-Provincial Inter-Jurisdictional Cooperation}

The results of the Spotted Owl litigation provide evidence that the Species at Risk Act has already been failing this endangered species, and that the Act is most likely failing many others. After evaluating legal inadequacies for the protection of species at risk at the federal level in Canada, it is apparent that there is still much room for improvement. Canada requires a tough, well defined, federal endangered species act, which directly protects all wildlife species that are most at risk. Critical habitat must also be preserved, regardless of where the species resides. Since only 4 percent of all land in Canada lies within federal jurisdiction, very few species are completely protected under the SARA (Austen, 1997). For example, in the case of the Spotted Owl, much of the oldgrowth forests that are currently being logged under the authority and permission of the $\mathrm{BC}$ government exist within provincial jurisdiction. For this reason, endangered species legislation must not be limited to the federal level of government.

It has been proven, as noted in the case of the Spotted Owl, that the $S A R A$ is not strong enough to withstand jurisdictional gridlock for preservation of a species at risk. If the federal government undertook much stronger protective measures, it would be posing a threat to the provincial government and its authority over economic development via resource exploitation. This is especially relevant to a province like British Columbia, which is rich in natural resources, where the province itself is an investor in the forestry 
industry, via the Timber Sales Program. The forestry industry is the largest industry in the province. It is very evident that conflict runs rampant in situations such as these, where jurisdictional issues lie at the heart of the discord. That said; it is also apparent that laws have no meaning without proper funding, monitoring, and enforcement. The government must be willing to appropriately train high performing personnel. Taxpayers must also be willing to allot their hard earned dollars to the issues at stake. These are all resources that are limited within the constraints of government and the economy. Without the collaboration of all these factors, the SARA will just linger as a document full of words with no meaning.

\subsubsection{Provincial Recommendations}

It is fundamental that individual provinces establish legislation for species at risk since the federal government has very little jurisdiction over them in comparison to provincial governments (Beazley and Boardman, 2001: 4). Wildlife is considered a natural resource. The management of these resources has traditionally been the responsibility of the provinces in accordance with the Canadian constitution. The establishment of provincial endangered species legislation is extremely important, so that species at risk may be protected at every level of government and every jurisdiction. Not all provinces currently have a legislation that was enacted specifically for the purpose of protecting species at risk. Manitoba, New Brunswick, Nova Scotia, Ontario, Prince Edward Island, and Quebec have passed endangered species legislation to date. Hence, proper legislation is lacking at the provincial level in British Columbia. This is one of the major reasons why both the province and the federal government are failing the Spotted Owl. Candace Batycki, of ForestEthics, reiterated this fact by stating that, "The BC government must pass meaningful endangered species legislation to remove the stigma created by its shameful forest policies" (ForestEthics, 2002). Therefore, a combination of strong federal and provincial legislation is crucial to adequately protect endangered species in all jurisdictions across the country, without allowing them to fall though the cracks of the legal framework. The laws must also incorporate and respect the precautionary approach. 
Canada requires a tough, well defined, federal endangered species act, which directly protects all wildlife species that are most at risk. However, tough provincial legislation, as in the case of Ontario, would also be beneficial for the protection of species at risk. The presence of both jurisdictional layers of protection would prove most optimal. For instance, if it were possible for the province of British Columbia to enact endangered species legislation at the provincial level, it could have greater prospects of success than maintaining sole reliance on $S A R A$ within the provincial context. It is clear that science-based policy must also allow for the preservation of critical habitat, regardless of where it is located. Since very few species are completely protected under the $S A R A$, inter-jurisdictional cooperation is imperative for the protection of critical habitat. For instance, in the case of the Vancouver Island Marmot, private land on Vancouver Island that is currently being logged does not fall within federal jurisdiction. This point also illustrates the importance of cooperation between the government and private landowners. It would be beneficial if BC followed a similar stewardship strategy to that which exists in Ontario.

Private landowner rights and voluntary stewardship are issues that arise in both British Columbia case studies as well as both Ontario case studies. Most species at risk critical habitat exists on privately owned residential or commercial property. Landowners are fundamental stakeholders and have the potential to play a crucial role in the protection of species at risk. In addition to legislative protection, the collaboration of private landowners via stewardship agreements is imperative to the preservation of critical habitat. The acquisition of land for the purposes of critical habitat conservation is another feasible alternative to command and control regulation. However, it can be a very costly option. A combination of these options could potentially be effective.

As it stands, the province of British Columbia has much to learn from other provinces that have enacted dedicated species at risk legislation. Ontario provides the best scenario from which to extract lessons. Even though the Ontario ESA, 2007 contains some flaws, the presence of multiple jurisdiction legislation is still a much better alternative to protection based solely on a federal statute. 


\subsection{Charismatic Species, Public Exposure, and Scientific Information}

Another important consideration in Canadian endangered species protection is the heavily skewed focus of conservation efforts towards aesthetically appealing and well studied charismatic species. To combat this issue, more scientific research must be conducted in order to inform the policy community about the importance of more obscure species at risk. Obscure species encompass an equally important role in the composition of ecosystem biodiversity.

The case of the Vancouver Island Marmot highlights the effect of charisma in garnering support via ENGOs to raise public awareness of endangered species. The increased public and media exposure of ENGOs grants them avenues to allow them to reach the general public via their various campaigns, and more increasingly via electronic media and the internet. Increased media exposure, and in turn public perception and public voice, elevates the sensitivity of government to adjust public policy based on ENGO and public pressure. For instance, in the case of the Vancouver Island Marmot, the Marmot Recovery Foundation and its pervasiveness via electronic and other media campaigns as well as the designation of the "cute" species as a mascot for an important international event highly increases the visibility of the species, while other more obscure species at risk may not have the benefit of "cuteness", charisma, and heightened public interest. As a consequence, obscure species may lag behind on the species at risk policy agenda, subsequently suffering from a lack of recovery efforts and funding.

In addition, extensive academic and scientific research has been conducted on the Vancouver Island marmot over a period of about thirty years, having been the focus of conservation efforts since the 1980s (Vancouver Island Marmot Recovery Team, 2008: 11). The heightened academic and intellectual investment in a species allows for informed policy and decision making. On the other hand, more obscure species may not reap the same benefits. The case of the Vancouver Island Marmot in particular serves to highlight the imbalance and partiality.

Current scientific information is crucial to informing recovery strategies. The BC government must ensure that critical habitat is defined in all recovery strategies. For instance, in the case of the Vancouver Island Marmot, if the captive breeding program is to be successful in the long term, it is imperative that marmot critical habitat be defined 
within the recovery plan. Once it is defined, adequate policy must be established and proper protectionist measures be set in place via an effective action plan in order to protect the habitat. Proper enforcement measures are also imperative in order to ensure that protectionist measures are being appropriately implemented.

As is apparent in all the other case studies, mobilization to protect a species by preserving its critical habitat is imperative. Recovery strategies are only as good as the scientific information they are based on. It is important to base maps of critical habitat on existing sound science. The importance of quality and availability of information for establishing adequate protectionist measures is a theme that arises in all cases. Yet, the case of the Vancouver Island Marmot in particular illustrates that policy makers must embrace scientific information and include it among the set of policy tools to facilitate species at risk preservation. Currently, all available information is not being utilized to its full potential, as shown by a lack of definition of critical habitat within recovery strategies for this species, alongside many other $\mathrm{BC}$ species at risk. 


\section{CHAPTER 9.0 CONCLUSIONS AND APPLICATIONS FOR FUTURE}

\section{RESEARCH}

This thesis is a representation of the policy cycle in action. It is specifically an example of an evaluation of policy analysis (see Figure 1.1, (5)). The recommendations for change or reform of existing legal tools for species at risk legislation can be applied to various Canadian jurisdictions. It is hoped that this thesis will continue paving the way to similar research on other case studies that may uncover similar challenges for different species at risk, or with the same species in different jurisdictions.

An interpretive qualitative evaluation of existing legal tools for species at risk in Canada was conducted. Case studies were used to stress the importance of current scientific information and a precautionary approach in the formulation of policy instruments for the protection of species at risk, in light of the current biodiversity crisis in Canada. The evaluation led to a questioning of the effectiveness of the existing legal measures in light of the overarching policy goal of preserving species at risk.

Several important lessons can be drawn from the research. The causes of biodiversity loss must be understood and one must rely on the best available scientific facts to find these answers. The protection of species at risk is central to mitigating extinctions. As extracted from the case study analysis, it is becoming ever apparent that Canadian legal tools are presently not sufficient to promote and sustain biodiversity and ecosystem health in Canada. Especially at the provincial level of government, existing legal measures are not adequately protecting endangered species. The effectiveness of these tools were assessed and highlighted by the case studies.

Federal protection alone is not sufficient to protect all species at risk in Canada. For this reason, provincial legal measures must be strengthened to make up for federal weaknesses. Ontario currently has dedicated species at risk protection: the Endangered Species Act, 2007. British Columbia, on the other hand, relies solely on statutes that very briefly mention species at risk, yet are not dedicated to their protection. After comparing both provinces, it is recommended that inter-jurisdictional cooperation is the best option for protecting species at risk. Such cooperation would strengthen the impact of federal initiatives given the limits of their application across provincial jurisdictions. It is also 
recommended that provinces enact dedicated species at risk legislation similar to the Ontario statute.

The significance of this research consists in its contributions to the scientific and legal literature, particularly considering the relative scarcity of discussions that specifically focus on species at risk protection at the provincial level. A crucial focus of the research is on the importance of provincial policy tools for the protection of species at risk in Canada, in cooperation with federal legal measures. An emphasis on incentives for private landowner participation and understanding the crucial role these stakeholders play in species at risk protection in Canada is also an integral component of the research. The case study method serves to highlight inadequacies and implementation gaps in the existing legal measures. In essence, the overarching message of the research is the requirement for more effective management tools for the problem of biodiversity loss and species at risk in Canada. These tools must be rooted in scientific understanding about the specific causes of species decline and the habitat requirements for the recovery of declining species. Legal and management tools must be implemented at both the federal and provincial levels for more comprehensive management of species at risk in Canada.

The recommendations based on the evaluation of legal inadequacies are elaborated in Chapter 8. An overarching theme is the importance of inter-jurisdictional and intra-jurisdictional cooperation for effective species at risk policy; the careful and scientifically informed use of flexibility instruments, permits, and exemptions to existing law; and the importance of funding private landowner stewardship efforts. Scientific information and the proper definition of critical recovery habitat for species at risk alongside the importance of using a precautionary approach are also discussed.

Evidently, there is much more research potential in the realm of endangered species in light of the heightening biodiversity crisis. The issue has reached vast proportions on global and local scales. It is imperative that all stakeholders including governments, decision makers, private landowners and citizens be sufficiently informed. Armed with the proper information, each stakeholder can play a crucial role in attempting to reverse the crisis by protecting species at risk.

The research is centered on species at risk policy and legislation in federal and provincial jurisdictions. An expanded analysis of the cooperation between different 
jurisdictions in a harmonized effort to protect all officially listed species at risk would make for an interesting follow-up. In addition to the research on inter-jurisdictional cooperation, and also stemming from the current research at hand, recommendations could be made to allow for the cooperation of municipalities via the development of specific policies and regulations in support of protection for certain endangered species. This could be initiated through inter-jurisdictional agreements. For instance, in the case of the Eastern Loggerhead Shrike, house cats and feral cats as well as pesticides are detrimental to the health of the species and have greatly contributed to its drastic decline in number (Eastern Loggerhead Shrike Recovery, n.d.). Municipal regulations requiring that house cats be kept indoors and the introduction of programs to reduce the feral cat population could be potential options to control the outdoor feline population. In a similar light, pesticide bans or the introduction of limits to amounts of pesticides used for cosmetic purposes are reasonable steps that municipalities can take to participate in the effort to help reverse declines in migratory songbird populations like that of the Eastern Loggerhead Shrike. Hence, it is imperative not to underestimate the importance of the municipal jurisdiction, even though this particular level of government was not discussed thoroughly here. This is definitely an important area of future species at risk policy research.

Alongside the contributions to future policy reform and development, the policy recommendations that resulted from the case study evaluations could lead to applications involving non-governmental organizations and other active partners involved in stewardship initiatives. Another application includes the furnishing of important information that will aid ENGOs in developing policy documents and campaigns.

The present research will also set the stage for future directions whereby the policy analysis of legal protection of species at risk can be expanded to other cases. For instance, the Polar Bear is of timely interest. The species was not included among the case studies in my research because it is a species that merits individual attention that is beyond the scope of this paper. Also, analysis of legal protection of marine organisms and marine mammals is warranted, especially considering that the federal government has full jurisdiction over marine environments and inland fisheries. Policy on 
aquaculture and the farming of fish could also be included in future research (Volpe and Shaw, 2008).

Other future directions of the present research could include a comparative analysis of similar case studies in other jurisdictions, such as the United States. The significance of multi-lateral international agreements and their effects on the protection of these species could also be analyzed to see whether the agreements are adequate and if they are being followed. Such research would help uncover any implementation gaps in legal tools in other jurisdictions where endangered species reside. 


\section{CHAPTER 10.0 REFERENCES}

Accord for the Protection of Species at Risk Backgrounder. No Date.

http://www.sararegistry.gc.ca/approach/strategy/Accord_Backgrounder_e.pdf.

Amos, W, Harrison, K., \& Hoberg, G. (2001). In Search of a Minimum Winning Coalition: The Politics of Species-At-Risk Legislation in Canada. In K. Beazley \& R. Boardman (Eds.), Politics of the Wild (pp. 137-166). Toronto: Oxford University Press.

Attridge, I. (1996). Biodiversity law and policy in Canada: review and recommendations. Toronto: Canadian Institute for Environmental Law and Policy.

Austen, C. (1997). Evaluating the proposed Canadian Endangered Species Act. http://www.umich.edu/ esupdate/library/97.03-04/austen.html.

Austin, M, D., Buffett, D.J., Nicolson, G., Scudder, G.E. \& Stevens V. (Eds.). (2008). Taking nature's pulse: The statues of biodiversity in British Columbia. [Electronic]. www.biodiversitybc.org.

British Columbia Ministry of Environment. (1998). Northern Spotted Owl. http://www.env.gov.bc.ca/wld/documents/spottedowl.pdf.

Barney, G. O. (1980). Global 2000 Report to the President. Washington: US Government Printing Office (GPO).

Bartuszevige, A.M., Capparella, A.P., Harper, R.G., Frick, J.A., Criley, B., Doty, K., \& Erhart, E. (2002). Organochlorine pesticide contamination in grassland-nesting passerines that breed in North America.. Environmental Pollution, 117: 225-232.

Beazley, K. \& Boardman, R. (Eds.). (2001). Politics of the Wild: Canada and Endangered Species. Toronto: Oxford University Press.

Benedickson, J. (2009). Environmental Law. Toronto: Irwin Law.

Berry, R.J. (1971). Conservation aspects of the genetical constitution of populations. In Duffey, E. \& Watt, A.S. (Eds.). The scientific management of animal and plant communities for conservation (pp. 177-206). Oxford: Blackwell.

Bird Studies Canada. No Date. Loggerhead Shrike Recovery Actions. http://www.bsc-eoc.org/losh.html.

Blackburn, I. \& Godwin, S. (2004). Accounts and measures for managing identified wildlife: Spotted Owl (Strix occidentalis). British Columbia Ministry of Environment. http://www.env.gov.bc.ca/wld/frpa/iwms/documents/Birds/b_spottedowl.pdf. 
Boardman, R. (2008). Polar Bears and the Canadian Arctic: Local Communities in a Globalizing World. In C. Gore and P. Stoett, (Eds.), Environmental Challenges and Opportunities: Local-Global Perspectives on Canadian Issues (pp. 305-326). Toronto: Emond Montgomery Publications.

Bocking, S. (Ed.). (2000). Biodiversity in Canada: Ecology, Ideas, and Action. Peterborough: Broadview Press.

Bocking, S. (2004). Nature's Experts: Science, Politics, and the Environment. Piscataway: Rutgers University Press.

Bocking, S. (2009). Making Space for Species: Local and Global Challenges of Biodiversity. In C. Gore and P. Stoett, (Eds.), Environmental Challenges and Opportunities: Local-Global Perspectives on Canadian Issues (pp. 13-38). Toronto: Emond Montgomery Publications.

Boyd, D.R. (2003). Unnatural Law: Rethinking Canadian Environmental Law and Policy. Vancouver: UBC Press.

Burke, D.M. \& Nol.E. (2000). Landscape and fragment size effects on reproductive success of forest-breeding birds in Ontario. Ecological Applications, 10: 17491761.

Canadian Association of Zoos in Ontario (CAZA). (2009, June). Newsletter Bulletin. http://www.caza.ca/media/Pdf/Newsletter_Archive/CAZA_NEWS_june_0 9_excerpts.pdf.

Canadian Council of Forest Ministers. (2005). Criteria and Indicators of Sustainable Forest Management in Canada. http://www.ccfm.org/ci/rprt2005/English/pg3147 1- 2-1.htm.

Canadian Intergovernmental Conference Secretariat. (1999, September). Species at Risk: The Main Concern of Canadian Wildlife Ministers. http://www.scics.gc.ca/cinfo99/83066000_e.html.

Canadian Broadcasting Coporation (CBC). (2007). Environment Canada Budget Cuts. http://www.cbc.ca/news/yourview/2007/09/environment_canada_budget_cuts.html.

Convention on Biological Diversity (CBD). 2010a. International Year of Biodiversity 2010. http://www.cbd.int/2010/welcome/

Convention on Biological Diversity (CBD). 2010b. Text of the Convention on Biological Diversity. http://www.cbd.int/convention/text/

Chabot, A.A., Titman, R.D., \& Bird, D.M. (2001). Habitat use by Loggerhead Shrikes in Ontario and Quebec. Canadian Journal of Zoology, 79: 916-925. 
Cooney, R. \& Dickson, B. (2005). Biodiversity and the precautionary principle: Risk and uncertainty in conservation and sustainable use. London: Earthscan.

Committee on the Status of Endangered Wildlife in Canada (COSEWIC). (No Date). Redpath Museum, McGill University. http://redpath-staff.mcgill.ca/cosewic.htm.

COSEWIC. (2000). Assessment and Update Status Report on Vancouver Island Marmot. http://dsp-psd.pwgsc.gc.ca/Collection/CW69-14-109-2002E.pdf.

COSEWIC. (2010). Summary of COSEWIC Assessment Results as of November 2010. http://www.cosewic.gc.ca/rpts/Full_List_Species.htm.

COSEWIC. (2010b). About COSEWIC. http://www.cosewic.gc.ca/eng/sct6/sct6_4_e.cfm.

Cunningham, N. \& Robert, K. (2005). Regulation and business behaviour. Law and Policy 27: 213-218.

Currie, J. (2001). Public International Law. Toronto: Irwin Law.

Canadian Wildlife Service (CWS). (2009a). Hinterland Who's Who: Curb cat predation, http://www.hww.ca/hww2.asp?id=151\&cid=43.

Canadian Wildlife Service (CWS). (2009b). Migratory Birds Conservation. http://www.cws-scf.ec.gc.ca/mbc-com/default.asp?lang=En\&n=27E3A91 A-1.

David Suzuki Foundation. (2005). Environmental groups launch federal court case in historic bid to save Spotted Owl. http://www.davidsuzuki.org/WOL/ News_Releases/web_of_life12060501.asp.

David Suzuki Foundation. (2009a). Why is biodiversity important? http://www.davidsuzuki.org/Forests/Biodiversity/Importance.asp.

David Suzuki Foundation. (2009b). Threats to biodiversity. http://www.davidsuzuki.org/Forests/Biodiversity/Threats.asp.

David Suzuki Foundation, Ecojustice, Environmental Defence, \& Nature Canada. (2009, April). Canada's Species at Risk Act: Implementation at a snail's pace. http://www.ecojustice.ca/publications/reports/canadas-species-at-risk-actimplementation-at-a-snails-pac e/attachment.

David Suzuki Foundation. (2010, April). It's getting harder to spot the Spotted Owl. http://www.davidsuzuki.org/blogs/science-matters/2010/04/its-getting-harderand-harder-to-spot-the-spotted-owl/.

Dearden, P. \& Mitchell, B. (2009). Environmental Change and Challenge: A Canadian Perspective. Toronto: Oxford University Press. 
Department of Fisheries and Oceans Canada (DFO). (2009). Frequently Asked Questions. http://www.dfo-mpo.gc.ca/species-especes/faq/faq-eng.htm.

Eastern Loggerhead Shrike Recovery. No Date. http://www.shrike.ca/recovery.html.

Ecojustice. (2007, May). B.C.'s spotted owl near extinction: Province urged to fund fiveyear plan to capture and breed birds in captivity.

http://www.ecojustice.ca/media-centre/press-clips/b-c-s-spotted-owl-nearextinction-province-urged-to-fund-five-year-plan-to-capture-and-breed-birds-incaptivity/

Ecojustice. (2009). Greater Sage-Grouse Recovery. http://www.ecojustice.ca/cases/greater-sage-grouse-recovery.

Ecojustice. (2009b). Environmental groups set high bar for BC's new Species at Risk Task Force. http://www.ecojustice.ca/media-centre/pressreleases/environmental-groups-set-high-bar-for-bc2019s-new-species-at-risk-taskforce.

Edmonson, H. (2003). Salamander offers clues about state of ecosystem. http://www.uoguelph.ca/atguelph/03-11-19/articles/salamander.html.

Elgie, S. (2003). Protected Spaces and Endangered Species. In Hughes, E \& Lucas, A. (Eds.), Environmental Law and Policy (pp. 477-520), Third Edition. Toronto: Emond Montgomery.

Elgie, S. (2009). The Politics of Extinction: The Birth of Canada's Species at Risk Act. In VanNijnatten, D. \& Boardman, R. (Eds.), Canadian Environmental Policy and Politics (pp. 197-215). Toronto: Oxford University Press.

Elton, C. S. (1958). The Ecology of Invasions by Animals and Plants. Methuen. London, England.

Environment Canada. (2001, September). Recovery of Nationally Endangered Wildlife. http://www.ec.gc.ca/media_archive/press/2001/010919-4_b_e.htm.

Environment Canada. (2007, July). The Species at Risk Act in Ontario. http://www.on.ec.gc.ca/wildlife/factsheets/fs_sar_act-e.html\#aboutsaract.

Filion, F. L., Jacquemot, A., DuWors, E., Reid, R., Boxall, P., Bouchard, P., Gray, P. A. $\&$ Bath, A. (1994). The importance of wildlife to Canadians: The economic significance of wildlife-related recreational activities in 1991. Ottawa: Canadian Wildlife Service.

Folke, C., Perrings C., McNeely, J.A. \& Myers, N.. (1993). Biodiversity conservation with a human face: Ecology, economics and policy. Ambio, 22: 62-62. 
Forest Practices Board. (2005). BC Timber Sales Program Gets Clean Audit in 100 Mile House. http://www.canadian-forests.com/prov-gov.html.

Forest Service of British Columbia. (2007). B.C. Timber Sales. http://www.for.gov.bc.ca/bcts/

ForestEthics. (2002, September). Spotted Owls Going Extinct in Canada -- New Report Shows Logging Is Biggest Threat. http://www.forestethics.org/article.php?id=434.

Frankel, O.H. \& Soulé, M.E. (1981). Conservation and Evolution. Cambridge: Cambridge University Press.

Franklin, I.R. (1980). Evolutionary change in small populations. In Soulé, M.E. \& Wilcox, B.A. (Eds.). Conservation biology: an evolutionary-ecological perspective (pp. 135-149). Sunderland: Sinauer Associates.

Friesen, L., Cadman, M.D. \& MacKay, R.J. (1999). Nesting success of neotropical migrant songbirds in a highly fragmented landscape. Conservation Biology, 13: 338-346.

Gau, R., Carriere, S., Clark, K., \& Yonge, L. (2007). Have you met SARA? Arctic, 60: iii-v. [Electronic Version] http://pubs.aina.ucalgary.ca/arctic/Arctic60-3-iii.pdf.

Geist, V. \& McTaggart-Cowan, I. (1995). Wildlife Conservation Policy. Calgary: Detselig Enterprises.

Gore, C. \& Stoett, P. (Eds.). (2009). Environmental Challenges and Opportunities: Local-Global Perspectives on Canadian Issues. Toronto: Emond Montgomery.

Gray, P.A., Duwors, E., Villeneuve, M., Boyd, S. \& Legg, D. (2003). The socioeconomic significance of nature-based recreation in Canada. Environmental Monitoring and Assessment, 86: 129-147.

Greenbaum, A. \& Wellington, A. (2010). Environmental Law and Policy in the Canadian Context. Toronto: Captus Press.

Harrison, K. (1996). Passing the Buck: Federalism and Canadian Environmental Policy. Vancouver: UBC Press.

Hebda, R., McDadi, O., \& Mazzucchi, D. (No Date). Habitat History and the Decline of the Vancouver Island Marmot (Marmota vancouverensis). http://www.llbc.leg.bc.ca/public/pubdocs/bcdocs/400484/hebda_edited_final_feb 8.pdf. 
Hector, A., Joshi, J., Lawler, S., Spehn, E.M. \& Wilby, A. (2001). Conservation implications of the link between biodiversity and ecosystem functioning. Oecologia, 129: 624-628.

Helferty, N. (2007). CSEB Newsletter, 64: 8 http://cseb-scbe.org/files/Newsletters/CSEB_Vol64-2.pdf.

Heritage Canada. (No Date). Legislation., The Canadian Biodiversity Website, In cooperation with McGill University. http://canadianbiodiversity.mcgill.ca/english/legislation/index.htm.

Hess, P. (2009). News and Notes: Loggerhead Shrike Recovery. Birding, 41:32 http://www.aba.org/birding/v41n4p30.pdf.

Hessing, M., Howlett, M. \& Summerville, T. (2005). Canadian Natural Resource and Environmental Policy: Political Economy and Public Policy (pp. 272-273). Vancouver: UBC Press.

High Beam Research. (1999, January). Province acquires parkland on Vancouver Island. British Columbia Ministry of Environment, Lands, and Parks. http://www.highbeam.com/doc/1G1-53663782.html.

Hughes, E. \& Lucas, A. (2003). Environmental Law and Policy. Toronto: Emond Montgomery.

Hughes, R.M. \& Noss, R.F. (1992). Biological Diversity and Biological Integrity: Current concerns for lakes and streams. Fisheries, 17: 11-19.

Hutchinson, G.E. (1959). Homage to Santa Rosalia or why are there so many kinds of animals? The American Naturalist, 93: 145-159.

Illical, M. \& Harrison, K. (2007). Protecting Endangered Species in the US and Canada: The Role of Negative Lesson Drawing. Canadian Journal of Political Science, 40: 367-394. [Electronic]. http://www.politics.ubc.ca/fileadmin/template/main/images/departments/poli_sci/ Faculty/harrison/illical_harrison_2007.pdf.

Janz, D., Bryant, A., Dawe, N., Schwantje, H., Harper, B., Nagorsen, D., Doyle, D., deLaronde, M., Fraser, D., Linsday, D., Leigh-Spencer, S., McLaughlin, R., \& Simmons, R. (2000). National Recovery Plan for the Vancouver Island Marmot (2000 Update). RENEW. http://www.marmots.org/pdf/vanmar_e.pdf.

Jefferson Salamander Recovery Team. (2010). Recovery strategy for the Jefferson Salamander (Ambystoma jeffersonianum) in Ontario. Ontario Recovery Strategy Series. Peterborough: Ontario Ministry of Natural Resources.

Jeffries, M. (1995). Biodiversity and Conservation. London: Routledge. 
Kramer, R. A., van Schaik, C., \& Johnson, J. (1997). Last Stand: Protected areas and the defense of tropical biodiversity. New York: Oxford University Press.

Kryzanowski, T. (2009, April). Ontario needs to get its act together for the forest industry. Logging and Sawmilling Journal. [Electronic Version]. http://www.forestnet.com/LSJissues/april_09/ontario.php.

Kube, S. \& Traxler, C. (2010). Journal of Public Economic Theory, Forthcoming. [Electronic]. http://www.coll.mpg.de/DOWNLOAD/Traxler/KubeTrax.pdf

Kyonka, N. (2008, July 4). The vulnerable Jefferson salamander just one of several species threatened by exemptions in protection act. The Toronto Star. [Electronic]. http:// www.thestar.com/news/GTA/article/454111.

Licht, L. (2003). Shedding light on ultraviolet radiation and amphibian embryos. BioScience, 53: 551-561.

Lindenmayer, D. \& Burgman, M.A. (2005). Practical conservation biology. Melbourne: CSIRO Publishing.

Lowcock, L.A., Licht, L.E. \& Bogart, J.P. (1987). Nomenclature in hybrid complexes of Ambystoma (Urodela: Ambystomatidae): No case for the erection of hybrid "species". Systematic Biology, 36: 328-336.

Lowcock, L.A., Griffith, H. \& Murphy, R.W. (1991). The Ambystoma lateralejeffersonianum complex in central Ontario: ploidy structure, sex ratio, and breeding dynamics in a bisexual-unisexual community. Copeia 1991:87-105.

Lynch, M. \& O'Hely M. (2001). Captive breeding and the genetic fitness of natural populations. Conservation Genetics, 2: 363-378.

MacArthur, R. H. (1955). Fluctuations of animal populations and a measure of community stability. Ecology 36:533-536.

Mallett, J. (1995). A species definition for the Modern Synthesis. Trends in Ecology and Evolution, 10: 294-299.

McCann, K. S. 2000. The diversity-stability debate. Nature 405: 228-233.

Millennium Ecosystem Assessment (MEA). (2005). Ecosystems and Human Well-being: Synthesis. Washington: Island Press. [Electronic Version]. http://www.maweb.org/documents/document.356.aspx.pdf.

Miller, G. (2009, February). The Last Line of Defence: A Review of Ontario's New Protections for Species at Risk. Report of the Environmental Commissioner to the Legislative Assembly of Ontario. 
Ministry of Natural Resources (MNR). (2007). Species at Risk Stewardship Fund: Backgrounder.

http://www.mnr.gov.on.ca/en/Newsroom/LatestNews/MNR_E004076.html.

Ministry of Natural Resources (MNR). (2010, May). Endangered Species Act 2007. http://www.mnr.gov.on.ca/en/Business/Species/2ColumnSubPage/STEL01_13132.html.

Ministry of Natural Resources (MNR). (2010b). Ontario's First Habitat Regulation Under ESA 2007. http://www.mnr.gov.on.ca/en/Business/Species/2ColumnSubPage/268554.html.

Mosquin, T. (2000). The Roles of Biodiversity in Creating and Maintaining the Ecosphere. In Bocking, S. (Ed.). Biodiversity in Canada: Ecology, ideas, and action (pp.107-134). Peterborough: Broadview Press.

Muldoon, P. (2003). Bilateral and Multilateral Dimensions of International Environmental Law. In Hughes, E. \& Lucas, A. Environmental Law and Policy (pp. 607-655). Toronto: Emond Montgomery.

Muldoon, P., Alastair L., Robert G., \& Pickfield, P. (2009). An Introduction to Environmental Law and Policy in Canada. Toronto: Emond Montgomery.

Murphy, D.D. (1986). Challenges to Biological Diversity in Urban Areas. In Wilson, E.O. (Ed.), Biodiversity (pp. 71-72). Washington: National Academy Press.

Myers, Norman. (1993a). Tropical forests: The main deforestation fronts. Environmental Conservation, 20: 9-16.

Myers, Norman. (1993). Biodiversity and the Precautionary Principle. Ambio, 22: 74-79.

Nature Canada, (2006). Species at Risk Act, Three Years Later. http://www.naturecanada.ca/pdf/SARA_2006e.pdf.

Nature Canada. (2009). Canada's Species at Risk Act: Implementation at a Snail's Pace. [Electronic]. http://www.naturecanada.ca/endangered_atrisk_saraRC2009.asp.

Nature Conservancy of Canada. (2009). Eastern Loggerhead Shrike. http://www.natureconservancy.ca/site/News2?abbr=on_ncc_\&id $=7347 \& p a g e=N$ ewsArticle\&news_iv_ctrl=-1

Ninan, K.N. (2009). Conserving and valuing ecosystem services and biodiversity: economic, institutional and social challenges. London: Earthscan. 
Noël, S., Dumoulin, J., Ouellet, M., Galois, P., \& Lapointe, F.J. (2008). Rapid Identification of Salamanders from the Jefferson Complex with Taxon-Specific Primers. Copeia, 1: 158-161.

Norris, A.T., Bradley, D.G., \& Cunningham, E.P. (1999). Microsatellite genetic variation between and within farmed and wild Atlantic salmon (Salmo salar) populations. Aquaculture, 180: 247-264.

Novacek, M.A. \& Cleland. E.J. (2001). The current biodiversity extinction event: Scenarios for mitigation and recovery. Proceeding of the National Academy of Sciences, 98: 5466-5470.

Odum, E. P. (1953). Fundamentals of Ecology. Philadelphia: W. B. Saunders.

Ontario Biodiversity Council. (2008). Interim Report on Ontario's Biodiversity 2008. https://ozone.scholarsportal.info/bitstream/1873/12080/1/280473.pdf.

Ontario Nature. (2008). New Endangered Species Act Undermined by Proposed Exemptions.

http://www.ontarionature.org/act/action_alerts/alert_template.php?n_code $=408$

Paehlke, R. (2000). Biodiversity: The Policy Challenge. In Bocking, S. (Ed.), Biodiversity in Canada: Ecology, ideas, and actions (pp. 273-296). Toronto: Broadview Press.

Page, D. Staff lawyer for Ecojustice Canada. Personal communication. E-mail: November 21, 2007.

Patton, M. Q. (2002). Qualitative Research and Evaluation Methods. Thousand Oaks: Sage Publications, Third Edition.

Payton, B. (2006). Last Call for the Spotted Owl. Canadian Geographic, 126: 3.

Pimm, S.L., Russel, G.J., Gittleman, J.L. \& Brooks, T.M. (1995). The future of biodiversity. Science, 269: 347-350.

Plotkin, R. Biodiversity policy analyst for the David Suzuki Foundation. Personal communication. E-mail: December 4, 2007.

Pojar, J. (2010, January). A New Climate for Conservation: Nature, Carbon, and Climate Change in British Columbia. http://www.forestethics.org/downloads/NewClimate_report_FE.pdf.

Redpath Musem. McGill University. (No Date). Part 1: Impacts on Biodiversity. Quebec Biodiversity Website.

http://redpath-museum.mcgill.ca/Qbp/3.Conservation/impacts.htm\#represents 
Resource Futures International (RFI). (1995, June). Rare and Endangered Species Legislation Economic Analysis, Draft for Discussion Prepared for the Canadian Endangered Species Coalition.

Richmond Hill Naturalists. (2009, November). Species gain new ground under Endangered Species Act. http://www.rhnaturalists.ca/blog/2009/11/23/speciesgain-new-ground-under-endangered-species-act/.

Rogers, R. \& Wilkinson, C. (2000). Policies of Extinction: The Life and Death of Canada's Endangered Species Legislation. Policy Studies Journal, 28: 190205.

Romanuk, T. N., Vogt, R.J \& Kolasa,J. (2006). Nutrient enrichment weakens the stabilizing effect of species richness. Oikos, 114:291-302.

Royal Ontario Museum. (2008). Ontario's Biodiversity: Species at Risk, Loggerhead Shrike. http://www.rom.on.ca/ontario/risk.php?doc_type=fact\&id=122.

Scudder, G. (1999). Endangered Species Protection in Canada. Conservation Biology, 13: 963-965.

Sisk, T.D., Launer, A.E., Switky, K.R., \& Ehrlich, P.R. (1994). Identifying extinction threats. BioScience, 44: 592-604.

Species at Risk Public Registry. (2010). http://www.registrelep.gc.ca/default_e.cfm.

Spotted Owl Population Enhancement Team (SOPET). (2007, March). Northern Spotted Owl Population Enhancement and Recovery in British Columbia: Proposed FiveYear Action Plan. British Columbia Ministry of Environment. http://www.env.gov.bc.ca/sarco/so/files/SOPET_Proposed_5year_Action_Plan_2 0070330.pdf .

Stauffer, J. (2007). Donut Dilemmas. Home on the Range, 5, 2, Fall/Winter 2007.

Stone, M. \& Reid, R. (1997). Opportunity costs of Spotted Owl Management Options for British Columbia. Canadian Public Policy, 23: 69-82. [Electronic Version]. http://economics.ca/cgi/jab?journal=cpp\&view=v23n1/CPPv23n1p069.pdf

Stutchbury, B. (2007). Silence of the Songbirds. Toronto: Harper Collins.

Suzuki, David. (2001). Preface. In Beazley, K. \& Boardman, R. (Eds.), Politics of the Wild (pp. vi-vii). Toronto: Oxford University Press.

Telfer, E.S. (2010). Loggerhead Shrike. Canadian Wildlife Service: Hinterland Who's Who. http://www.hww.ca/hww2.asp?id=52. 
Townsend, C., Harper, J. \& Begon, M. (2000). Essentials of Ecology. Massachussets: Blackwell Science Inc.

United Nations Environment Programme (UNEP). (2002). Marmota vancouverensis. http://www.unepwcmc.org/species/data/species_sheets/vanismar.htm.

United States Environmental Protection Agency (US EPA). (2010, April). Biological Integrity. Biocriteria Glossary. http://www.epa.gov/waterscience/biocriteria/glossary.html.

Valiante, M. (2009). The Courts and Environmental Policy Leadership. In VanNijnatten, D. \& Boardman, R. (Eds.). Canadian Environmental Policy and Politics (pp. 3045). Toronto: Oxford University Press.

Vancouver Island Marmot Recovery Foundation. (2007). The Vancouver Island Marmot. www.marmots.org.

Vancouver Island Marmot Recovery Team. (2008). Recovery Strategy for the Vancouver Island Marmot (Marmota vancouverensis) in British Columbia. Victoria: British Columbia Ministry of Environment.

Van Dyke, F. (2003). Conservation Biology: Foundations, Concepts, and Applications. Boston: McGraw-Hill.

VanNijnatten, D. \& Boardman, R. (Eds.). (2009). Canadian Environmental Policy and Politics. Toronto: Oxford University Press.

Volpe, J. \& Shaw, K. (2009). Fish Farms and Neoliberalism: Salmon Aquaculture in British Columbia. In Gore, C. \& Stoett, P., (Eds.), Environmental Challenges and Opportunities: Local-Global Perspectives on Canadian Issues (pp. 131-158). Toronto: Emond Montgomery.

Western Canada Wilderness Committee (WCWC). (2005). Safeguarding BC's Wildlife. http://www.wildernesscommittee.org/campaigns/wildlife/bc.

Western Canada Wilderness Committee (WCWC). (2007, August). http://media.wildernesscommittee.org/print.php?id=12431.

Western Canada Wilderness Committee (WCWC). (2008). Why doesn't BC have Endangered Species Legislation? Wilderness Committee Educational Report, 27(5). http:/historic.wildernesscommittee.org/wildlife/bc/reports/Vol27No05/article1.

Western Canada Wilderness Committee (WCWC). (2008b, October 22). BC Government-Approved Logging Discovered at Rare Spotted Owl Site. Media Release. 
http://wildernesscommittee.org/press_release/bc_government_approved_logging _ discovered_rare_spotted_owl_site.

Western Wilderness Committee. (2009, May). http://media.wildernesscommittee.org/news/2009/05/12594.php.

Western Wilderness Committee (WCWC). (2009, April). Political interference endangers Vancouver Island Marmot.

http://wildernesscommittee.org/press_release/political_interference_endangers_ vancouver_island_marmot.

Western Wilderness Committee (WCWC). (2010, April). Biologists hope 2 Spotted Owls can help save the species. http://wildernesscommittee.org/news/biologists_hope_2_spotted_owls_can_help_ save_the_species.

Wildlife Preservation Canada (WPC). (2005). Nest discovery major landmark in efforts to save endangered bird: Captive breeding program pays off. http://www.wptc.org/about/pop_newsrelease_061405.htm.

Wildlife Preservation Canada (WPC). (2007). Shrike Field Report 2007. http://www.wptc.org/reports/pop_shrike_fr5_07.htm.

Wildlife Preservation Canada (WPC). (2008). Shrike Field Report 2008. http://www.wptc.org/reports/pop_shrike_fr6_08.htm.

Wilson, E.O. (Ed.). (1988). Biodiversity. Washington: National Academy Press.

Wilson, E.O. (1992). The Diversity of Life. Cambridge: Harvard University Press.

Wilson, E.O. (1993). The Biophilia Hypothesis. Washington: Island Press.

Wilcox, B.A. (1984). In situ conservation of genetic resources: Determinants of minimum area requirements. In McNeeley, J.A. \& Millers, K.R. (Eds.). National Parks, Conservation and Development: The Role of Protected Areas in Sustaining Society (pp. 639-647). Proceedings of the World Congress on National Parks, Bali, Indonesia, 11-22 October 1982. Smithsonian Institution Press.

Winter, M. \& Faaborg, J. (1999). Patterns of area sensitivity in grassland-nesting birds. Conservation Biology, 13: 1424-1436.

Yosef, R. (2001). Nesting ecology of resident Loggerhead Shrikes in Southcentral Florida. The Wilson Bulletin, 113: 279-284. 


\section{LIST OF PERTIENT STATUTES}

\section{A. Federal Statutes}

Canada National Parks Act, S.C. 2000, c. 32.

Canada Shipping Act, 2001, S.C. 2001 c. 26

Canada Wildlife Act, R.S.C. 1985, c. C-11.

Canadian Environmental Assessment Act, S.C. 1992, c.37.

Canadian Environmental Protection Act, 1999 [CEPA, 1999], S.C. 1999, c.33.

Environmental Contaminants Act, 1974 [Note: Repealed by the CEPA, 1999].

Fisheries Act, R.S. 1985 c. F-14

Migratory Birds Convention Act, S.C. 1994, c.22.

Species At Risk Act, S.C. 2002, c.29.

The Constitution Act, 1867, 30 and 31 Victoria, c. 3. (UK).

The Constitution Act, 1982, being Schedule B to the Canada Act 1982 (UK), 1982. c.11. Wild Animal and Plant Protection and Regulation of International and Interprovincial Trade Act, S.C. 1992, c.52.

\section{B. Provincial Statutes: Ontario}

Aggregate Resources Act, R.S.O. 1990, c. A.8.

Conservation Land Act, R.S.O. 1990, c. C.28.

Endangered Species Act, R.S.O. 1990, C.E.15 as amended by S.O. 1997 c. 41, s. 116

[Note: Repealed by the Endangered Species Act, 2007].

Endangered Species Act, 2007, S.O. 2007, c. 6.

Environmental Assessment Act, R.S.O. 1990, c. E.18.

Environmental Protection Act, R.S.O. 1990. c. E.19.

Fish and Wildlife Conservation Act, S.O. 1997, c.41.

Forestry Act, R.S.O. 1990, c. F.26.

Planning Act, R.S.O. 1990, c. P.13.

Provincial Parks Act, R.S.O. 1990, c. P.34.

\section{Provincial Statutes: British Columbia}

Forest Act, S.B.C. 1996. c. 157.

Forest and Range Practices Act, S.B.C. 2002, c. 69.

Forest Practices Code of British Columbia Act, R.S.B.C. 1996, c. 159. 